Portland State University

PDXScholar

\title{
The function of phrasal verbs and their lexical counterparts in technical manuals
}

Brock Brady

Portland State University

Follow this and additional works at: https://pdxscholar.library.pdx.edu/open_access_etds

Part of the Applied Linguistics Commons

Let us know how access to this document benefits you.

\section{Recommended Citation}

Brady, Brock, "The function of phrasal verbs and their lexical counterparts in technical manuals" (1991). Dissertations and Theses. Paper 4181.

https://doi.org/10.15760/etd.6065

This Thesis is brought to you for free and open access. It has been accepted for inclusion in Dissertations and Theses by an authorized administrator of PDXScholar. Please contact us if we can make this document more accessible: pdxscholar@pdx.edu. 
AN ABSTRACT OF THE THESIS OF Brock Brady for the Master of Arts in Teaching English to Speakers of Other Languages (TESOL) presented March 29th, 1991.

Title: The Function of Phrasal Verbs and their Lexical Counterparts in Technical Manuals

\section{APPROVED BY THE MEMBERS OF THE THESIS COMMITTEE:}

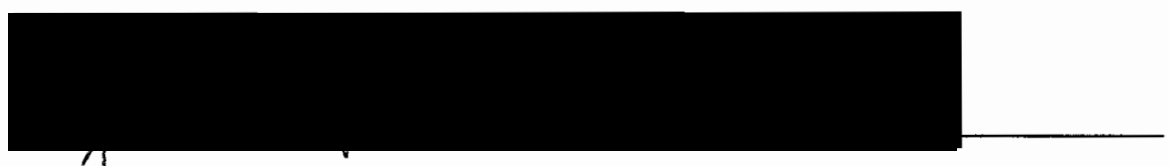

Jeahette S. DeCarrico, Chair

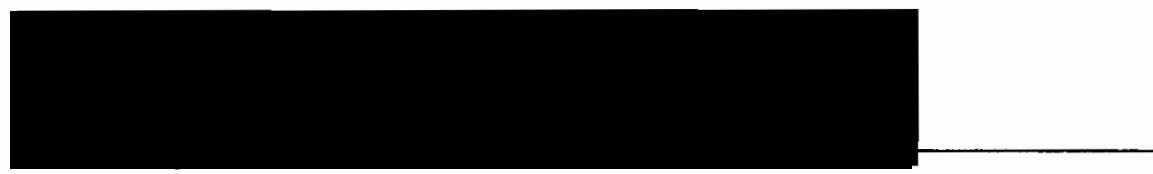

Marjorie Terdal

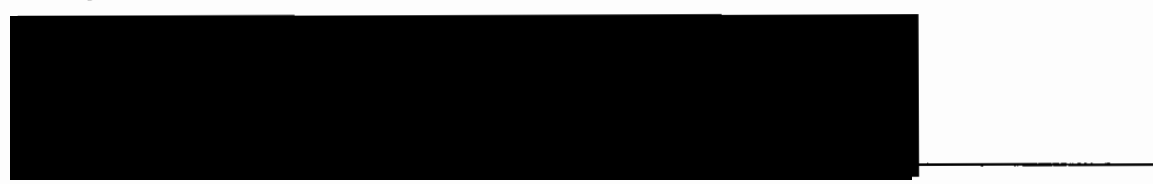

Thomas Dieterich

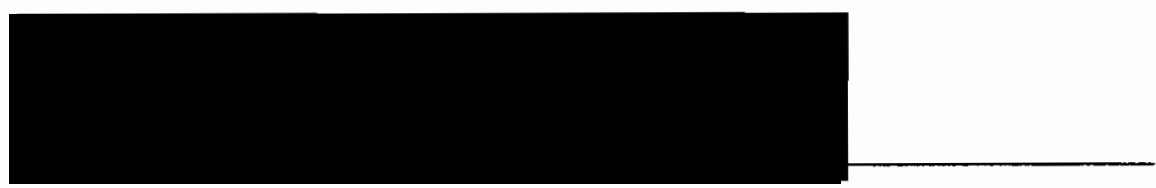

Sister Rita Rose Vistica

This study investigates the use of phrasal verbs and their lexical counterparts (i.e. nouns with a lexical structure and meaning similar to corresponding phrasal verbs) in technical manuals from three perspectives: (1) that such two-word items might be more frequent in technical writing than in general texts; (2) that these two-word items might have particular functions in technical writing; and that (3) 
frequencies of these items might vary according to the presumed expertise of the text's audience.

The technical manual was studied because it is the fundamental genre of technical writing and is applicable to a wide audience. Both "lay" manuals (written for the general public) and "expert" manuals (written for specialists) were considered and compared to a general, informal text (the daily newspaper) to examine the issue of audience expertise. Corpora of 36,000 words were analyzed for two-word items in these genres in terms of frequency, figurative level (figurative vs. non-figurative iterns) and lexical variance (ratio of types to tokens). Additionally, in the two technical manual corpora, the rhetorical function of sentences with two-word items, the semantic contribution of the particle component, and the common semantic fields of two-word items items, were analyzed to determine their function in technical discourse.

Results of the frequency counts and rhetorical function analysis suggest that these items play an important role in technical manuals. This role is not as "pragmatic markers of informality" as has been claimed for phrasal verbs in less specific discourse contexts. This study's figurative level analysis shows that the majority of two-word items in technical manuals, unlike more general texts, are non-figurative, and neutral in regard to formality. In technical manuals therefore, the role of two-word items is almost exclusively semantic: they seem to provide additional orientation and/or precision. However, between the two sub-genres of technical manuals, the ratio of phrasal verbs to their lexical counterparts varies meaningfully, with phrasal verbs being predominant in the "lay" manuals and lexical counterparts appearing more frequently in the "expert" corpus. Implications of this variance are discussed and considered in terms of appropriate instructional strategies for different clients. 
THE FUNCTION OF PHRASAL VERBS AND THEIR LEXICAL COUNTERPARTS IN TECHNICAL MANUALS

$$
\text { by }
$$

BROCK BRADY

A thesis submitted in partial fulfillment of the requirements for the degree of

\section{MASTER OF ARTS}

in

TEACHING ENGLISH TO SPEAKERS OF OTHER LANGUAGES

Portland State University

1991 
TO THE OFFICE OF GRADUATE STUDIES:

The members of the committee approve the thesis of Brock Brady presented March 29th, 1991.

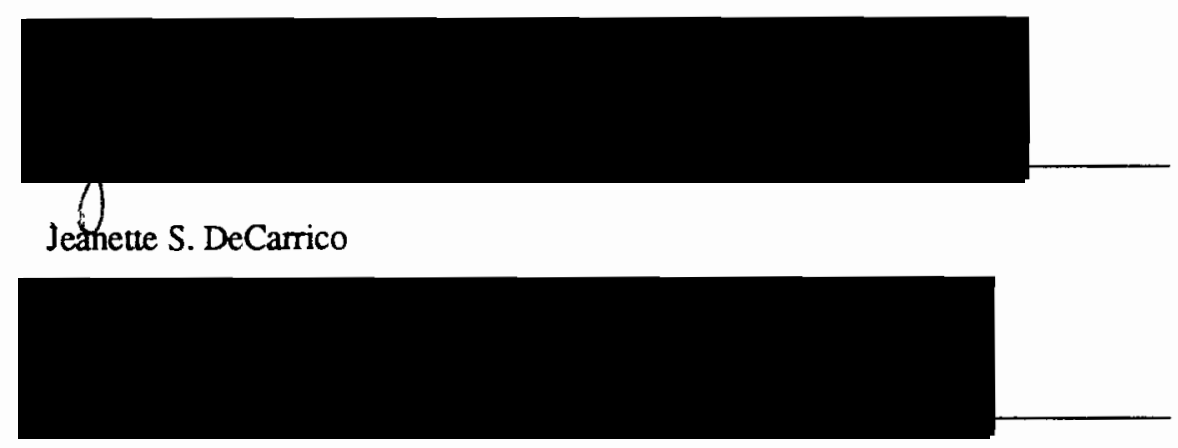

\section{Marjorie Terdal}

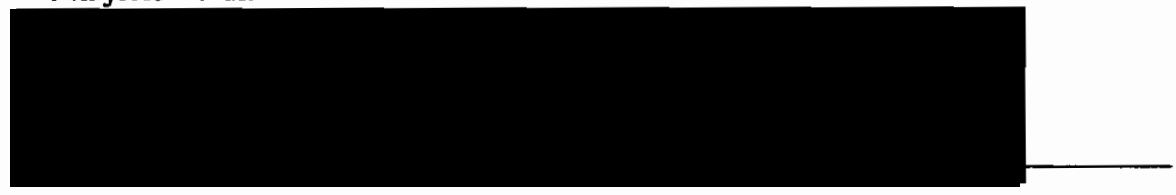

Thomas Dieterich

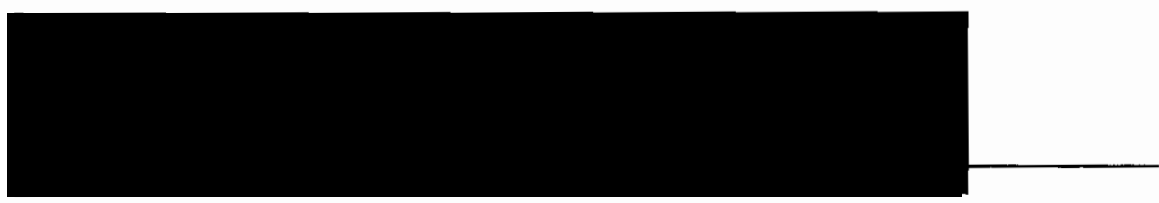

Sister Rita Rose Vistica

\section{APPROVED:}

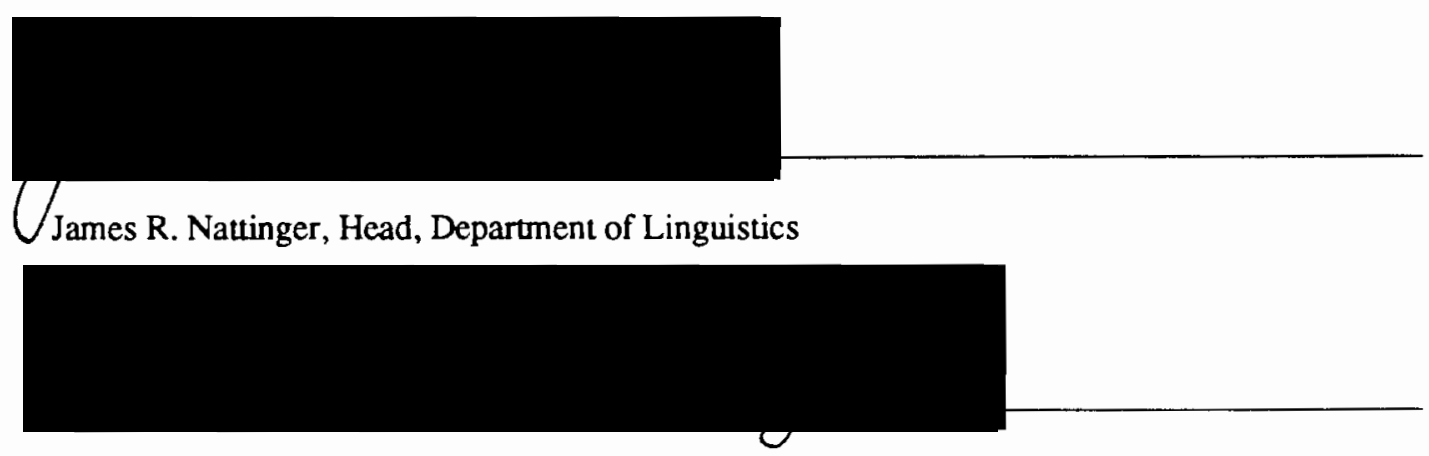

C. William Savery, Vice Provost for Graduate Studies and Research 


\section{ACKNOWLEDGEMENTS}

My special thanks to my family who was there when nobody else was, especially my brother Kerry, who furnished technical materials and advice. I am also very grateful to Jeanetue DeCarrico, Marjorie Terdal, and Thomas Dieterich, who not only provided cogent advice but support. Additionally, I thank Robert Pierce, whose research suggested numerous ways to circumvent difficulties in the present study. Finally, a word of thanks is due to Dan Hobbes, who pointed me in the right direction for resources on technical writing; Gina Crocetti, who assisted me in establishing inter-rater reliability; Randy Wulff and Nancy Billingsley of ABE/ESL at Clark Community College, who allowed the use of the department's Macintosh to produce this document; and Sister Vistica, who graciously consented to be the final member of my examination committee. 


\section{TABLE OF CONTENTS}

\section{PAGE}

ACKNOWLEDGEMENTS. .iii

LIST OF TABLES.......................................................................................

LIST OF FIGURES..................................................................................

\section{CHAPTER}

INTRODUCTION

Research Questions..........................................................5

Definitions.....................................................................6

Other Definitons and Acronyms..................................................10

II REVIEW OF THE RELATED LITERATURE........................................11

English for Special Purposes/English for Science and Technology.............11

Contexts of ESP...............................................................16

Phrasal Verbs and their Lexical Counterparts ...................................19

Syntactic Characteristics of Phrasal Verbs.......................................22

Semantic Properties of Phrasal Verbs...........................................27

The Prosody of Phrasal Verbs.......................................................29

Functions of Phrasal Verbs........................................................32

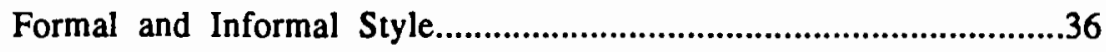

Lexical Counterparts............................................................38

Technical Manuals............................................................40

Formal Properties of Technical Manuals........................................42 


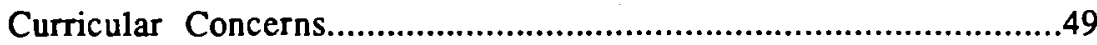

Phrasal Verbs as the Focus of an Instructional Unit..................................54

III RESEARCH METHODS AND PROCEDURES............................................57

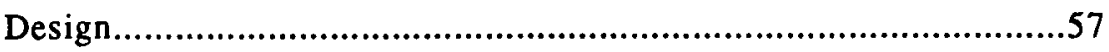

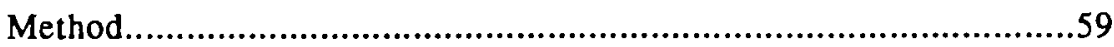

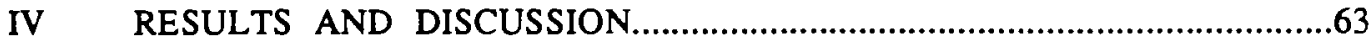

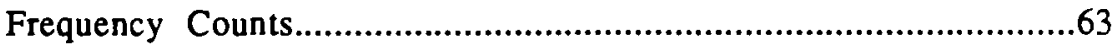

Figurative Items.................................................................................6

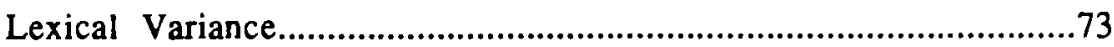

Rhetorical Function..........................................................................76

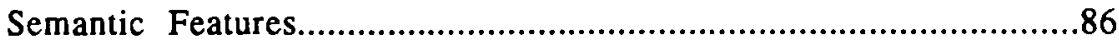

Semantic Fields............................................................................

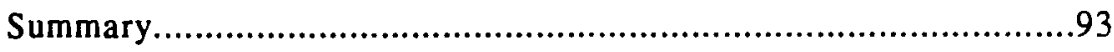

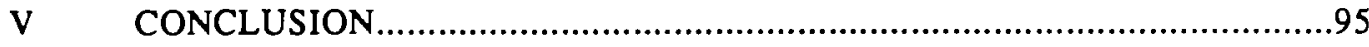

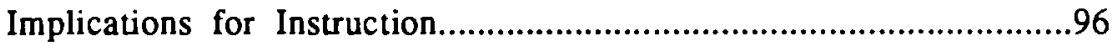

Suggestions for further research.......................................................99

REFERENCES

\section{APPENDICES}

A SIMPLE COUNDS RESSEMBLING LEXICAL COUNTERPARTS...................106

B A SAMPLE LESSON FOR LEXICAL COUNTERPART INSTRUCTION..........107

C - A SECTION FROM THE DEVRONIZER TEXT OF THE EXPERT US

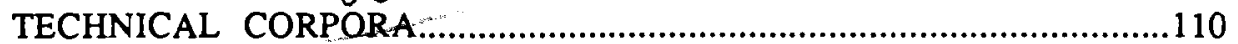

D A SECTION FROM THE VOLKSWAGEN TEXT OF THE LAY

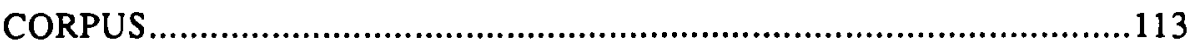

E TWO "OREGONIAN" ARTICLES FROM THE GENERAL CORPUS................116 


\section{LIST OF TABLES}

TABLE

I Trimble's Hierarchy of Rhetorical Functions............................................................43

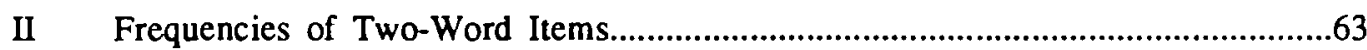

III Rhetorical Function of Sentences Containing Figurative (FIG) and Non-Figurative

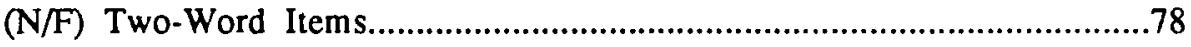

IV Figurative Phrasal Verbs Found in "Pure" Instruction in the Lay Manual......................86

V Most Frequent Phrasal Verbs Found in the Technical Corpora...................................88

VI Most Frequent Lexical Counterparts Found in the Technical Corpora.........................90 


\section{LIST OF FIGURES}

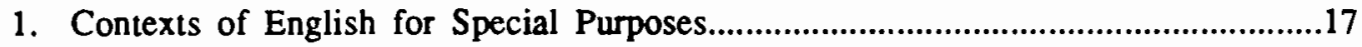

2. Sample Phrasal Verb Exercise Diagram...........................................................54

3. Percentage of Two-Word Items in the General Newspaper and Technical Corpora.............65

4. Percentage of Two-Word Items in the Lay Technical and Expert Technical Corpora..........66

5. Percent of Figurative Items to Total Items by Genre...............................................68

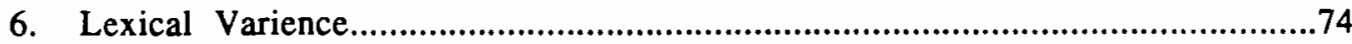

7. Frequency of Phrasal Verbs by Rhetorical Function.................................................79

8. Frequency of Lexical Counterparts by Rhetorical Function $\ldots \ldots \ldots \ldots \ldots \ldots \ldots \ldots \ldots \ldots . \ldots \ldots$

9. Descriptive Passage from the Devronizer Systems Manual (1990a)..............................83 


\section{CHAPTER I}

\section{INTRODUCTION}

Much recent attention has been devoted to the semantic, syntactic, and pragmatic properties of phrasal verbs--those two-part lexical items like "put on" and "tighten up", along with suggestions regarding effective methods of teaching them to non-native speakers. According to Comell (1985), phrasal verbs, "have been 'discovered' as an important component in curricula for English as a Foreign Language"

(p. 1). However, it is very possible that they have become objects of current research primarily because of their complexity: their polysemy, their idiomaticity, their syntactic restraints, a complexity that means covering phrasal verbs in an ESL/EFL course can be a time-consuming process.

Therefore, as Bolinger (1971), Celce-Murcia \& Larsen-Freeman (1983), and Cornell (1985), all note, it is important to determine those contexts or discourse areas where phrasal verbs are more frequent or prominent, especially because no such frequencies studies currently exist; and to identify what kinds of phrasal verbs (e.g., figurative or not) are important in such contexts, so as to make instruction as effective and relevant as possible to any particular group of students.

This is especially important in the field of ESP (English for Specific Purposes). ESP practitioners recognize that developing an ESP course is an extremely time-consuming experience (Burwell 1990; McSwain \& Morihara 1990) To be sure, lengthy parts of this process are the Needs Analysis (where the ESP practitioner through interviews, observation, and analysis of language used in the situation, determines the client's specific English needs) and the development of the specific class activities and materials. But too often there is an important gap in the process: a lack of resources 
concerning the characteristics or use of a language feature (e.g. phrasal verbs), even in different, but related contexts (e.g. physics textbooks), and an uncerainty concerning which examples of that feature may be most appropriate for instruction (e.g. does "take out" occur prominently in technicial manuals?). Studies like this one can provide such points of departure.

One domain where phrasal verbs seem to play a large role, possibly because of the emphasis on movement and process, is technology (consider such expressions as "to tune up", "to burn out", "to put in", "to take out", "to hook up", "to build in", "to break down"). This research examines the assumption that phrasal verbs are in some way integral to technical contexts, and concludes that they are legitimate objects of ESP study, for in technical contexts they are often more precise than their single word synonyms. Therefore their treatment must be considered in textbooks and coursework.

This issue is of special interest because some scholars have suggested (esp. Nattinger and DeCarrico, 1990), that phrasal verbs have a pragmatic dimension of informality, and are especially associated with informal, oral discourse. Sometimes certainly, perhaps in part for historical reasons, this seems to be the case (Celce-Murcia \& Larsen-Freeman, 1983; MacArthur, 1989; Meyer, 1975). However, phrasal verbs are not purely conversational. They do appear in texts, and in fact, more phrasal verbs seem to appear in technical texts than in general texts (e.g. a daily newspaper). Furthermore, many of the twoword verbs found in instruction manuals seem semantically to orient, to specify, or to insist on precision--suggesting they play a special role in technical discourse.

However the domain of technology is vast, covering many specialities, and many genres within each speciality, such as research reports, textbooks, academic lectures, and conference discussions. Therefore caution must be taken to avoid overgeneralization, the claims of any research must be strictly limited, and this study cannot provide a basis for phrasal verb instruction in all technical contexts. Yet despite such limitations, selecting of the technical manual as a genre of study means that the present research has broad applicability: technical manuals focus on a device, and therefore are not limited to 
one technical or scientific subject area, so the audience of a particular manual may come from many specialty backgrounds. Also technical manuals typically include a full range of readers: (1) foreign technicians who need only a reading knowledge of English, (2) foreign engineers who participate in English-language seminars and training, and (3) foreign students studying applied science in Englishspeaking countries, as well as (4) native speaking technicians. Technical manuals also have a certain applicability to research scientists, for while the foreign technician may have no reason to read research reports, the researcher may well need to understand an operator's manual in English on a particular piece of equipment (e.g. an oscilloscope or an electron microscope).

Therefore this research examines technical manuals, perhaps the fundamental genre of technical discourse, in comparison to a corpus of equal size drawn from a more general text which acts as a control: a daily newspaper (see Appendix D), to determine how the frequency and distribution of phrasal verbs vary according to genre and sub-genre ("lay" vs. "expert"--i.e., those manuals designed for the general public, vs. those designed for a specialist audience). Attention is also given to the lexical counterparts of phrasal verbs (that is, nouns and adjectives like "output", "breakdown", and "tune-up", which seem to be derived, or at least closely related to their verbal equivalents), concerning their frequency and contexts.

Phrasal verbs and their lexical counterparts are not only considered as to simple frequency but also in terms of their lexical variance (the ratio of different items to total number of items). One reason for considering lexical variance is that if a particular item appears repeatedly in a genre or speciality, it is less likely to be a source of comprehension problems. Additionally, such a low lexical variance would suggest that the simplest, most effective instructional technique would be to introduce these phrasal verbs and lexical counterparts as vocabulary items, spending litule time on their semantic ambiguity, and ignoring their syntactic complexities. On the other hand, A high lexical variance would imply more vocabulary items to comprehend and suggest that students could benefit from a systematic treatment of two-word items, even though such a systematic treatment is potentially complicated. 
This study also attempts to determine the figurative level of two-word items found in the texts (i.e. is the item figurative or non-figurative?). Making this identification is useful for two reasons: (1) figurative and non-figurative two-word items may sometimes have different pragmatic functions. For example, many of the two-word items considered characteristic of informal discourse are figurative (MacArthur, 1989), whereas many non-figurative items seem to be pragmatically neutral; and (2) previous studies have suggested that figurative phrasal verbs are more likely to cause comprehension problems for ESL leamers (Celce-Murcia \& Larsen-Freeman, 1983), and thus the percentage of figurative items found in a genre can allow some indirect claims to be advanced regarding the comprehensibility of the text.

The rhetorical function of the sentence where these two-word items appear in technical manuals is also considered with frequencies of figurative and non-figurative items being tabulated according to categories of rhetorical function identified by Trimble in English for Science and Technology: A Discourse Approach (1985). Knowing the rhetorical function of sentences where two-word items appear (1) aids in determining the pragmatic functions of the items, and (2) allows us to make statements about the rhetorical importance of the two-word items within the total discourse. Following advice and observations from Crookes (1984), Swales (1981) and Trimble (1985), thetorical analysis of phrasal verbs and their lexical counterparts is done on a sentential level to avoid ambiguity and overly complex discourse characterizations.

The semantic features of two-word items found in the technical manuals are additionally considered, in particular the particle's contribution to meaning, with the most common items grouped according to semantic fields (e.g. "movement" or "activation" ) to discover the particular "themes" they may represent in technical discourse, and to suggest how these themes may be used to systematize instruction. These items are taken from a list of the most frequent phrasal verbs and lexical counterparts, which is also provided as an aide-memoire to assist instructors in lesson preparation, along with a separate list of 
common compound nouns resembling lexical counterparts (see Appendix A).

The results of this research are then related to current trends in ESP methodology and appropriate teaching strategies, according to the language context of the client (i.e. ESL, EFL, ELIT (English as a Language of Information Transfer)) are considered. However, this research is not primarily concerned with developing explicit techniques or materials for teaching phrasal verbs and lexical counterparts; instead, only some suggestions are made for "teaching what to whom when".

\section{RESEARCH QUESTIONS}

1. Do frequencies and lexical variances (word type vs. word token ratio) of phrasal verbs and their lexical counterparts differ meaningfully according to text genres : a "general" newspaper text is compared to a "lay" technical manual, which is also compared to a technical manual intended for "experts".

2. What portion of phrasal verbs and their lexical counterparts is figurative in each genre and rhetorical function? Are there meaningful differences between genres and rhetorical functions?

3. On a sentential level, in what kinds of rhetorical functions (e.g. description, instruction, definitions, classifications, etc.) do phrasal verbs and their lexical counterparts commonly appear, and within each metorical function, what is the distribution of figurative items? Does this distribution differ meaningfully between rhetorical functions?

4. Do phrasal verbs and their lexical counterparts display particular semantic features, and are these features indicative of the role(s) that two-word items tend to play in technical discourse? 


\section{DEFINITIONS}

\section{Phrasal Verbs}

Phrasal verbs (PVs) are verbs followed by a particle (certain prepositions and short adverbs) which seem to function as a single verb. There are intransitive phrasal verbs (e.g. "to break down" , to come in") and transitive phrasal verbs. Transitive phrasal verbs are further divided into two categories:

separable phrasal verbs, e.g. "to put in" , "to pick up", where the direct object can, and sometimes must be inserted between the verb and its particle, and inseparable phrasal verbs, among which are phrasal verbs like "to put up with", "to wind up with", and "to check up on", which are always followed by another preposition.

Phrasal verbs are distinguished from (1) prepositional verbs (e.g. "to rely on", "to think about", "to agree to"), where the preposition adds no semantic information to the verb and where many syntactic properties associated with phrasal verbs are lacking; and (2), simple verb + preposition combinations (e.g. "The spider climbed up the wall").

\section{Lexical Counterparts}

Lexical counterparts (LexCs) are nouns (often acting as modifiers) which are lexically related to phrasal verbs. Examples are "output", "inlet", "breakthrough" and "tie-down". They are distinguished from words formed of prepositions and verbs which are simply compound nouns such as "an override", "an upgrade", and "an outline". In general, these "simple compounds", have a verbal equivalent of identical form (i.e. "to override", "to upgrade"), and their meaning is distinct from their possible phrasal verb equivalents: "an overhaul" has no semantic relation to "to haul over"; nor does "an outline" to "to line out" (see Appendix A).

However some noun compounds like "an overlap" or "a backspace", are special cases, for with 
expressions such as these, two verbal counterparts exist: a compound verb (e.g. "to overlap", "to backspace"), as well as a phrasal verb (i.e. "to lap over" and "to space back"). Such expressions will be considered as lexical counterparts in this study. Even so, while accepting "an overlap" or "a backspace" as lexical counterparts, the compound verbs based on them (e.g. "to overlap" and "to backspace") have not been tabulated as phrasal verbs.

\section{Two-Word Items}

"Two-Word Item" is simply an operational definition which refers to both phrasal verbs and their lexical counterparts as a single category.

\section{Figurative Phrasal Verbs and Lexical Counterparts}

Figurative phrasal verbs and their lexical counterparts are those whose meaning cannot be determined by the sum of their parts (e.g., "to put up with" = "to tolerate", "to turn on" = "to activate"), and which often have a single verb synonym. Figurative Phrasal Verbs are distinguished from (1) Completive Phrasal Verbs (e.g., "to burn down", "to wipe out", "to use up"), where the particle has a sense of "completion" and does not usually alter the basic meaning of its verb; and (2), Literal Phrasal Verbs (e.g. "to put in", "to lift out"), where the meaning of the verb and particle can be easily analyzed because each constituent retains its literal meaning.

Also, in this study, phrasal verbs formed from combinations of "to turn/to switch/ to go/ to be/ L (-)shut--on/off", because of their high frequency of appearance in technical contexts, will not be considered as "figurative". They are too common to cause comprehension problems (our purpose in considering this issue), and to count them as figurative badly skews the research results.

\section{Technical Manual}

"Manuals form a one-way communication link between the builder of something and the user of that 
something" (Thorton, 1969). A technical manual (TM) tells someone how to use, maintain, or repair a device; its characteristics, and what will happen if the device isn't used or maintained in the prescribed manner.

Expert Technical Manuals. These texts are designed for the installer, repairer, or maintainer of the device. This person is assumed to have specialized education or training. Such manuals "make little concession to the reader's pre-professional background...they assume that the reader has a knowledge of the basics of whatever their field might be" (Trimble et al., 1979, p. 80). Such manuals can be identified by their titles (e.g. A Databook for Engineers), their placement in a hierarchy of manuals (e.g. auto manufacturers typically write manuals for 5 levels of operation or maintainance (Schulman, 1971)), or simply by asking company technical writers or engineers for whom the manual was designed (see Appendix C for a section from one such text).

Lay Technical Manuals. These are documents designed for the general public, and presumably make concessions to their audience's lack of professional background, i.e., they are "user-friendly". Again, these manuals are also frequently identifiable by their titles, comments in their prefaces, or according to their hierarchical level in a system of manuals (see Appendix D for a section from one such text).

\section{Lexical Variance}

As defined by Barber (1962), lexical density is the ratio of tokens (total number of words) to types (number of different words). However, determining the ratio in this fashion has two inconveniences: (1) defined as such, there is no upper limit to lexical density, and (2) characterized in this fashion it is impossible to determine the significance of results using the chi-square method. Therefore I have chosen to simply use the inverse ratio-that is, the number of different items (types) over the total number of items (tokens), and call it lexical variance (L/V) This allows us to speak of Lexical Variance in terms of percentages, establishes an upper limit (i.e. 100\% lexical variance, where every token is of a different 
type), and permits chi-square analysis. In this study, the lexical variance of phrasal verbs, lexical counterparts, and combined two-word items will be considered, and the higher the lexical variance, the higher the percentage of different two-word items in the text.

\section{Rhetorical Functions}

Rhetorical Function (R/F) is "the name for what a given unit of discourse (some finite piece of text) is trying to do...[it is] the foundation of the rhetorical approach to the analysis of writuen EST discourse" (Trimble, L. 1985, p. 18). Trimble treats 5 rhetorical functions in detail, and a brief description of them follows:

Description. This category inclues three types of description:

Physical: dimensions, materials; other physical characteristics, and spatial relations of the device and its parts

Function: purpose of a device, or a part of the device, in relation to the whole

Process: a special case of function description which is sequential: describing all steps leading to a goal

Definition. Includes formal (i.e. Term, Class, and Differences from other members), semi-formal, and non-formal. One "complex" form of definition is "operation" which tells the reader "ho w to experience whatever is being defined". Timble explicitly distinguishes Definition and Classification(see below) from "Partition", which is, "the process of naming all the parts an object consists of" Trimble et al., 1979, p. 379).

Classification. The division of parts into manageable types according to some principle.

Instructions. A special case of process description defined by its use of imperatives (direct instructions) or modals functioning as polite commands (indirect instructions, e.g. "the rollers should be cleaned each week"). It also includes instructional information: Cautions, Wamings, Specifying Statements (e.g., " only model A-32 has a built-in microphone"), and Theory (the "why" of an instruction). In this study, we will refure to "pure" Instruction when it is necessary to distinguish the more fundamental instruction it describes from Instructional Information 
Yisual-Verbal Relations. Deals with the relation of the illustrative material (i.e. charts, figures, figures) to the text.

Table. Because of the importance of tables in Technical Manuals, and the difficulty of determining the rhetorical function of words in a table, I have created the thetorical category table. The Rhetorical Function of table is to easily identify key words and concepts and identify where they are defined and discussed.

\section{OTHER DEFINITIONS AND ACRONYMS}

$\mathrm{ESL}=$ English as a Second Language: English is a significant medium of communication in the environment, but a second language for the speaker.

EFL = English as a Foreign Language: English may be used in certain contexts, but is not a significant global medium of communication

ESP $=$ English for Specific Purposes

EST = English for Science and Technology

EAP = English for Academic Purposes

EOP = English for Occupational Purposes

ELIT = English as a Language of Information Transfer: English is only read, to provide access to information resources

NNS = Non-Native Speaker 


\section{CHAPTER II}

\section{REVIEW OF THE RELATED LITERATURE}

\section{ENGLISH FOR SPECIAL PURPOSES/ENGLISH FOR SCIENCE AND TECHNOLOGY}

The notion, ESP (originally English for Special Purposes, later English for Specific Purposes (cf. Coffey,1983, p. 2)) originating sometime in the late 60 s, developed as a result of dissatisfaction with

...conventional foreign language instruction as part of the humanistic segment of a general school education, [which] has the unspoken assumption...made by both the learner and the teacher, that the target for acheivement is 'the whole of the foreign language. (Strevens, 1977 p. 145).

It was felt that such an approach was not meeting the needs of many students. Especially in the fields of science, technology and business, learners found that the general ESL courses were not providing them with the language skills they needed in their careers. One reason for this may have been that traditional ESL courses concentrated only on the literary or cultural aspects of the language (Higgins, 1967;

Strevens, 1972). Another may have been that the carefully graded, glossed, and simplified materials used in general ESL courses did not develop strategies to deal with the untreated English that clients encountered in the real world (Allen \& Widdowson, 1974; Phillips \& Shettlesworth, 1978), or possibly, it may have been due to the more general "structural" problems of typical EFL courses, such as three noted by Higgins (1967, pp. 30-31):

1. The students are demotivated towards English due to past failure.

2. The standards of English in the relatively large classes are very variable. 
3. There is a lack of time for English on the timetable.

In addition, as Hutchinson \& Waters (1980) and Widdowson (cited in Swales, 1985) note, language in the classroom does not often simulate what occurs in real-world communication. Often, in the classroom, there is a concern for the usage of English rather than its use in communication. This may be particularly the case regarding technical contexts, as Fanselow (1980) has dramatically demonstrated.

The use of English in a particular context is a predominant concern of ESP. English is an instrument, a tool to acheive a specific goal, or to carry out an activity; rather than a goal in itself. However, this doesn't imply the instruction of a limited English. In fact, ESP courses are typically taken after the learner has developed some basic competence through general ESL courses. Therefore ESP is usually less a restriction of the English to which the learner is exposed than it is a refinement of his previous abilities and competencies directed towards more effective participation in the learner's declared sphere of interest.

Consequently, Strevens (1977) establishes the following criteria for ESP instruction (p. 150--edited to be more concise):

(A) The language-using purposes of the learner are paramount.

(B) The content of the ESP course is thereby determined in some or all of the following ways:

(1) Restriction of basic skills (e.g. reading, writing, speaking, understanding) to those required for the leamer's purposes

(2) Selection of those vocabulary and grammar patterns and functions of language salient or relevant to the learner's purposes

(3) Themes, topics, situations, and discourse are only considered and presented if they are required for the learner's purposes

(4) Communicative needs considered are only those which occur in communicative contexts where the learner participates 
(C) The methodology employed is appropriate to the learning/teaching situation (i.e. ESP is net a methodology itself).

Therefore the question of restriction is a question of the scope of study, not the form of the language. As Coffey (1983) states, "in ESP work, the objective of the restrictive process is clearly defined by the purpose" ( p.4), not the language itself. Still some theoretical base is also needed; some principle of selection must be found to determine the language features to be presented. Coffey (1983) in his overview of ESP notes three major principles which have been used in ESP studies (pp. 4\&5):

\section{(1) Register Analysis:}

Based on the notion that a register of "Scientific English" exists, language from "Scientific and Technical" contexts is analyzed (usually by means of frequency counts) to determine ESTs essential features (cf. Barber, 1967; and Ewer \& Latorre, 1971-72).

\section{(2) Discourse Analysis:}

The analysis of a text or spoken corpus according to its rhetorical features, such as description, classification, definition, etc., Logether with an awareness of how these functions are realized in language and how they are sequenced. (cf. Selinker,1971; and Trimble, 1985)

\section{(3) Needs Analysis:}

Where the ESP practitioner (through interviews, observation, and analysis of situational language use) determines the clients' specific English needs (cf. Munby, 1978).

Of these three principles, Needs Analysis is the predominant principle; however, as Coffey (1983) remarks,

the whole process is so complicated that in most circumstances there is never time to put it into practice. Much has to be, and probably should be, intuited. This of course requires intimate knowledge of the milieu, students, and purposes of the course. (p. 4) 
And even when following this caveat and taking a more informal approach to Needs Analysis, developing a particular ESP course is often an extremely time-consuming process ( Burwell, 1990; McSwain \& Morihara, 1990). Therefore, as a question of expediency, it is often desirable to base curricular design on aspects of Register Analysis or Discourse Analysis.

Today, Register Analysis in ESP is generally discredited simply because it is commonly agreed that there is no special "scientific English". As Strevens (1977) observed,

The study of scientific language shows it is 'normal' language in the deepest sense that (i) a scientist doesn't use a different accent or pronunciation when he is being a scientist than the one he uses as a husband, brother or son; (ii) the rules of grammar he uses for science are the same rules of grammar he uses for the language as a whole; (iii) the rules of spelling and orthography are not suspended for scientists; (iv) even the vocabulary he uses, although it may include some special items...can also make use of any and every lexical item in the whole language ( p. 153)

Such perceptions account for the resignification of the "S" in ESP from special to specific. It is also why Coffey (1983) tells us, "the term EST has fallen into disuse" (p. 4): in early EST research based on Register Analysis, all kinds of discourse in Science and Technology were considered one and the same; and from any one corpus pronouncements could be made about the characteristics of EST as a whole.

Still, some aspects of Register Analysis may retain validity, especially if the scope of research is limited to a genre or subject area. The fact that frequency counts are generally associated with Register Analysis (Coffey, 1983) does not imply that frequency analysis inevitably ends in register analysis. If this thesis uses frequency counts, it is to see how a language feature of interest (e.g. twoword items), functions in a discourse domain (e.g. technical manuals), not to attempt to find linguistic features that are unique to a domain. And since, "in recent years, phrasal verbs have been 'discovered' as an important component in curricula for EFL" (Comell, 1985, p.1), it is reasonable to assume that some ESP instructors would like to know how phrasal verbs function in certain "specific" contexts. 
The problem with Register Analysis is two-fold: (1) it is simply too general; and (2), it has the tendency to characterize EST only in terms of high frequency forms. This is typical of early ESP research, such as Barber's, "Some Measurable Characteristics of Modem Scientific Prose" (1962) where he analyzes two textbooks and a joumal article as a single corpus to determine the use of such features as sentence length, average number of clauses per sentence, frequency of the passive, frequency of use of the different tenses, percentage of different modals and frequencies of non-finite verbs.

Allen \& Widdowson (1974) have argued that this tendency to characterize science as a global genre "revealing a high frequency of forms" is perverse. Rather the issue is "how English language expresses certain scientific facts and concepts" (p. 75). The growing acceptance of such reasoning is why Swales begins the anthology, Episodes in ESP with Barber's article, and ends with one by Tarone et al. (1981). The increase in rigor is striking (the following is essentially a paraphrase of Swales, 1985, p. 186): Barber considers two textbook sections and a journal article as "science text"; Tarone analyzes two astrophysics papers from a single journal, uses an expert informant, and makes very limited claims as to the application of her study. Also, while Barber was interested in a wide variety of features, Tarone is interested only in the question of voice. Barber simply offers his statistical information; Tarone tries to explain the use of a feature using statistical findings as evidence. Similarly, when Barber is descriptive; Tarone is experimental: a hypothesis is developed and tested. Finally, Barber doesn't challenge the adequacy of traditional linguistic treatment, while Tarone challenges it on both rhetorical and functional grounds.

Therefore in this thesis,

(1) only one genre of text is considered and it is assessed in terms of two sub-genres and results are compared to a general text. In addition, while not limiting itself to a subject area (e.g. astrophysics), this research is limited to texts which instruct readers about technical devices.

(2) This research is limited to phrasal verbs and their lexical counterparts, not other language features.

(3) This paper offers explanations for phrasal verbs and lexical counterpart use, based on statistical evidence 
(4) Frequency and types of two-word items are evaluated in terms of the rhetorical function of their contexts.

(5) Informants (a technical writer from Tektronix and an engineer from Devron-Hercules) have been consulted to guide research and confirm assumptions.

(6) This research is an attempt to test the following assumptions: (a) two-word items are more frequent in technical manuals than in more general texts; (b) phrasal verbs have other functions than simply being pragmatic markers of informality; (c) in technical manuals, two-word items are predominantly non-figurative which implies they will cause few comprehension problems.

Finally, despite the reservations noted earlier concerning "scientific English", this writer has chosen to retain the acronymn EST because the term is firmly established (and therefore easily recognizable) in ESP literature. When the term is used in the current research we refer to the study of English as it is used in the domains of Science and Technology, not a register of English that is unique to scientific or technical discourse.

\section{CONTEXTS OF ESP}

This issue of EST touches the related subject of other ESP sub-specialities and the interrelation of their contexts. In addition to ESP and EST, three other acronymns relate to this study: EAP , English for Academic Purposes; EOP, English for Occupational Purposes; and ELIT, English for Information Transfer. Figure 1 on page 19, following Strevens (1977, p. 153), shows the interrelations of the various contexts: 


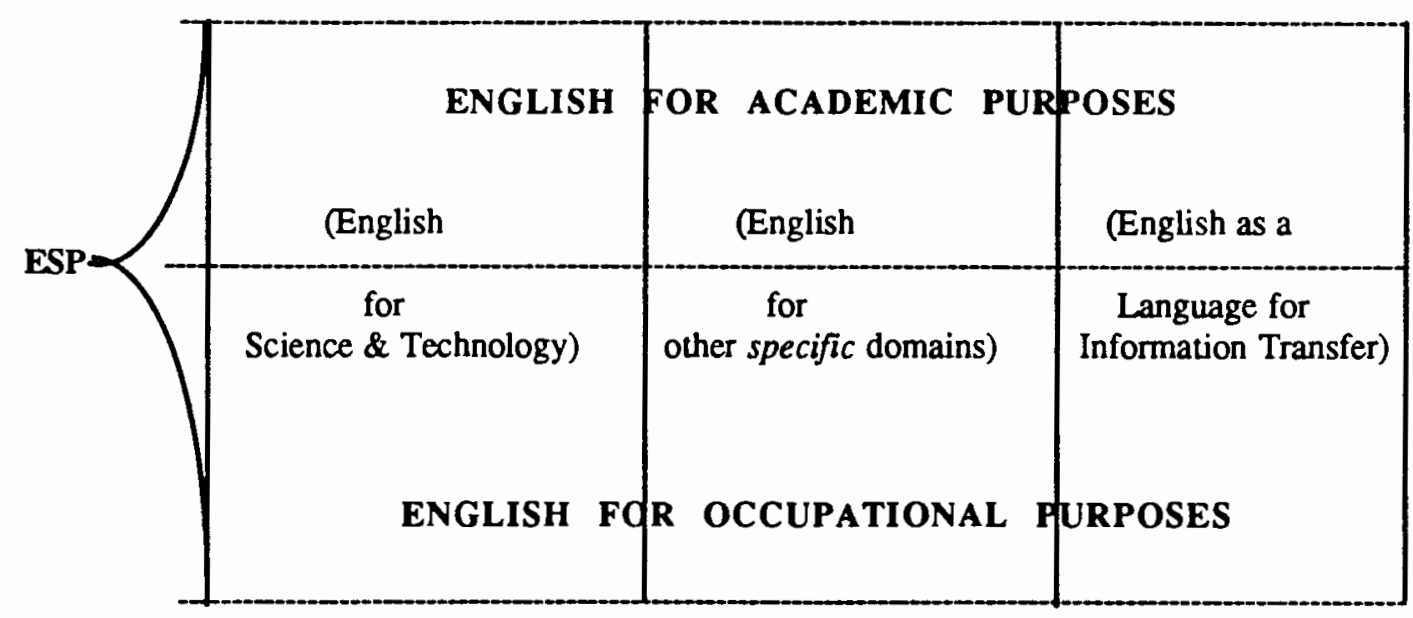

Figure 1. Contexts of English for Special Purposes

The acronymn ELIT is my own creation. Strevens however, was aware of such a context for elsewhere he remarks,

Thus the recipients of technical aid frequently face, for a period of years, a low-level, specialized language-learning requirement among non-academic sector of the working population whose vocational training lacks the help of properly qualified language teachers. Russian for Syrian bulldozer drivers; Hungarian for Egyptian locomotive engineers; English for oil tanker berthing masters at the ports of the Arabian Gulf. (1977, p. 148)

Trimble also acknowledges the need for instruction to meet such needs,

it is because of the great volume of technology spreading throughout the world that we choose the area of technical manuals. There has been a virtual flood of such literature into developing countries. In one way or another, many people who will work with these manuals--the technicians--will have to learn to read the very specialized English they contain. (Trimble et al., 1979, p. 77)

Tinkham (1979) emphasizes the exclusivity of his students' English needs: "We soon realized that our students would never read an English newspaper, go to an English movie, or spend time in conversation with an American" (p. 2). The same conditions often hold for academic English abroad. Ewer (1971-72) remarks that 44 to $65 \%$ of required college texts used at the University of Santiago in Chile were in English. Naranjo (1971) notes that in Ecuador, the first objective for university language 
requirements was "to enable students to read books written in English and related to their areas of specialization". He further notes, "that the objective of the language course in vocational schools is primarily passive [i.e. reading] rather than active use of the language" (pp. 4 \& 11).

Similarly, Allen and Widdowson (1974) note that, "at the tertiary level of education, English teaching has been called upon to provide students with the basic ability to receive--this is particularly so in the 3rd world countries where essential textbook material is not available in vernacular language" (p. 73). Finally, Swales (1980) devotes an entire article to arguing that the most promising avenue of ESP growth is in the area of "Research English", that is, providing the skills for reading ( and in some cases writing) of research reports by graduate students and professors in non-anglophone countries .

In this study, I have chosen to refer to the need for "reading" English in such situations as ELIT, because unlike Swales, this study not specifically concerned with research reports. However if one speaks of "Research English" or "ELIT", some general characteristics criteria can be established:

(1) clients usually do not need to produce written or spoken English, and comprehension is essentially reading comprehension

(2) reading is concerned with only one or two genres of text, probably in a single domain of research or endeavor

(3) clients will likely be unwilling or unable to devote large amounts of time to English instruction

Therefore, recommendations concerning ELIT leamers should (1) address only reading comprehension; (2) should address only language features most useful in understanding the "specified" text genre; and (3) use instructional means which can provide the learner with the most directly applicable information in the least amount of time. This is particularly the case concerning such complex features as phrasal verbs and their lexical counterparts. 


\section{PHRASAL VERBS AND THEIR LEXICAL COUNTERPARTS}

Bolinger (1971), Celce-Murcia \& Larsen-Freeman (1983), Comell (1985), MacArthur (1989), Meyer (1975..), Nattinger \& DeCarrico (1990), Pierce (1990), all identify phrasal verbs as characteristic of informal registers and more common in oral discourse. Nattinger \& DeCarrico (1990) go as far as to claim that phrasal verbs are, "markers of informal register". Celce-Murcia \& Larsen-Freeman (1983) make a distinction between the conversational "to put out" and the more formal "to extinguish", noting that in many contexts, "extinguish sounds pedantic and awkward" (p. 265). MacArthur (1989) says, "phrasal verbs are often informal, emotive and slangy" (p. 40).

Clearly, some phrasal verbs are associated with informal contexts. Charles Brusaw, in Handbook of Techrical Writing (1982) defines Informal Writing and then provides the following passage from Townsend's $U p$ the Organization (1970), as an example of informal discourse:
All you need is a talent for spotting the idiocies now built into the system. But you'll have to give up being an administrator who loves to run others and become a manager who carries water for his people so they can get on with the job. And you'll have to keep a suspicious eye on the phonies who cater to your uncertainties or feed your ego on press releases, office perquisites, and optimistic financial reports. You'll have to give substance to such tired rituals as the office party. And you'll certainly have to recognize, once you get a hunk of your company's stock, that you aren't the last man who might enjoy the benefits of shareholding. These elegant simplicities require a sense of justice that won't be easy to hang on to.

(Townsend, p. 11, cited in Brusaw, 1982, p. 299, italics mine)

In this short passage, phrasal verbs make up $2 \%$ of the total discourse, a far higher percentage than was found in any of the research corpora. Similarly, Trimble (1985) associates phrasal verbs with informal contexts when he disparages the tendency of some technical writers to go from formal to informal style in a single text, noting that "students have difficulty with such terms as 'check out', 'simply draw', and 'jotting down'" (p. 100). 
MacArthur (1989), Nattinger \& DeCarrico (1990) and especially Meyer (1975), claim a historical basis for this informality noting that phrasal verbs and their lexical counterparts have a Germanic/Anglo-Saxon origin making them a pan of "folk language" (Meyer, 1975, p. 8), which contrasts with, "their leaméd single word counterparts of Latin and French origin that are associated with academic endeavor" (Meyer, 1975, p. 1).

Perhaps because of biases arising from such perceptions, phrasal verbs have not been a traditional subject in English swdy, particularly in EFL environments, where the Latin and French literary forms are the dominant scholarly focus (Burnaby \& Sun 1989, and Comell, 1985).

However as Celce-Murcia \& Larsen-Freeman (1983) note, "no one can speak or understand conversation or informal English easily without a knowledge of phrasal verbs" (p. 265). Therefore it is not surprising to find Comell (1985) claiming,

There can be no doubt that phrasal verbs have received a considerable amount of attention in recent years. One might almost say they have been 'discovered' as an important component of curricula for English as a foreign language. This is due to various factors, not the least the general increase in interest in the spoken language. (p. 269)

Accordingly Pierce (1990, p. 20) observes that more and more ESL texts are devoting sections or chapters of textbooks to phrasal verb instruction, with Celce-Murcia \& Larsen-Freeman (1983); Comell (1985); Gairns and Redman (1986); and Nattinger \& DeCarrico (1990), all noting that phrasal verbs can cause comprehension as well as production problems.

While Celce-Murcia \& Larsen-Freeman (1983); Meyer (1975); and Nattinger \& DeCarrico (1990), all note that non-germanic languages have no equivalents to phrasal verbs, making them difficult to acquire for leamers of other language backgrounds, Nattinger and Decarrico also note that it is nevertheless, "essential to leam phrasal verbs because they are so common". Indeed, Hook (1981) claims, "they are the most commonly used verbs in English", noting that, "there are at least 3 to 4,000 
established phrasal verbs in English" (p. 1). However, especially because most languages have no equivalent forms, "most ESL/EFL students will find such verbs strange and difficult" (Celce-Murcia \& Larsen-Freeman, 1983, p. 265). This problem is compounded because (1) many phrasal verbs are idiomatic or figurative (e.g. "to give up" means " to surrender", but this cannot be determined from the meaning of each of its constituents, "to give" and "up"); (2) polysemy (e.g. "put s.o. up for the night" vs. "put s.o. up to something" vs. " to put up a good fight" vs. "to put up with fighting"--cf. Comell, 1985, p. 270) ); and (3) the lack of generalizability and semantic extension: you can "put up with s.o.", but you can't "put down with s.o."; You "plug in" a machine, but you don't "plug out" a machine (cf. Palmer, p. 180).

Therefore it is not unexpected to learn that there is "something demoralizing about phrasal verbs when non-native speakers confront them" (Comell, 1985, p. 270). In the same vein, Nattinger \& DeCarrico note "the confusion and mystery that these forms often present to second language learners" (1990) and Gaims \& Redman (1986) add, "this latter category (i.e. figural phrasal verbs)...creates [the] most difficulty and contributes to the mystique which surrounds multi-word verbs for foreign learners" (p. 33). They continue in noting, "we have already mentioned the obsession with multi-word verbs which seems to grip many foreign leamers, particularly as they pass through the intermediate level" (p. 34). Indeed, a popular French self-study book, Les 100 Pièges de l'Anglais (Rogers \& Olorenshaw, 1985), for leamers of Intermediate to Advanced levels, devotes almost one-third of its contents to various multi-word verb expressions.

This frustration has a number of sources: (1) figurative phrasal verbs cause comprehension problems (Celce-Murcia \& Larsen-Freeman, 1983); (2) but even literal phrasal verbs can cause difficulties "because the meaning of the particle is unpredictable" (Nattinger \& DeCarrico, 1990). Also, (3) there is the problem of semantic variance between phrasal verbs in British and American English (Cornell, 1985). Furthermore, (4) many phrasal verbs have unique syntactic properties, "which means that leamers need to be able to distinguish phrasal verbs from other superficially similar forms" 
(Nattinger \& DeCarrico, 1990); this is particularly a problem (5) for separable phrasal verbs in those contexts where the separation is obligatory or preferable (ibid). Finally, (6) production is also a problem when learners confuse particles, a phenomenon which is sometimes caused by First Language interference (e.g., the German who says "drink out" (austrinken) instead of "drink up" (Comell, 1985, p. 274). Clearly, the characteristics of phrasal verbs are a thomy problem which must be addressed before any instructional treatment can be proposed.

\section{SYNTACTIC CHARACTERISTICS OF PHRASAL VERBS}

Traditional grammarians define a phrasal verb as a verb followed by a particle (variously described as a preposition, an adverb, or some combination of the two), and although particular descriptions may vary in their details, phrasal verbs are usually divided into the following syntactic classes:

\section{(A) Intransitive Phrasal Verbs.}

They take no direct object. They may be truly intransitive,

My car broke down.

or superficially intransitive:

Harold got off at 42 nd Street. (understood direct object, "the subway")

\section{(B) Transitive Phrasal Verbs.}

They take a direct object. There are three types: 
(1) Two-Word Inseparable Phrasal Verbs.

Evan came across it in a magazine.

Greta ran into an old friend.

(2) Three-Word Inseparable Phrasal Verbs. where the third word is variously defined as a preposition or a second particle (Nattinger \& DeCarrico, 1990):

I won't put up with this nonsense.

She gets along with Igor very well.

(3) Separable Phrasal Verbs. where the direct object is inserted between the verb and the particle:

They took his wife away in a strait jacket.

Often, with regular noun phrases, the separation is Optional, but with some phrasal verbs, the separation is Obligatory:

How can I get my message through to him?

*How can I get though my message to him.

And with pronouns, if separation is ever possible, the separation is alway obligatory:

Pick it up.

*Pick up it.

In addition, it is necessary to distinguish phrasal verbs from simple Verb + Preposition constructions:

He worked over the other workers on a scaffold. (above them, simple Verb + Prep) He worked over the other workers with a club. (he beat them, phrasal verb) 
Also there are Prepositional Verbs, where the preposition following the verb is syntactically necessary, but it contributes no semantic information:

I'm interested in French.

You can depend on Allstate.

\section{Syntactic Tests for Phrasal Verbs.}

\section{Eor Intransitive Phrasal Verbs.}

(1) Prepositions need Noun Phrases: Not really a test, but if nothing follows a feature that looks like a preposition, that feature must really be a particle, because prepositions must be followed by a noun phrase:

The train slowed down.

\section{For Transitive Phrasal Verbs.}

(1) Separation: if the NP can be inserted between the verb and the following constituent, the combination is a phrasal verb:

He burned the hotel down.

She gave the attempt up.

This is a very effective test. Unfortunately, obviously, it is only applicable to separable phrasal verbs. A partial solution for one type of inseparable phrasal verb is another quasi-test proposed by Nattinger and DeCarrico (1990). They suggest that,

(2) The Double Particle Construction of 3-Word Phrasal Verbs: (e.g. "put up with" and "catch up on"), is such that "[these constructions] are not likely to be confused with adverbial phrases." 
(3) WH Fronting: Prepositions can be moved to the front of a WH question, particles cannot:

\author{
At what did Sara look? \\ *Up what did Sara look?
}

Unfortunately, such WH questions sometimes sound formal and stilted, even with what are clearly prepositions. In fact, as Nattinger \& DeCarrico (1990) note in the following examples, with some verbs, Prep Fronting seems downright unacceptable:

?At what did Sara peek?

??At what did Sara scream?

???At Whom did Sara leer?

Additionally, the WH fronting test does not seem to eliminate prepositional verbs from phrasal verb candidacy:

?About what did you talk?

?To what did the misunderstandings lead?

(4) A test similar to WH fronting is the Relative Clause Fronting Test:

Sara looked at the picture. .-.> The picture at which Sara looked.

The Relative Clause test has an advantage over the WH Fronting test in that it seems a bit more amenable to fronting, however Nattinger and DeCarrico still note problems:

??The fence over which she looked. (1990)

(5) Adverb Insertion: Celce-Murcia \& Larsen-Freeman (1983, p. 269) note that an adverb may be acceptably inserted between a Verb and a Prepositional Phrase, but not between a Verb and its Particle: 
However, they also note that the test is problematic for some phrasal verbs like,

? He got quickly over his cold.

? I came suddenly across an interesting article.

which many native speakers find acceptable. This is unfortunate. For this writer, there is no question about the unacceptability of these sentences. If this were the case for all native speakers, one advantage of the Adverb Insertion test would be to more easily distinguish between phrasal verbs and prepositional verbs. Even so, this test may not exclude all prepositional verbs from phrasal verb candidacy:

??He was interested suddenly in gourmet cooking.

? They depended clearly on his good will.

(6) Passivization: Palmer (1968) notes that true phrasal verbs may be passivized like single word verbs (p. 180):

She was tolerated

She was put up with.

* The stairs were walked up by John.

The trouble with this test is that clear phrasal verbs, that are clearly figurative, aren't clearly acceptable:

??An appetite was worked up by John.

The unreliability of such tests, and the English Language Learner's inability to use them to make judgements about grammaticality, has caused some researchers to consider the semantic characteristics of phrasal verbs, and try to develop some semantic tests, which might help to distinguish phrasal verbs from other multi-word expressions. 
SEMANTIC CHARACTERISTICS OF PHRASAL VERBS

Celce-Murcia \& Larsen-Freeman (1983), and Nattinger \& DeCarrico (1990) following Fraser (1976), have characterized phrasal verbs according to three semantic levels:

\section{Literal:}

Those phrasal verbs where the meaning of each constituent retains its literal sense:

I hung up the picture.

\section{Completive:}

Those phrasal verbs where the particle indicates a completed action:

I tore up the piece of paper.*

\section{Figurative:}

where the sense of the combination cannot be derived from the meanings of its constituent parts:

Cheryl looked up the answer.

Rock 'n Roll turned Jeffrey on.

Bolinger (1971), MacArthur (1989), and Palmer (1968) however prefer to consider only two semantic levels. MacArthur for example, considers phrasal verbs to be either (1) "Conventional and Literal", or (2) "Idiomatic and Figurative" (p. 40). This may be a better analytical criteria, for as Celce-

* Fraser also notes that one common characteristic of many literal and completive phrasal verbs is that the particle may often be deleted without affecting the acceptability of the sentence:

I hung the picture.

I tore the piece of paper. 
Murcia \& Larsen-Freeman (1983) note, "problems can emerge when one tries to classify a large number of phrasal verbs according to Fraser's criteria. For example, is 'write up' figurative or completive? " (p. 274). In fact, Pierce's (1990) initial attempt to classify phrasal verbs found in academic lectures by Fraser's criteria was abandoned due to an inability to achieve inter-rater reliability (DeCarrico, 1990, personal communication). Pierce instead found it necessary to adopt the semantic categories of Figurative and Non-Figurative, which strongly ressemble MacArthur and Bolinger's criteria.

\section{Semantic Tests}

Nattinger \& DeCarrico (1990) are especially concerned with the semantic characteristics of phrasal verbs, and they therefore provide two semantic tests:

(1) Semantic Unity Test: "to ask whether or not the literal meaning of either the verb or the particle changes when the two enter into combination." Nattinger \& DeCarrico (1990) continue, "further, if either a different verb or a different particle is substituted, the literal meaning of the substituted verb or particle will be lost".

The problem with this test is that it seems to eliminate all "literal" phrasal verbs from Phrasal Verb candidacy (e.g. "hang up", "pull up", "take off")--a problem for the present research, as it appears that the majority of phrasal verbs found in Technical Manuals are of the literal variety.

(2) The WH Question Test: depends on the possible answer to WH questions about the preposition and noun phrase following the verb. For transitive phrasal verbs there must be a direct object. Thus, if the answer involves "where", "when", or "why" (or other adverbial functions such as "how" or "with"), the lexical material following is a prepositional phrase functioning as an adverbial. (Nattinger \& DeCarrico, 1990)

John ran up a hill. --> Where did John run?

John ran up a bill. --> What did John run up? 
The immediate problem one senses with this test is, why one would not "naturally" ask, "What did John run up?", as the question corresponding to "John ran up the hill."? However, with a litule practice, the noun phrase / adverbial phrase distinction becomes more obvious, and in most cases, even with a large number of items, the WH question can be useful.

The second problem which Nattinger \& DeCarrico (1990) acknowledge, is that the WH Test distinguishes Verb + Prepositional Phrase combinations from phrasal verbs, but it doesn't distinguish prepositional verbs from phrasal verbs. Because of this, "it is necessary to supplement the WH Test with the Test of Semantic Unity". This is justifiable for Nattinger and DeCarrico, because "semantic unity is the basic criterion for phrasal verbs". And to be just, one of Nattinger \& DeCarrico's primary aims is to find tests that Non-Native Speakers can use to make judgements about grammaticality, even if such test have certain limitations. However, as was noted earlier, this criterion of "semantic unity" seems to exclude "literal" phrasal verbs from phrasal verb candidacy--a big problem for this thesis, even though elsewhere Nattinger and DeCarrico (1990) acknowledge the existence of such literal phrasal verbs.

\section{THE PROSODY OF PHRASAL VERBS}

Bolinger (1971), Frank (1972), MacArthur (1989), and Palmer (1968) all note the prosodic charateristics of phrasal verbs and propose prosodic tests to determine phrasal verb candidacy. MacArthur is the most succinct in his characterization when he states,

in a phrasal verb proper, in normal speech, where no special emphasis is employed, the adverbial particle is stressed:

She picked up the book.

However...prepositional verb[s] [are] not normally stressed like this:

I didn't bárgain for that. 
In three part fusions, the stresses combine the two patterns as in,

He lóoks UP to péople like that.

Bolinger (1971), on the other hand, devotes an entire chapter to the prosody of phrasal verbs . Even so , the degree of applicability of such prosodic tests for ESL learners is doubtful, for as Nattinger \& DeCarrico note, (1990), for Non-Native Speakers, the subtleties of such tests are very difficult to master. In fact, this writer has found the same to be true for native speakers, when attempting to analyze a large number of multi-word verbs, prosodic tests are simply too delicate to be effective research tools.

In summary, lacking globally effective tests to determine phrasal verb candidacy, it is not surprising that authorities differ on phrasal verb characteristics. Dieterich \& Sohn-Vasbinder (1990), and Quirk et al. (1985) considering phrasal verbs within the general framework of English structure, consider only intransitive and separable transitive phrasal verbs as genuine. Comell (1985) and Courtney (1983), following a European tradition (and this tradition may be "European" because while Romance languages lack phrasal verbs, they do have "Verb + Postposition" constructions), consider both phrasal verbs and prepositional verbs as phrasal verbs*. Finally, Nattinger \& DeCarrico (1990) want to consider phrasal verbs within their Lexical Phrase description of language as polywords: "short, fixed lexical phrases whose meaning is not analyzable by regular rules". Therefore, they stress semantic concerns over syntactic ones.

Clearly, in the close cases, what constitutes a phrasal verb is dependent on the researcher's perspective. Here, tests used in data collection have been primarily syntactic to ensure rigor; on the other hand, the focus of this research is on ESL. Consequently, pedagogical usefulness remains an important criteria for inclusion.

* Although Courtney (1983), succeeds in having her cake and eating it too by using "idiomacity", designated by a rough and ready "*", 10 distinguish between prepositional and phrasal verbs. 
Therefore, in practice, with practice, determining whether an expression is a phrasal verb or not is usually not difficult. In the present research, intransitive phrasal verbs, transitive separable phrasal verbs, inseparable transitive phrasal verbs, and three-word phrasal verbs are all considered genuine. In addition, although many grammarians tend to consider "to be + Particle" constructions as examples of predicate adjectives (Dieterich, 1990, personal communication), here they are grouped as phrasal verbs because of their close semantic relation to their "syntactic" phrasal verb counterparts (e.g. "tum on / tum off", "switch on / switch off" ==> "to be on / to be off"). Also, because of the technical nature of the corpora examined, a few short adverbs (esp. "apart" and "together") have been considered to sometimes function as particles (a determination supported by Courtney, 1983, and Bolinger, 1971). However, it must be added that the frequency of phrasal verbs containing such particles was too low to have any appreciable effect on research results.

Finally, this study has paid particular attention to the characterization of two-word inseparable phrasal verbs. Some inseparable two-word verbs combinations have been admitted by this research as genuine phrasal verbs; however, many combinations that Nattinger \& DeCarrico (1990) consider phrasal verbs, are here considered simply prepositional verbs. This is because (1) in cases like "turn into" and "call on", the would-be "particle" seems to have only a syntactic function, contributing no semantic value to the fusions. For example, the simple "turn" like "turn into" has a sense of "become":

The milk turned sour.

Leaves turn brown in the Fall.

The caterpiller turned into a butterfly.

and because (2) according to this writer's intuition, adverbial insertion is acceptable with these combinations:

The caterpiller turned suddenly into a butterfly.

The teacher called immediately on the student.

vs. 
* I came suddenly across an interesting article.

* He ran continually into his old friend.

as is (3) Relative Clause Fronting. Compare,

The butterfly into which the caterpiller had turned flew across the meadow. The student on whom the teacher had called sat down.

to

* An article across which I came yesterday.

* An old friend into whom he ran last week.

However, occasional disagreement of this kind should be expected. As MacArthur (1989) notes, there is "an uneasy continuum between phrasal verbs proper... and straight-forward prepositional phrases" (p. 42). One telling example is the following:

(1) He plugged the iron in.

(2) He plugged the iron into the outlet.

Where sentence (1) employs a phrasal verb, and sentence (2) uses a verb with a prepositional phrase. MacArthur (1989) would explain sentences like (1) by saying, "the preposition has, as it were, been 'stolen' from its own phrase and fused to the verb" (p. 42). For him, "a phrasal verb relates basically to movement and position" (1989, P. 42). Meyer (1975, p. 17) also supports this assumption, when refering to the second element of two-word verbs: "they are all words which in their earliest history, indicated location or direction in space." Furthermore, Bolinger (1971) notes, "in its core meaning, the particle must contain two features, one of motion, the other of terminus or result" (p. 85), and he later suggests that "most technical verb formation [is] done with phrasal verbs" (p. 172).

\section{FUNCTIONS OF PHRASAL VERBS}

This continuum between "semantically unified polywords" and prepositional phrases of location or direction has important consequences for this study. It is natural that figurative phrasal verbs are more 
interesting to researchers, but in this analysis of Technical Manuals, it seems that literal phrasal verbs, those that relate to position, direction and activation, are the phrasal verbs that dominate.

Actually, this is not surprising. Ewer and Latorre (1972) note that many of the verbs found in Technical Manuals are those that deal with "control and adjustment" (p. 170). Cobb (1972), in a study of Technical Manuals found 135 verbs common to manuals which were not on West's General Service List, and who knows how many more would have been found if West hadn't analyzed "verbs" and "prepositions" separately. Indeed, in his analysis of Technical Manuals, Tinkham (1979) notes "to touch" as a verb appearing only once in semantic imperative sentences, but then to give an example of a "semantic imperative" he provides the following sentence with "touch up" not "touch":

Damaged or reworked areas must be touched up by brush cadmium plating. (p. 10, underline mine)

This tendency to give prominence to certain lexical items is also discussed by Salager (1979) who notes the "doublet phenomenon" (where English has 2 synonyms: one of Germanic and one of Latin origin, (e.g., "to yield" and" to produce")), and notices that alternating between the two forms is widespread in EST texts, which causes comprehension difficulties for Romance Language Speakers leaming English. This self-same "doublet phenomenon" Meyer (1975) explicitly associates with phrasal verbs, as does Bolinger (1971), suggesting that phrasal verbs may be an important issue in considerations of EST discourse. Therefore we should question Meyer's earlier claim that "new terminology in the sciences continue[s] to be developed by using Greek and Latin" (1975, p.1), especially when he himself states,

The two word verb is the most productive and creative pattem of word formation in the American language. New forms are being created constantly in many such fields as science, technology, social development, sports, art, warfare, human relations and mass communication. (p. 1) 
Likewise, we should be wary when Nattinger and DeCarrico (1990) say that one criteria for phrasal verbs is that "they have a single word counterpart or simple paraphrase", for these single word "counterparts" may not be truly equivalent as Cornell (1985) notes,

Phrasal verbs cannot be presented simply as a battery of synonyms...they are often more specific in meaning than their equivalents, and often carry connotations which the potential learner must be aware of (p. 275, italics mine).

On the whole, there seems to be a tendency to devalue phrasal verbs as colloquialisms. For example, Tumer (1974) considers words "like 'blueprint', 'break down', 'overall' , and 'target' as vague words to think twice about using" (p. 61).However, we must note that Tumer later turns around and contradicts himself, stating,

the verb and adverb combination is often used to cover a new thought or idea (e.g. breakthough, blackout, rundown). Practically all abstract ideas can be expressed by one of the following words, either by itself or combined with an adverb. If these short AngloSaxon, idiomatic words are used, the writer's meaning generally becomes clearer. (p. 163).

This advice is followed by a list of 50 "common verbs" and 20 "adverbs they can combine with" (p. 164).

Such contradictions seem to abound in phrasal verb research. Nattinger and DeCarrico (1990), following Fraser (1976) take the view that figurative phrasal verbs were once more literal, "based on existing contexts which have since disappeared" (e.g. "putting up a guest" = literally, "putting them in an attic room"). Therefore, for them, many such metaphorical " associations are lost to contemporary speakers" (1990, italics mine). But Bolinger (1971), like Tumer in the citation above, argues the opposite: "expressions like 'to step out' are always motivated and hence strikingly expressive...[because] in all its meanings the metaphorical core lies bare" (p. xii, italics mine). Schulman (1971) also values such "anglo-saxon" vocabulary for he tells Technical Writing students, 'words must be chosen for impact and action. For example 'get' is better than 'obtain', and 'do' is better 
than 'perform'" (p. 57).

I believe the problem here, the main reason for these contradictions is that writers often pay brief lip service to literal and completive phrasal verbs and then pass on to their main discussion: figurative phrasal verbs. For example, Nattinger \& DeCarrico (1990) say, phrasal verbs "are especially frequent in conversation and since most are conversational in style, they function as one of the markers of informal register", but elsewhere in the same text they briefly remark,

phrasal verbs are of course, rarely formal in register, and while many function to signal informal register, some are also neutral, conventionalized forms and occur in formal speech and writing as well as conversation.

Cornell (1985) also states that,

phrasal verbs occur on the whole more frequently in spoken than in written language...though the situation is by no means static--a phrasal verb hitherto felt to be colloquial or informal may, sometimes quite abruptly, become accepted in more formal contexts. (p. 269)

Likewise, MacArthur (1989) calls phrasal verbs, "informal, emotive, and slangy" (p. 40), but acknowledges in passing a few pages later, "the massive use of the literal [phrasal verb] system" (p. 43).

The answer to this contradiction is evident. At one point, Brusaw (1982) "improves" an example sentence by inserting a phrasal verb:

change Pass card through punch area for debris.

to Pass a card through the punch area to clear away debris.

(p. 302, italics mine)

His justification for this is, "the meaning of the phrase 'for debris' needed to be made clear. The adaption is easily and quickly understood" (p. 303). 
Indeed, I think it is clear: while some figurative phrasal verbs mark informal discourse, others, along with almost all literal phrasal verbs are neutral. In fact in many cases, these two-word items are preferable to their latinate counterparts because they are more concrete, and if we remember Cornell's observation (cf. p. 35 of this study) regarding "doublet" counterparts--more precise. For example consider this obviously formal passage from Newmeyer's, Linguistic Theory in America: the First Quarter-Century of Transfarmational Grammar (1980):

The principles of blind application on transformational rules (section 6.3) has speeded $u p$ the search for perceptually based explanations of acceptability judgements, since such explanations generally allow complex conditions to be removed from the statement of transformational rules.

(p. 222, italics mine)

Surely here Newmeyer does not choose this figurative phrasal verb for its informality. Moreover, although Nattinger and DeCarrico (1990) mention that figurative phrasal verbs "are especially numerous in English", this is not be the case for all discourse areas, particularly in technical discourse for as Brusaw (1982) notes, "technical writing style is unadorned with figurative language except where a figure of speech genuinely improves understanding" (p. 588). In fact, most phrasal verbs found in technical manuals are non-figurative and seem not to be informal, suggesting they may have different semantic and pragmatic roles. In order to better describe such a difference, we should consider the question of formality.

\section{FORMAL AND INFORMAL STYLE}

As was just noted, most researchers associate phrasal verbs with informal language style. But what are the characteristics of formal and informal styles? Warringer's English Grammar and Composition (1977) states that, "formal English is chiefly written. Its sentences are likely to be longer than those of formal English...Formal English rarely admits slang and makes little use of contractions" (p. 104). Additionally, Brusaw (1982) says of technical writing, "although it is not as formal as it once was, technical writing is nonetheless formal...and the vocabulary is specialized" 
(p. 229). Certainly the technical manual is a relatively controlled and conventionalized genre. Style books and related journals abound.

As to Informal English, Warringer (1977) says,

[it] is everyday language most of us use. When it appears in books and newspapers, it's often close to formal English; when it appears in friendly conversation and letters, it may contain some slang...good informal prose usually has been carefully written and edited, but tries not to sound like it (pp. 103 \& 105).

Brusaw (1982), the Technical Writing instructor, adds that, "this style is relaxed and colloquial...it is found in most private letters, many mass circulation magazines and some business correspondance" (p. 295). This is traditionally not the perferred style of technical manuals. In his Handbook of English in Engineering, Howe ( 1940) remarks, "informal writing should never be used. Colloquialisms, that is, loose expressions tolerated in ordinary conversation, are not considered good usage in formal writing" (p. 33)

Certainly phrasal verbs, in their Anglo-Saxon origins, are everyday language; perhaps that is why one technical writing manual recommends deleting certain phrasal verbs in a lesson on "avoiding wordiness" (Masters, 1986, pp. 232-233). Blicq (1986) shows similar preconceptions when he suggests, "we write 'put' when we would do better to write 'position', 'insert', 'drop', 'slide' or any one of numerous descriptive verbs that describe action better" (p. 348). He further recommends eliminating "vague words", and gives examples like "get it out", "pick up", and "spare parts".

On the other hand, it seems that the lowly phrasal verb is capable of contaminating its betters. MacArthur (1989, p. 41) notes that "even Latinate forms can become phrasal verbs" (e.g. "divide up"), and for every "traditionalist" technical writer like Blicq, we can find another like Schulman (1971) who advises that, " words must be chosen for impact and action...'make' is better than 'fabricate"' (p. 57). Moreover, even traditionalists don't reject phrasal verbs out of hand. In discussing colloquialisms in 
technical writing, Howe (1940) condemns those who would use "pan out" in place of "tum out" (p. 34).

Once again we find contradictions, and once again it seems very possible that they stem from a failure to distinguish between figurative, colloquial two-word items and more literal phrasal verbs. That technical manuals are written, already gives them more formality than most oral discourse, and they usually display the characteristics that Brusaw (1982), Howe (1940), and Warringer (1977) associate with formal style. For example, while contractions may appear in Technical Manuals in the special case of "warnings" (i.e. negative imperatives), contractions in general, are rare. True, sentence length is often short to enhance clarity, but on the other hand the vocabulary is obviously specialized, and it is formal in being addressed to a specialist audience (cf. Brusaw, 1982, p. 229). Therefore technical manuals tend to exhibit tendencies associated with formal style. Yet they contain a higher percentage of phrasal verbs than more general texts, which shows that not all phrasal verbs are of informal register. Indeed, unlike more general texts, the phrasal verbs that appear in technical manuals tend to be nonfigurative in nature, suggesting they are pragmatically neutral .

\section{LEXICAL COUNTERPARTS}

The lexical counterparts of phrasal verbs are nouns like "breakdown", "input", and "upkeep" which are lexically and semantically related to a corresponding phrasal verb. Although the expression "lexical counterpar ${ }^{n}$ is of my coining, Bolinger (1971), MacArthur (1989), and Meyer (1975) have discussed such phenomena:

MacArthur (1989) notes that lexical counterparts may be formed in two ways: (1) "in a sort of consolidation where the phrasal verb becomes a noun simply through a stress shift: 'bréak down' becomes 'brékdown"; and (2), "when the word order is reversed: 'onrush' or 'upsurge". He continues to note that "sometimes these dual processes allow two such compound nouns to be assigned to a single phrasal verb", such as "outbreak" and breakout" (p. 42). 
Meyer (1975) speaks of lexical counterparts as, "the noun and adjective elements needed for communication in our present day, rapidly evolving society", adding that, "this type of verb and noun formation appears particularly congenial to the American mind" (p. 1), and Bolinger (1971) considers that, "next to $N+N$ combining (i.e. nominal compounds), these combinations of verb + adverb or preposition are the most prolific source of new nouns in English" (p. iii-iv).

Earlier we noted that Trimble (1985) found some phrasal verbs caused comprehension problems for non-native speakers. Curiously, he does not find this to be the case for lexical counterparts for he remarks, "These short, fused compounds cause little trouble as most of them yield to literal translation and to turning into simple phrases" (Trimble et al., 1979, p. 94).

Certainly, the lexical counterparts of phrasal verbs have a role in technical writing. Turner (1974, p. 163), a Technical Writing instructor, says of lexical counterparts, "If these short, Anglo-Saxon, idiomatic words are used, the writer's meaning generally becomes clearer". Similarly Brusaw (1982) provides the following passage as an example of Technical Writing Style:

The executive software controls all program-related functions such as handling input and output operations, interpreting and executing macro-instructions, providing format and translation capabilities, and handling error conditions. To conserve valuable memory space, only pertinent software overlays are memory-resident during program execution; all other software overlays reside on disc and are called into memory only when needed.

The software overlays that reside in memory during program execution are collectively called the executive software. Program-related software overlays (such as arithmetic and logic routines, the program overlay call, the GET and PUT routines, the format and translation routines, etc.) are included in the user's object program. Other executive routines and certain hardware control information are read into dedicated memory locations (called the Resident Executive Area) by Monitor at the start of the day and between programs; this group of routines and the control information comprise the Resident Executive. When necessary, the Resident Executive's Special I/O routine calls disc-resident software overlays into the Primary Software Overlay Area (PSOA), which is a 512-byte area of memory located beyond the user's program area.

(NCR Century Operating System Manual, Dayton, NCR Corp., 1969, p. 14; in Brusaw, 1982, p. 589, italics mine) 
Finally, it is interesting to note that in Texas Instrument's Bipolar Microcomputer Component Databook for Design Engineers (1979), of the 65 terms defined in the glossary, 39\% contain lexical counterparts. Similarly, of the 69 acronyms used in the databook and glossed in the introduction, $28 \%$ contain lexical counterparts. Clearly, lexical counterparts play an enhanced role in technical manuals.

\section{TECHNICAL MANUALS}

Technical Manuals, in the most general sense, "tell how to perform an activity" (Hicks, 1961, p. 207). They tell the reader, "how to install, design, repair, build, maintain, assemble, or use a device or product" (Trimble et al., 1979, p. 75). As Thorton states (1969, cited in Trimble et al., 1979), "They form a one-way communication link between the builder of something and the user of that something", the user being, "the installer, repairer, or maintainer of something" (Trimble et al., 1979, p. 85). Schulman (1971, p. 4) adds that Instructional Manuals are "a continuing reference for the life of the product which contains information that is neither necessary or desirable to remember."

Technical manuals generally "make little concession to [the] pre-professional background" of the reader (Trimble et al., 1979, p. 80). A cernain level of knowledge is presupposed. This is why Hicks ((1961, p. 208) insists to would-be technical writers, "Underlying theory is almost never discussed...Do not describe underlying theory unless under orders to do so". Indeed, this perspective is one basis for Brusaw's (1982, p. 229) characterization of technical manuals as "formal": "Formal style is usually the work of a specialist in a particular field writing to other specialists"; or as Trimble (1985) states on a more concrete level, "the text assumes that the user knows various controls, and can read code terms such as $88 \mathrm{~A}^{\prime \prime}$ (p. 95).

The exception to this may be manuals for "leamers, apprentices, and hobbists (i.e., "lay" manuals)...[which] provide more definitions" (Trimble, 1985, p. 95). In fact, one writer of such a manual explicitly states an intention to make concessions to his readers' backgrounds saying, "we work 
as a team", adding that he wants to "fill the gap between what to do and how to do. There are books to satisfy what to do with élan, but you have to have the preliminary knowledge" (Muir, 1990, p. 5, italics mine).

Truly, this is often the problem with technical manuals for Native Speakers and Non-Native Speakers alike. As Tinkham (1979. p.3) astutely observes, "There would be nothing difficult about the sentence, 'Remove the spiralox retainer', if one knew what a spiralox retainer were". Such problems are literally global: Trimble (1985, pp. 98-99), in discussing selection of materials for teaching instructions notes, "not all are well-written". And this is not only a problem for technicians, elsewhere Trimble (1985) notes that

while there is often a marked difference between instruction for technicians and academic personnel, there's a broad area of overlap--most often seen in laboratory and other manuals used by both trained technicians in research facilities and by academics (i.e. students and teachers) in laboratories .(p. 95)

Nor is the problem isolated geographically: "There has been a virtual flood of [technical manuals] in almost every country in the world and one factor these materials have in common is that they are written for native speakers of English" (Trimble et al., 1979, p. 79-80). Almost 10 years later this continues to be the case. True, some technical writing manuals pay lip service to needs of ESL audiences ( Schulman, 1971; Tumer, 1974), but they address no specifics about how to adapt instructional presentation. Also, while some corporations like Caterpiller, McDonnel-Douglas, and Eastman Kodak (Grimas, 1987; Sanderlin, 1988) publish their technical manuals in "controlled" or "fundamental" English, they are exceptions to the rule. Therefore, Non-Native Speakers, "have problems of lexis, style, and syntax to some degree, in virtually every technical manual" (Trimble, $1985, \mathrm{p} .85)$. 


\section{Some Criteria.}

Hicks (1961) defines an Instructional Manual as "any set of instructions on operation, maintenance or assembly of 4 pages or more" (p. 211). If the text is less than 4 pages he calls it a bulletin. Other writers refer to sheets or booklets, as well as bulletins. In this study, the three expressions are synonymous as are the two expressions Technical Manual (preferred for example by Trimble and Brusaw) and Instructional Manual (preferred by Hicks and Schulman). Both terms are appropriate: Strevens (1972, p. 229) defines Technical Services "[as being] concerned with how to construct and maintain the devices invented by technology according to principles established by the sciences" (italics mine). Additionally, we should note that one important difference between general information texts (e.g. a newspaper) and a manual is that a technical manual provides instructional information.

\section{FORMAL PROPERTIES OF TECHNICAL MANUALS}

EST research of the 70 s and 80 s typically examined the formal properties of a text or genre on three levels: Rhetorical, Grammatical and Lexical. Here we adopt the same organization.

\section{Rhetoric.}

Trimble (1985) defines rhetoric in the context of EST as, "the sequencing of features, the kinds of relations between features, [and the refusal to consider feaures] as isolated items, [but rather their relation to] larger discourse units they are found in" (p.10). "EST exists at several levels of discourse" (ibid), and Trimble notes four levels in the chart on the following page, with Level A being the largest, most general level of thetorical organization and Level $D$ being the most localized (see Table 1 on the following page). 
TRIMBLE'S HIERARCHY OF RHETORICAL FUNCTION

\section{LEVEL} DESCRIPTION OE LEVEL

A. Objectives of the total discourse

EXAMPLES: 1. Detailing an experiment

2. Making a recommendation

3. Presenting new hypothesis or theory

4. Presenting other types of EST information

B. The general rhetorical functions that develop the objectives of Level A

EXAMPLES: 1 . Stating Purpose

2. Reporting past research

3. Stating the Problem

4. Presenting information on apparatus used in an experiment

(a) Description

(b) Operation

5. Presenting information on experimental procedures

C. The specific rhetorical functions that develop the general rhetorical functions of Level $B$

EXAMPLES: 1. Description: physical, function, and process

2. Definition

3. Classification

4. Instructions: direct, indirect, and instructional information

5. Visual-verbal relationships

D. The rhetorical techniques that provide relationships within and between the rhetorical units of

Level $C$

EXAMPLES: I. Orders

1.Time order

2. Space order

3. Causality and result

II. Patterns

1. Causality and result

2. Order of importance

3. Comparison and constrast

4. Analogy

5. Exemplification

6. Illustration 
Trimble (1985) defines Level A as "the purpose of the total discourse", and Level B as "those major pieces of the text..usually marked in scientific and technical writing by section headings and subheadings" (p. 10). As such, Trimble's Level B Rhetorical Process seems to be the level that other authors generally consider when describing the organization of technical manuals. For example, Turner (1974) notes that many of the following sections are often found: General Information, Operating Instructions, Maintenance Instructions, Specifications, Parts Lists, and Troubleshooting. Schulman (1971) lists all the above and adds, Table of Contents, Warranty, Preface, Introduction, Theory of Operation, Description, Installation, and Operating Controls . Similarly, Reisman (1963, p. 63) remarks, "The technical manual describes the equipment, explains how to install, troubleshoot, repair and adjust it; and often includes detailed circuit analyses, and tables of replaceable parts" . Muir (1990) states in a General Introduction that his "procedures", "consist of diagnosis, maintenance, and repair"(p. 6). Schulman (1971) further observes that technical manuals can "provide Operational or Maintenance instruction or both" (p. 31).

In general, authorities agree that there is no fixed General Rhetorical Function organization to technical manuals, but that there will be operating or maintenance instructions and often there are sections on Specifications, Parts Lists, and Troubleshooting . In fact, sometimes experts disagree: Schulman (1971) states that instruction manuals are never concerned with installation or assembly, but Trimble (1985) specifically includes these activities. Similarly, sometimes writers even contradict themselves: we noted earlier that Hicks (1961) says, "in technical manuals, underlying theory is almost never discussed" (p. 208), but he later states that "manuals often have a dual purpose: to give the reader a basic understanding of the process, and relate this knowledge to correct working procedures" (p. 211).

Such contradictions are not surprising, given all the different types of products and different levels of service. With even something as straight-forward as a shop manual, Ford provides publications that approach this echelon of maintenance from 2 directions: (1) by model (e.g., all systems of the 1978 
Ford Fiesta--Ford Motor Co., 1977a), or (2) by system (e.g. Ignition Systems for all 1978 Ford products--Ford Motor Co., 1977b).

Similarly some manuals are strictly for operators; others strictly for repairmen, and while a bulldozer's operator may be a skilled professional, the nature of his professional knowledge and skill is different from that of the bulldozer repairman (cf. Schulman,1971, p. 30). Then, some manuals combine instructions for the operator and the maintainer in the same book, as a matter of convenience and to assist overall management. On the other hand, some manuals are system manuals, concerned with the workings of several devices and their inter-relations (cf. Devron-Hercules, $1990 \mathrm{a}$ or b). Finally, some technical manuals contain almost no instructions; merely furnishing their readers with specifications, capacities and applications (cf. Texas Instruments, 1979).

Clearly, the rhetorical organization and the General Rhetorical Functions included in a particular manual will vary according to product, purpose, and audience; and as such, the contradictions noted earlier are not consequential--if we accept that (1) technical manuals tend to concentrate on the operation and/or maintenance of a device (or devices), (2) several other General Rhetorical Functions that are associated with, but not essential to technical manuals (e.g. Troubleshooting, Diagnosis, Parts Lists), and (3) "instructions are found most often in technical discourse, usually in Technical Manuals" (Trimble, 1985, p. 14, italics mine).

In fact, it may be counterproductive to consider analysis of linguistic features above Trimble's Level C in the Rhetorical Process Chart: the level of Specific Rhetorical Function. There are two problems encountered in attempting to analyze the broader rhetorical levels (i.e. Levels A \& B):

(1) It has been noted that Operation and Maintenance are two typical and distinct sections of many technical manuals and Trimble (1985, p. 10) explicitly categorizes "Operation" as a Level B, General Rhetorical Function. However, there is really no reason to suppose that the discourse domain of 
Operation is linguistically different from the discourse domain of Maintenance. In fact, the rhetorical function common to both domains, their generally shared characteristic is that both are instructional--a Level C "specific" thetorical function.

(2) As the Technical Writing instructor Weiss (1982), and the ESP researcher Trimble (1985) both observe, one of the distinct features of Technical Manuals, like many other reference works (of which technical manuals are likely one of the more extreme cases), is that they are not meant to be read in their entirety, or even sequentially. The idea of a technical manual is that readers will and should read no more than is absolutely necessary to supplement their existing knowledge and complete the activity they are engaged in. Weiss (1982) remarks,

Manuals are hard to plan because manuals are not 'read', they are used or consulted or followed or studied. Consequently, it is difficult to anticipate the audience for a manual and all the uses to which it will be put. (p. 125)

Schulman (1971) concurs saying,

Most manuals are used only in negative circumstances; that is when something goes wrong and the equipment owner seeks to make the equipment perform properly...[so] frequently the owner will not refer to the manual until or unless he cannot do otherwise.

(pp. 16-17)

Later he adds, [it is not] likely that any one person, except a staff engineer will ever take the trouble to read an entire manual" (Schulman, 1971, p. 44). As such, there may be Level B functions found in Technical Manuals that are non-instructional, yet in being non-instructional (i.e. having only a supplementary role), are used rarely. For example, Schulman (1971) notes,

The importance of specific instruction bears no relation to the length of the treatment. For instance, troubleshooting information may be considered by both the writer and the user as the most important part of a manual yet it may occupy only 5\% of the total space. The theory of operation may turn out to be a total waste of effort as far as most readers are concemed, going into detail beyond their needs. Nevertheless, some manuals may cover this area extensively because of the tariff and import requirements of many countries and the sales and the design-description values of such material. (p. 45) 
If this is the case, it is questionable how helpful an analysis of such manual sections would be.

Indeed Trimble remarks (1985),

In addition, manuals have two metorical features found less commonly in other scientific and technical writing: the interpretation of illustrations and instruction. This does not mean that the other rhetorical functions are not found in manual writing; it does mean that these are prominent and frequent and therefore of most concern for teaching and materials preparation. (p. 83, italics mine)

This may well be why Trimble in, English for Science and Technology (1985), where his rhetorical system attains its most comprehensive development, accords such prominence to the Specific Rhetorical Function of Instruction. Trimble notes other specific thetorical functions that are "heavily used" in technical manuals: the three types of description, (a) physical, (b) function, and (c) process; and Visual-Verbal relationships (called "information transfer" by Widdowson, 1979). Elsewhere he suggests that "lay" manuals may provide more definitions* (Trimble, 1985). However he devotes his greatest atention to Instruction. A summary follows:

Instructions, henceforth referred to as "pure" Instructions to distinguish from Instructional Information below, are either direct (i.e. imperative constructions) or indirect (passive modals functioning as semantic imperatives). Instructional Information is,

Information which helps the reader make better use or better understand the instructions. Instructional information can stand alone, but it is always associated with one of the two types of instructions; adding one or more of the following kinds of information to the instructions:

(1) Cautions: "This circuit will short out under any overload."

(2) Wamings: (often a kind of negative instruction); "Do not use the intake duct as a shelf for tools."

(3) Notes: "Ripple " functions to provide a path for AC voltages."

(4) Specifying Statements: "Only manual transmission models have two thermosensors, automatics only one."

* Which does not seem to be confirmed by the present study. 
(5) Theory: (the "why" an instruction is to be carried out as specified):

"The VRU mounting must be a rigid and flat horizontal plate, to avoid introducing errors due to flexing of the mounting plate."

( Trimble, 1985, pp. 97-98)

The result is significant: since the major portion of almost all Technical Manuals is devoted to the activity of instructing, and since much information associated with direct or indirect instructions is instructional, instruction is the major thetorical function of Technical Manuals. Indeed, in preliminary studies, using earlier criteria developed by Trimble, (1979), this writer attempted to characterize the rhetorical function of of the clauses where phrasal verbs and their lexical counterparts appeared, and judgements seemed quite equivocal. However Trimble's 1985 criteria are established in such a way as to insist on interpretation on a sentential level, and at this level, many formally equivocal determinations clearly became Instruction, revealing the rhetorical function's prominence.

\section{Grammar}

As Tinkham (1979) states and Trimble (1979 \& 1985) concurs, the grammar of Technical Manuals is often quite limited. The imperative, which Trimble calls "direct instruction", is one of the most common structures. Also, there are many passive modals which Trimble refers to as "indirect instruction", which act as semantic imperatives. There are almost no questions and litule use of the past tense. Another grammatical feature noted by Trimble et al. (1979) and Brusaw (1982), is inconsistant ellipsis of articles.

\section{Lexis}

Boch Tinkham (1979) and Trimble et al. (1979) note that the vocabulary of Technical Manuals is generally sub-technical. Cowan (1974) seems to be the originator of the term. He uses it to describe "context independent words which occur with high frequency across technical and scientific disciplines", but which are not found in general word lists "because [word lists] are comprised of many different registers" (p. 39). Implicitly, sub-technical lexical items are familiar to almost all native speakers. In 
Tinkham's (1979) study, this preminence of sub-technical vocabulary is so great that he states, "terms become technical primarily by compounding" (p. 15). However, Tinkham found the vocabulary in the Technical Manuals he studied, to be quited limited. In a count of verbs in a section of a Technical Manual, he found that the five most common verbs acounted for $42 \%$ of all verb occurences and observed, "whereas common descriptive verbs like go, come, and have, didn't appear on the list, yet remove, or install were found in one out of every three sentences" (p. 9).

Nouns on the other hand were far more frequent. Tinkham (1979, p. 14) notes that the number of different nouns on 5 sample pages exceeded the number of different verbs on 50 pages. This is not surprising, for in his list of the 30 most frequent nouns, almost half have verbal counterparts (ibid). This phenomemon of "deverbalization" is explicilly mentioned by Brusaw (1982): "You can make sentences shorter by leaving out articles, some pronouns and some verbs" (p. 304, italics mine). Perhaps such processes are only the result of the nominal compounding so frequently associated with technical writing (cf. Bartolic, 1977; Selinker, 1971; Trimble et al., 1979; Tinkham, 1979), which tends to reduce verbiage. Consider one "gem" found by Tinkham (1979): "output shaft carbon seal drain tube and hose assembly" (p. 15). In fact technical writing manuals sometimes encourage technical writers to use nominal compounds, as we can see with Turner's explicit recommendation $(1974$, p. 163) to employ lexical counterparts: "such verb and adverb combinations are often used to cover a new idea. Practically all abstract ideas can be expressed and the writer's meaning made more clear if these words are used". This tendency to nominalize may well provide an explanation for the frequency of lexical counterparts in certain specialized genres of technical discourse.

\section{CURRICULAR CONCERNS}

Curricular concerns are a question of what to teach to whom when, and how to teach it. Of the various aspects of this question, for phrasal verbs and their lexical counterparts, the "who" is possibly the most important, because it aids in making determinations along the passive/active, 
comprehension/production continuum, in accordance with the leamer's needs. This is why one cannot simply teach ESL students this and EFL students that--because the matter of English "participation" is a continuum, where the needs of one kind of student blend into those of another.

Therefore the accurate assessment of productive needs is pre-eminent. The syntactic properties of phrasal verbs (e.g. separability), their slippery polysemy, and their lack of combinatory predictability, their collocational restrictions, and their idiomaticity, clearly indicate that attempting to attain productive capacity is a time-consuming process; and especially for leamers with limited English needs, such time might be better spent. True, as Celce-Murcia \& Larsen-Freeman (1983) and Nattinger \& DeCarrico (1990) claim, phrasal verbs seem to permeate informal discourse. Moreover, phrasal verbs may be important in a whole range of contexts where the typical ESL learner must successfully participate, especially those clients involved in the Applied Sciences; even contexts we might consider more "formal" than everyday discourse, such as academic lectures (Pierce, 1990). As such, productive capacity might be highly desirable for foreign students studying in Anglophone countries, especially since Engineering seems to be the predominant field of study for foreign students and since many of these Engineering students remain in English-speaking countries on completion of their education (Huckin, 1984).

At this level, Receptive/Productive distinctions are important for as Cornell (1985) notes, phrasal verbs are important, and because they are important, they are worth dealing with specifically, in a practical language course--but not without a process of selection and gradation having taken place, even at the risk of controversial inclusions and omissions.

For example, we might wish that our foreign students actively produce the neutral, difficult to paraphrase, idiomatic, "run out of", but be content if they merely understand the more colloquial, "show ofr". 
However the importance of productive capacity is less evident for EFL learners who only participate in English from time to time (e.g. the occasional seminar, conference, or training session). Here, with such learners, because of the limited production needs and wide availability of single word "equivalents", instruction time spent on producing phrasal verbs should be minimal.

Then, moving on to the EFL learner who rarely or never participates in oral/aural contexts, it is not clear that any emphasis should be placed on productive capacity at all--if indeed the leamer even needs to know there are such items as separable and inseparable transitive phrasal verbs. For such leamers, phrasal verbs are simple vocabulary items to be considered according to such parameters as their frequency within the learner's need context, and presented in instruction for passive recognition only.

This is one reason why Bolinger (1971), Celce-Murcia \& Larsen-Freeman (1983), and Comell (1985), all point out the need for frequency studies of phrasal verbs; however, as was noted earlier (cf. p. 16, this paper), an overemphasis on frequency counts, in and of themselves, is misguided. In fact, Cornell (1985) notes this problem, and to rectify it proposes four critieria to determine if a phrasal verb should be included in instruction, noting that the first three complement frequency studies:

(1) Idiomaticity: is the meaning of the phrasal verb easily deducible from its constituent parts? (in the case of polysemic combinations, each meaning would of course have to be considered separately).

(2) Replaceability: Is there a one word or already familiar phrasal verb equivalent which the leamer can easily use instead? Can the meaning of the phrasal verb be easily and naturally paraphrased in already familar words?

(3) Restrictions: Is the phrasal verb subject to severe collocational restrictions which would have to be learned? Are there particular grammatical constraints which have to be observed?

(4) Frequency (and usefulness): Is the phrasal verb commonly used?

Then, as example, Comell (1985) provides his own list of 60 common phrasal verbs appropriate for instruction, dividing them into those that require passive recognition, and those that demand active acquisition . 
Similar techniques could be developed for deciding which lexical counterparts are suitable for instruction; however the fact that lexical counterparts seem to be less polysemous and more subject to collocational restrictions (i.e., they may tend to be clearly associated with certain contexts of subject areas) means that if anything, developing lexical counterpart instruction should be less problematic than it is for phrasal verbs.

As for the timing of when to teach phrasal verbs, most units or chapters on phrasal verbs tend to be presented in materials designed for students of high intermediate to advanced levels (cf. Du Vigan et al., 1988, Vols. 24\&25; Eichler, 1990; Feare, 1988; Hook, 1981; and Rogers \& Olorenshaw, 1985). However, Gaims and Redman (1986) note the inadvisability of waiting until the students reach such a level before introducing them to phrasal verbs:

We have already mentioned the obsession with multi-word verbs which seems to grip many foreign learners, particlarly as they pass through the intermediate level. Unwittingly teachers and materials writers have contributed more than anyone to this irrational obsession by often ignoring multi-word verbs in the early stages of learning, only to unleash them in massive doses on students preparing for the Cambridge Certificate Examination...no wonder they get confused. (p. 34)

In fact, Gairns and Redman (1986) question the efficacy of presenting phrasal verbs as a "unit" at all. For them, a graduated approach, like one of Comell's suggestions (1985), where phrasal verbs are presented basically as vocabulary items, at a time appropriate to the learner's language development, would be the best. Similarly, Nattinger \& DeCarrico (1990) consider phrasal verbs as "polywords" within their Lexical Phrase approach to language. Therefore they recommend that phrasal verbs be learned along with their single word counterparts, a technique which puts the emphasis on phrasal verb as vocabulary item; not as linguistic category. This permits the occasional, "according to need", introduction of particular phrasal verbs. 
However, as we noted earlier (cf. p.50), Comell argues for "dealing specially with phrasal verbs in a practical language course", and Nattinger and DeCarrico (1990) insist that students "learn to recognize those phrasal verbs they encounter on their own [as phrasal verbs, distinct from other Verb + Prep combinations], on analogy with those leamed in class". Looking at this distinction from a standpoint of semantics, Gairns \& Redman (1986) don't initially agree, stating, " In our experience, the distinction (between phrasal verbs and prepositional verbs) does not pose a significant teaching problem" (p. 33). However, they later add, "grammatically, students need to know whether a transitive multi-word verb is phrasal or prepositional" (ibid), effectively putting them on the same footing as Nattinger \& DeCarrico.

One typical approach to this "staging" of phrasal verb introduction in ESL/EFL courses which stress conversation has been to insist on introducing essential phrasal verbs (e.g. "turn on / off", "put on / take off") when first introducing students to other basic verbs through Total Physical Response (TPR )(Asher, 1977). In some of these courses, instructors supplement TPR activities with classroom objects, by bringing in an everyday device such as a cassette recorder to introduce such phrasal verbs as "take out", "pick up", "put in ", "lift up" , "push down", etc. (Du Vigan et al., Vol. III, 1988). When introduced at this early stage it seems much easier for students to partially acquire a sense of inserting pronouns in separable phrasal verbs, without the sense of frustration expressed by learners who encounter this syntactic phenomenon at a later point of instruction.

Similarly, it is typical in conversationally-oriented courses to provide review/expansion work concerning the functions of Permission and Request for High Beginner / Low Intermediate students. This also is an opportune context for phrasal verb acquistion and manipulation with exercises such as provided in Figure 3 on the following page: 
STUDENT A

(Ask your co-workers to pick up the boss at the airport tomorrow)

"Will someone pick up the boss

at the airport tomorrow?"
STUDENT B

(Agrees to help the boss)

"Sure, I'll pick her up!"

(Du Vigan et al., Vol XVI, 1988)

Eigure 2. Sample Phrasal Verb Exercise Diagram

Finally, for advanced learners who simply want to continue to build their vocabularies, there are many self-study books like Feare (1988), Hook (1981), and Rogers \& Olorenshaw (1985), which can easily be adapted and used in periodic "change of pace" classroom activities.

\section{PHRASAL VERBS AS THE FOCUS OF AN INSTRUCTIONAL UNIT}

While the intention of Gaims and Reman's caveat (to not wait until advanced levels and then suddenly introduce phrasal verbs as a unit), is well-taken, it is likely still desirable to present some type of instructional unit on phrasal verbs to intermediate and advanced ESL learners. This is precisely because phrasal verbs are an important phenomenon (cf. Comell, 1985, p. 275), one which students will likely perceive themselves (cf. Gaims \& Redman, 1986, p. 34), and one for which we should provide at least an overview, if not mastery. Indeed, this seems to be the basis for Nattinger and DeCarrico's (1990) observation that,

Teaching students how form relates to function is especially crucial in these cases (the three types of Verb + Prep combinations), for both production and comprehension, for students need to learn to produce these lexical phrases in their own speech and writing and to recognize and comprehend them in the speaking and writing of others.

Accordingly it seems that the first lessons of a phrasal verb unit should give an overview of the semantic levels and syntactic variations which are possible, with the tone of the presentation being paramount: we can "discouragingly" inform students that there are 3 to 4,000 phrasal verbs; they 
must be used in conversation, and all syntactic variations must be known--or we can introduce phrasal verbs as a difficult, but unavoidable, and often interesting aspect of English.

Clearly, experience has taught us how not to teach phrasal verbs. Gaims and Redman (1986) perceptively criticize three conventional techniques: (1) ignoring phrasal verbs in early stages of instruction; (2) then, massive doses of phrasal verbs in advanced units; (3) verb-based presentations (e.g. presenting "put" with 10 to 15 different particles). Also, while it is important for ESL learners to be able to differentiate phrasal verbs from other multi-verbs, we must remember that most of the syntactic and prosodic tests available are not very helpful to non-native speakers who can rarely hope to develop such a high level of communicative competence. Therefore, we are perhaps wise not to waste student's time presenting such tests; instead we should follow the lead of Nattinger \& DeCarrico (1990) by introducing students to the semantic tests for phrasal verbs, which while imperfect, are at least within the capacities of intermediate to advanced ESL leamers. In fact, Nattinger \& DeCarrico even show how one of these tests, the WH Question Test, can be adapted and expanded for use as a classroom activity.

Nattinger and DeCarrico (1990) also recommend explicit instruction of consistent completive particles like "up' and "out", and they show the value (even if the range of application is limited) of teaching phrasal verbs according to "metaphorical sets" such as those proposed by Lakoff and Johnson (1980). As such, Nattinger \& DeCarrico are following a modern but established tradition of concentrating on "systematic" phrasal verbs (that is, cases where particles have systematic meanings (cf. Bosworth-Gerome et al., 1987; Du Vigan et al., Vols. 24\&25, 1988; and Rogers \& Olorenshaw, 1986). Typically, such treatments present particles in "oppositional pairs" (e.g. "on-off", "in-out", "updown", "back-away"), explain the systematic meanings, and give example sentences:

She picked up the receiver. (upward direction)

He cleaned up the room. (completion)

Turn up the volume please. (increase) 
Afterwards, many different types of exercises are available:

(1) Modified cloze exercises on three levels of difficulty:

(a) find the correct particle

(b) find the correct verb

(c) find the correct verb + particle combination (cf. Cornell, 1985, p. 278)

(2) State the systematic meaning of the phrasal verb in a heavily contextualized example sentence:

He was so dressed up in his tuxedo that his grandmother didn't recognize him. -.-> (completion)

(Brady, in Du Vigan et al., 1988, Vol. 24, p. 16)

(3) Find the phrasal verb synonym of a single word verb in an example sentence:

Hickory, Dickory, Dock, the mouse quickly ascended the clock. ---> (went up)

(Brady, in Du Vigan et al., 1988, Vol. 24, p. 17)

Such methods at least have the benefit of assuring students that there is some method to the madness; however care must be taken, for too often the tendency is to present too much systematic meaning at a time, reducing the system to gobbledygook. Similarly as Nattinger and DeCarrico (1990) have noted, not even "systematic" particles are predictable: "when 'put' combines with other particles, the meaning is not at all related to other 'put + particle' combinations. So for example, 'put down' (belittle) is semantically unrelated to 'put up' (lodge)". Therefore an overemphasis on systematic meaning can lead to greater frustration on the part of students on those too frequent occasions when when these two-word items do not "follow the rules".

Also we should reiterate, most of the preceding discussion concerning "how" to teach phrasal verbs is directed at strategies for leamers living for a long duration in an English-speaking country or planning to work in close association with native speaking anglophones. For more "remote" EFL learners, only high frequency, high interest phrasal verbs should be considered, and in all likelihood, they should be scattered among other vocabulary items with an eye only to passive recognition. 
CHAPTER III

RESEARCH METHODS AND PROCEDURES

\section{DESIGN}

Size of Corpera. Several studies in Celce-Murcia \& Larsen-Freeman (1983, cf. pp. 433 \& 455), a respected ESL reference work, cite TESOL studies using corpora of 8,000 to 10,000 words in length. Barber (1962) in his seminal study of EST features used samples from three texts totalling 23,500 words. Therefore it seems reasonable to conclude that 8 to 10 thousand words would represent a minimum length for a corpus and that a corpus of 25,000 words or more would be considered adequately large to assure sound results. On the other hand, preliminary investigations indicated high variability of results in texts of the 3,000 to 7,500 range which compose each corpus. As a result, the size of each corpus analyzed was increased to $+36,000$ words to ensure stability and validity.

Nature of Corpora. Three corpora were analyzed:

(A) General Corpus (the control): A corpus of 36,000 words, drawn randomly fromthe Section A of "The Oregonian" was analyzed as a control to establish the frequency, type, and lexical density of phrasal verbs and their lexical counterparts found in a general, non-specialized text. Using "The Oregonian" permits a genuinely broad sampling of "informal" journalistic style because it includes articles from the Associated Press, Reuters, "The New York Times", "The Washington Post"; as well as member of "The Oregonian" staff. This. (see Appendix E) 
Also, a text drawn from "The Oregonian's" SCIENCE section was analyzed as part of preliminary investigations to determine if Phrasal Verb and Lexical Counterparts use would differ from their use in the section A. The results of this research showed two-word item use to be so similar in both sections that the SCIENCE section text was included as part of the General Corpus.

(B) "Expert" Corpus: This corpus (see Appendix C) was determined "expert" (i.e. written by specialists for specialists,) based on (1) titles, (2) the manual's echelon in a hierarchical manual system, and (3) information provided by informants using a particular manual. Texts in the corpus vary from 500 to 8,400 words in length, the shorter texts being instruction sheets analyzed in their entirety and the longer ones being randomly selected from booklength Technical Manuals, with the maximum length being determined by ease of analysis. One section of the corpus called the Trimble Text, is actually a compilation of sections from 21 "expert" technical manuals from Trimble et al. (1979), in an article on instructional materials for Technical Manuals. The "expert" corpus consists of the following texts:

Devron-Hercules Devronizer Systems Manual

Devron-Hercules Autoslicer Systems Manual

Air Conditioner Service Manual

Trimble Text

Sheffer A Series Maintenance Booklet

Microcomputer Component Data Book for Engineers

Ford Fiesta Shop Manual

Total
8,400 wds

$5,450 \mathrm{wds}$

500 wds

$6,000 \mathrm{wds}$

750 wds

7,450 wds

7.450 wds

36,000 wds

(C) "Lay" Corpus: This corpus was determined "lay", based on (1) titles, (2) hierarchical level of the manual in a instructional system, (3) comments in the preface or text, and (4) product types (i.e. operating and maintenance sheets for such "off-the shelf" items as hairdryers and steam irons). Texts vary in size from 600 to 7,100 words. Generally, the shorter texts represent the totality of a technical booklet and the longer texts are the maximum easily analyzable length of a section of a longer book-length manual. One text in the corpus, the L.A.S.T. Text is actually a compilation of sections from 15 different "lay" manuals found in L.A.S.T: Lire L'Anglais Scientifique et Technique (Bosworth-Gerome et al. ,1987), a text designed to help French university students to 
read EST with greater ease and comprehension. Another text, the Hara Text, is actually three instruction sheets which Hara (1979) provides as example materials to be used in lessons to EST students. Finally, the VW Text is taken from How to Keep Your Volkswagen Alive: A Manual of Step by Step Procedures for the Compleat Idiot (14th ed., 1990). This text was included because the manual was one of the first "user-friendly" technical manuals (see Appendix D), being published long before the term"user-friendly" was coined. The "lay" corpus is composed of--

L.A.S.T. Text

Macintosh Reference Manual

Cassette Recorder Instructions

The Hara Text

Rittal Air Conditioner Bulletin

Brothers Typewriter Instruction Booklet

The Oregon Commercial Driver's License Manual

Bobcat/Pinto Repair Guide (Chilton's)

Microtools Software, Appendices A \& B

VW Manual

Proctor and Silex Iron Instructions

Telephone Installation and Features Sheet

Ered Meyer Hair Dryer Instruction Sheet

Total
2,700 wds

4,450 wds

1,400 wds

600 wds

1,400 wds

3,500 wds

3,000 wds

3,500 wds

5,300 wds

7,100 wds

1,600 wds

300 wds

1.150 wds

36,000 wds

\section{METHOD}

(A) Phrasal verbs and their Lexical Counterparts were identified and recorded in all three corpora to determine their relative importance in different text genres:

(1) Phrasal verbs were identified using some or all of the following tests (as applicable):

(a) Intransitive Phrasal Verbs: if no Noun Phrase follows a "Preposition", it must really be a Particle.

(b) Particle Separation: If the Verb and Particle can be separated by their direct object, the item is a true phrasal verb.

(c) Prep Fronting: if the item is a true Preposition, it can be fronted in a WH question.

(d) Relative Clause Test: similar to Prep Fronting, but more forgiving, because it seems somehow less stilted to front a Preposition to a relative clause than a WH question. 
(e) Adverb Insertion: Adverbs can be inserted between Verbs and Prepositions but not between the components of Phrasal Verbs or Prepositional Verbs

(f) Semantic Unity: If the meaning of the Verb + Adverb can't be analyzed from the meaning of their parts, it's a phrasal verb.

(g) If the "logical" corresponding question to a statement with a Verb + Adverb/Preposition begins with "where" or "when", the item is a simple Verb + Preposition. If the logical question is "who" or "what" , the item is a Phrasal Verb or Prepositional Verb.

(h) Three word items (i.e. Verb + Particle + Particle/Preposition, e.g. "put up with") were considered phrasal verbs

(i) If a two-word compound verb had the structure Particle-Verb (e.g. "to backspace") it was not considered a phrasal verb

(j) "Be + Particle" comcompounds (e.g. "be on" and "be up") were considered phrasal verbs because of their close semantic relation to true phrasal verb counterparts (e.g. "tum on" and "turn up")

Often, in a given case, several of these tests were employed for confirmation. An example of an excluded item was "plug the cassette inte the outlet." Now "plug into" seems initally to satisfy the particle separation test; however the Prep Fronting Test gives "Into what do I plug the cassette?", which suggests that "into" is really a preposition. If the acceptability of the fronted "Into what" is a potential problem, the Relative Clause Test: "The outlet into which the cassette is plugged", and the "Logical Corresponding Question Test" (see (g) above): "Where do I plug the cassette?", confirm the identification of "into" as a prepostion and exclude "plug into" as a phrasal verb.

On the other hand, "come across" in "Refer to Chapter 7 if you come across any difficulties." is not subject to particle separation, suggesting "come across" is not a phrasal verb. However, it also fails the Prep Fronting Test, the Relative Clause Test, the Adverb Insertion Test, and the "Logical Corresponding Question" Test (suggesting the item is not a preposition), and "come across" cannot be analyzed through the individual meaning of its two consituents, all of which suggests that "across" here acts as a particle, permitting "come across" to be considered as a phrasal verb. 
However, as these examples clearly show, identifying items as phrasal verbs or not can at times become a confusing process. Therefore, in addition, to ensure reliability, the list of identified phrasal verbs was compared to and validated by entries in the Longman Dictionary of Phrasal Verbs (Courtney,1983).

(2) Lexical Counterparts were identified by the following tests:

(a) Is the item a compound of a Verb + Particle?

(b) Does the item have a phrasal verb counterpart?

(B) Phrasal Verbs and their Lexical Counterparts were tabulated by item along with their combined total according to text (esp. to determine the range of an item), corpus, and genre to establish their quantitative importance within each genre in response to Research Question 1 (see p. 5 of this study).

(C) Also in response to Research Question 1, lists of identified two-word items were analyzed, and repetitions of the same lexical item tabulated to determine lexical variance on corpus and genre levels. This is especially important because often repeated vocabulary items pose fewer comprehension problems. Lexical variance can also sometimes be used to suppor claims about stylistic tendencies (e.g. low lexical variance would tend to support a claim of much explicit textual cohesion. On the other hand, very high lexical varience is indicative of more implicit cohesion and a greater concern for diversity and vivacity of style; cf. Halliday \& Hasan, 1976).

(D) In response to Research Question 2 (see p. 5 of this study), frequency of figurative two-word items was tabulated using the following criteria to identify figurative phrasal verbs and their lexical counterparts, since (1) figurative items are more likely to cause comprehension difficulty and because (2) idiomaticity can play a role in the pragmatic force of an utterance:

(1) an item is figurative if its meaning cannot be analyzed from the meaning of its constituents (2) although figurative two-word items do not always have "doublet" counterparts, the above criteria 
will be confirmed if a single word synonym can be found.

Reliability of the figurative determination according to the criteria noted above was established through test of inter-rater reliability on the 8,400 word Devronizer Text (Devron-Hercules, 1990). Following Chadwick et al. (1982), reliability coefficients were established using the formula,

\section{total number of items commonly identified by Rater A \& Rater B total number of items}

where values exceeding $60 \%$ are considered acceptable.

(E) The rhetorical function of a sentence where an item appears (in Technical Manuals only) was identified using critieria provided by Trimble (1985--see "Definitions", pp. 9-10 of this study) in an attempt to address Research Question 3 (see p. 5 of this study). Phrasal Verbs and Lexical Counterparts in each thetorical function were further categorized as figurative or non-figurative. The purpose was to determine if phrasal verbs and/or their lexical counterparts are more frequent in some thetorical functions than others. Reliability was established through inter-rater reliability tests as mentioned in (D) above using the same 8,400 word text.

(F) Most frequent two-word items were identified and listed according to ranking by frequency and range. Also, "simple" compounds which resemble lexical counterparts (e.g. "an overview") were listed in the appendix. These lists (1) provide a body of significant items for use in semantic feature analyses; and (2) can assist teachers when selecting two-word items to be used in instructional materials.

(G) Thus using the list noted in (F) above, most frequent two-word items in Technical Manuals were evaluated using componential analysis, in terms of (1) particle meaning and (2) common semantic fields (e.g. "activation", "chaotive", "necessity"), to determine if two-word items represent certain "themes" in Technical Manuals, in response to Research Question 4 (see p. 5 of this study). 


\section{CHAPTER IV}

\section{RESULTS AND DISCUSSION}

\section{FREQUENCY COUNTS}

Appearances of two-word items were tabulated, with totals by type of item and genre reported in Table

2 below. Thus, in response to Research Question 1 (see p. 5 of this study), frequencies of two-word items were found to differ significantly according to text genre: $X^{2}(1, \mathrm{~N}=1281)=299.97, \mathrm{p}<.001$.

TABLE II

FREQUENCIES OF TWO-WORD ITEMS

\begin{tabular}{|l|c|c|c|}
\cline { 2 - 4 } & $\begin{array}{c}\text { PVs } \\
\text { (phrasal verbs) }\end{array}$ & $\begin{array}{c}\text { LexCs } \\
\text { (lexical counterparts) }\end{array}$ & Combined Totals \\
\hline $\begin{array}{l}\text { Newspapet } \\
\text { Corpus } \\
36,000 \text { wds }\end{array}$ & 122 & 30 & 152 \\
\hline $\begin{array}{l}\text { Lay } \\
\text { Corpus } \\
36,000 w d s\end{array}$ & 281 & 178 & 459 \\
\hline $\begin{array}{l}\text { Expen } \\
\text { Corpus } \\
36,000 \text { wds }\end{array}$ & 132 & 538 & 670 \\
\hline
\end{tabular}


At the outset, the observation to be made concerning these results is that phrasal verbs and their lexical counterparts do not account for a significant proportion of vocabulary items in any of the corpora. Particularly given the general rule-of-thumb that reading comprehension is effectively blocked when unknown vocabulary exceeds 10\% (Elliman, 1979), it is apparent that in and of themselves, two-word items do not constitute obvious or global impediments to comprehension.

Nevertheless, these frequency results do show that if we are to consider phrasal verb and/or lexical counterpart instruction in a general ESL course, we should certainly consider its inclusion in technicallyoriented courses, for the percentage of phrasal verbs found in all technical manuals is double the ratio found in the general newspaper corpus and the proportion of lexical counterparts is 10 times greater than in "The Oregonian" sample, as is seen in Figure 3 (p.65). Thus, lexical counterparts in particular seem to be a distinctive characteristic of the technical discourse found in instruction manuals.

A second remark concerning these findings is that they do not seem to support the contention that these two-word items are indicative of informal discourse. Conventionally, newspapers are characterized as having an informal style, while "technical writing" is considered more formal (cf. pp. 36-38 of this study). Also, newspapers go to great lengths to compensate for readers' possible lack of previous knowledge, a characteristic of more informal discourse usually not found in technical manuals (cf. Trimble et al, 1979, p. 80). Yet there are almost five times as many two-word items in the formal technical material than in the daily newspaper. Clearly two-word items do not always serve to mark informal discourse.

Moreover, the frequency of two-word items seems to be a question of style rather than subject. As was noted earlier, a portion from "The Oregonian" SCIENCE section was analyzed to see if it would have different frequencies of two-word items than the general Section A of the newspaper. The frequencies were so similar that the SCIENCE section was finally included as part of the overall newspaper corpus. Simply put, two-word items seem to play a much smaller role in newspaper style, designed to appeal to 
the general public, than they do in the concise, explicit language of technical manuals.

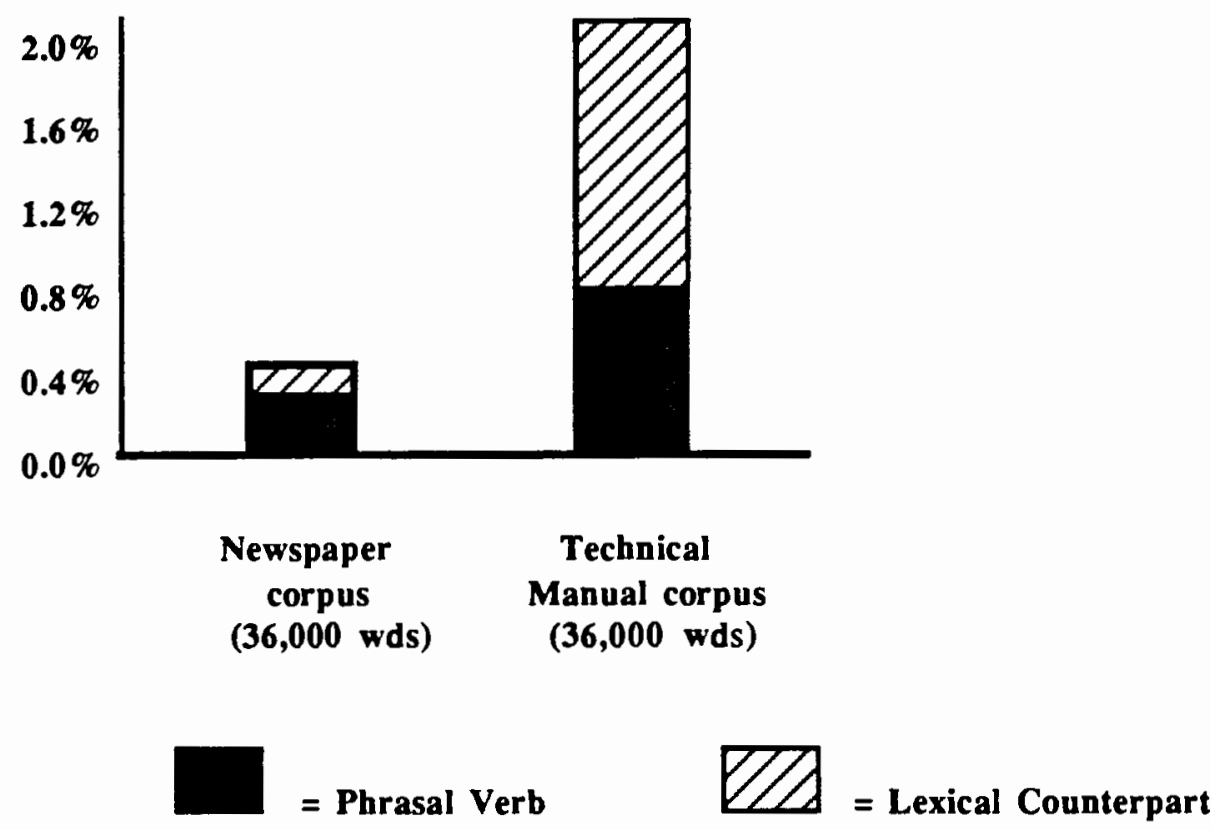

Figure3. Percentage of Two-Word Items in General Newspaper and Technical Corpora

Still, it is important to consider the distinction made between "lay" technical manuals which are "user-friendly" in that they make important concessions to the reader's possible lack of previous knowledge, and "expert" manuals which are directed towards the specialist in the field. This distinction was made precisely because it is reasonable to suppose that the difference of audience would be reflected in a difference of style. Therefore the observed frequencies of two-word items in these two sub-genres must be compared (see Figure 4, p. 66).

A first observation on these results is that in every category, there is a higher frequency of two-word items than was found in the general newspaper corpus. This is clearly the case with lexical counterparts. However it is interesting to note that while the expert corpus contained three times as many lexical counterparts as the lay corpus, it contained only half as many phrasal verbs. Indeed, the peercentage of 
phrasal verbs in the expert corpus was only slightly higher than in the newspaper sample...

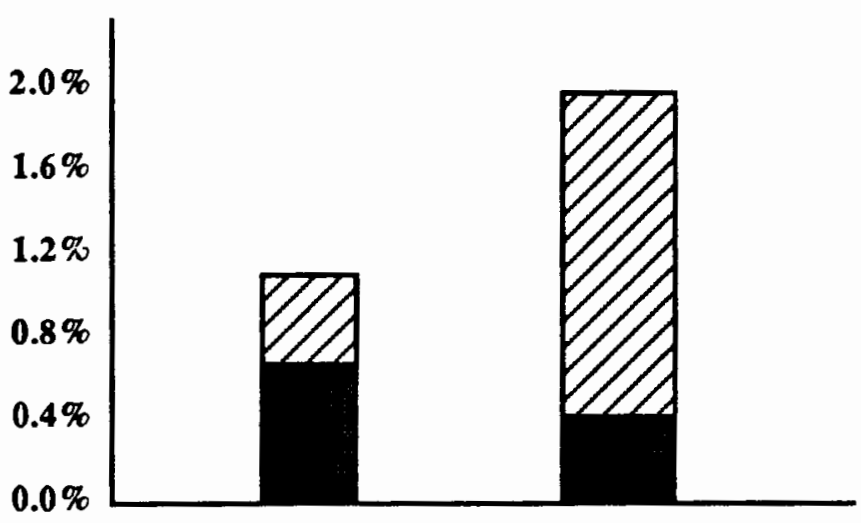

$\begin{array}{cc}\begin{array}{c}\text { Lay Technical } \\ \text { Corpus }\end{array} & \begin{array}{c}\text { Expert Technical } \\ \text { Corpus } \\ (36,000 \mathrm{wds})\end{array} \\ (36,000 \mathrm{wds})\end{array}$

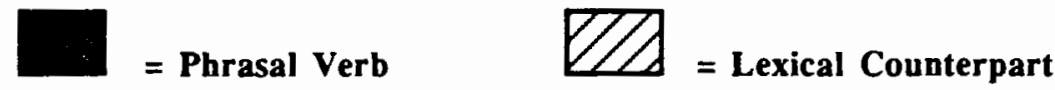

Figure 4. Percentage of Two-Word Items in the Lay Technical and Expert Technical Corpora

It is tempting to account for the frequency differences of items in the lay and expert corpora in terms of formality. Expert technical manuals more closely fit traditional formality criteria than their "userfriendly" lay counterparts, and they obviously make many more assumptions about their readers' knowledge (recall Tinkham's remarks about "spiralox retainers" cited on p. 41 of our investigation), a characteristic that almost all authorities on technical writing associate with formal style. Consequently, it could be claimed that the "omission" of phrasal verbs and the increased usage of their lexical counterparts corresponds 10 an increase in formality and a decreased interest in "filling in" the reader.

One might therefore assume that the decrease in phrasal verbs and the corresponding increase of their lexical counterparts in expert technical manuals is due to nominalization*--the transformation of verb phrases to noun phrases, a process sometimes associated with formality (cf. Strevens, 1980, p. 466). 
However those lexical counterparts that are of highest frequency in the expert corpus are much less frequent or even non-existent in the lay corpus. For the majority of these "expert" lexical counterparts, their corresponding phrasal verb never appears in either technical corpus : "input", "output", "inlet", "outlet" are among the most common lexical counterparts in the expert corpus, but nowhere are there appearances of "to put out", "to let in", "to put in", or "to let out".

It is as if these phrasal verbs, which do seem rather colloquial, gain respectability when manifested through their nominal counterparts. This may in part be due to the fact that lexical counterparts are less polysemous than many of their corresponding phrasal verbs, making them often times more neutral. For example, "to wipe out" can mean (1) "to wipe completely", (2) "to wipe in an outward direction", (3) "to destroy", (4) "to eliminate", (5) "to fall", and (6) "to fail". However "a wipeout" can only be "a failure" or "a fall". This seems to be a reasonable explanation for the decrease in phrasal verbs and the great increase in lexical counterparts found in the expert corpus when compared to the lay sample: specialist vocabulary is more rigorously specific. Howeverit should also be remembered that careful word choice and avoidance of vagueness are characteristics of formal style in general where a precise, monosemous term is likely to be preferred for its aptness and lack of ambiguity. This desire to reduce ambiguity is also revealed in the proportion of figurative to non-figurative two-word items found in the technical corpora.

* According to current theory, "nominalization" is a stylistic decision, not a syntactic transformation. 


\section{FIGURATIVE ITEMS}

Using fixed criteria, two-word items were categorized as either Figurative or Non-Figurative. Inter-rater reliability tests were used to assure the validity of the criteria and the resulting reliability coefficent of $91 \%$ was above the accepted threshold value of $60 \%$ (cf. p. 62 of this study). The percentages presented in the Figure 5 below are ratios of the number of figurative items in a lexical category (e.g. phrasal verbs) divided by the total number of items in that category. Thus, in response to Research Question 2 (see p. 5 of this study), the percent of two-word items was found to differ significantly according to text genre: $X^{2}$ $(1, \mathrm{~N}=256)=47.17, \mathrm{p}<.001$

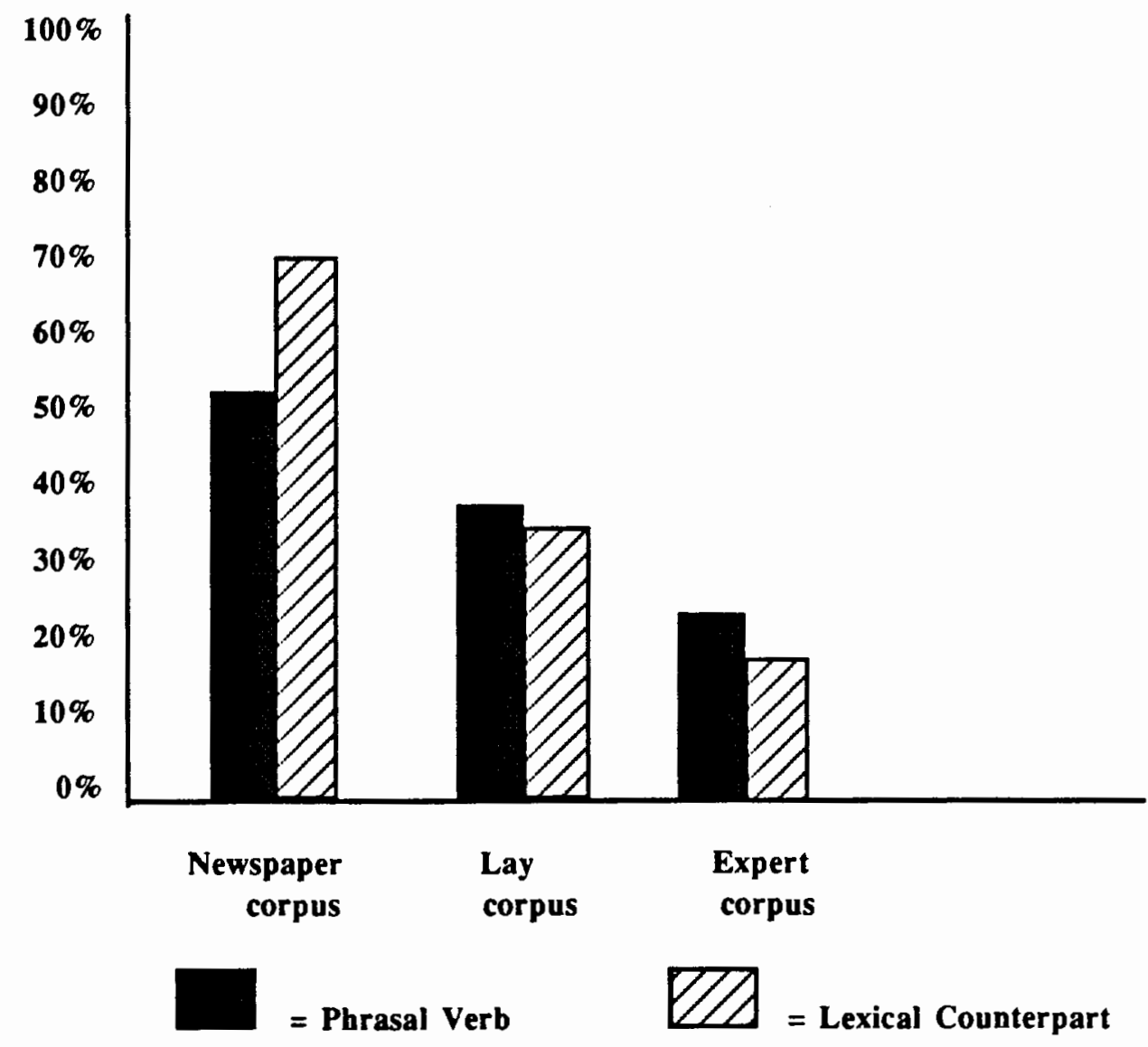

Figure 5. Percent of Figurative Items to Total Items by Genre 
Thus, as the corpora become more specialized and more concise, the percentage of two-word items which are figurative decreases. The explanation seems evident: in as far as it goes, previous research is correct in claiming that phrasal verbs can act as pragmatic markers of informality. However, there is really only one type of phrasal verb that consistently marks informal discourse, that kind of two-word item the most frequent in the general corpus and least frequent in the expert technical corpus: figurative two-word items.

Even so, not all figurative items mark informality. Some can be neutral (Nattinger and DeCarrico, 1990), and some can even attain formal status (cf. Comell, 1985, p. 269). One example which appears in both lay and technical corpora is "line up". Clearly this expression does not mean, "make a line in an upward direction", or "make a line completely", or "insert a protective layer in an upward direction", so the expression is figurative. In addition, "line up" has a doublet counterpart, "to align". In fact, in some texts both expressions are used, although "align" appears only rarely. However, in the contexts where they appear, it would be difficult to argue that "line up" is more colloquial or emotive (e.g. "Now line up the TDC mark with the notch or crack in the crankcase."; Muir, 1990, p. 84). In fact, according to this writer's intuitions, if there is a difference between "align" and " line up", it's that "line up" conveys greater precision. The reason is that while the expression is figurative: its meaning cannot be derived from an analysis of each of its constituents' meanings, one of its constituents still contributes an extra "emphasis" to the entire item: "line up" does not mean "make a line completely", but it does mean "align completely" (i.e. with great precision).

In fact, it is on precisely this point that pivots my claim of an "intensive" sense for some two-word items. They are that category of figurative item where the particle, while it does not directly contribute its sense to the meaning of the compound item, can contribute a completive/intensive sense to the item. Typically this intensive emphasis is available if (1) the item has a corresponding single-word doublet (hence choice enters into the picture) and (2) if the item is used in a context associated with explicit exposition (e.g. instructions). Some examples of items found in the technical corpora which can 
manifest this insistence are "shut down" which doesn't mean "close completely" but "stop completely"; and "top up" which doesn't mean "to best completely" but "to fill completely".

On the other hand, not all literal items are neutral. In the sentence, "The spilled pudding slopped all over the table", the effect of the phrasal verb is informality, not insistence or added precision. Yet "slop over" is a very literal expression whose meaning is clear from the sum of its parts. Here, the potential informality of the verb "to slop" is here enhanced by its particle, and the resultant pragmatic force is one of informality (Note that, "Jason slopped the hogs.", in and of itself, is not especially colloquial-common maybe, but colloquial, no).

However, it is not the type of literal two-word item that tends to appear in the technical corpora. The majority of literal two-word items and even a considerable number of the figurative items (cf. pp. 88-90 of this study) are not formal, or informal, but pragmatically neutral. Their actual role in instruction manuals is semantic, and has important ramifications for technological discourse where accuracy is paramount: they provide greater precision than many of their single word "synonyms".

Therefore, it is appropriate that the percentage of figurative items found in the lay corpus lies almost midpoint between the findings of the general and expert corpora, because in a sense, "user-friendliness" has two aspects. The first was suggested before: the attempt to supply precise, additional background information to compensate for the general audience's lack of experience. This means furnishing explicit orientation such as is found in the following paragraph:

To remedy this problem, slide under the car with a large screwdriver and a $13 \mathrm{~mm}$ wrench. Locate the four sheet metal screws that hold the sheet metal onto the heater box and engine case, and remove the screw with the large screwdriver. Pull the sheet metal out of the way and remove the bolt holding the thermostat to the bracket with a $13 \mathrm{~mm}$ wrench. Push the thermostat up enough so it can be screwed off the rod. Screw the new thermostat back on the rod and bolt it back on the bracket. Make sure the square protrusion on the bottom of the thermostat seats in the bracket. Replace the sheet metal and screws.

(Muir, 1990, p. 84) 
This concem for explicit orientation is the best general account of two-word item usage in the technical corpora: almost all non-figurative and many figurative items provide additional directional or completive information. In the section of the Muir manual analyzed in this study, he uses the expressions "pry up", "pry off", and "pry out". Perhaps one of first observations to be made here should be that "pry" in and of itself, is a low-frequency item appearing on few general word lists and unlikely to be taught in a typical ESL classroom. However, "pry" is an important vocabulary item for anyone discussing the manipulation of mechanical devices in English. Secondly if these "pry" phrasal verbs were replaced with "formal" single verbs, I believe the most obvious candidate for all three would have to be "remove". Now "remove" may be perfectly adequate for the experienced mechanic who disassembles carburetors in his dreams, but for novices, the three "pry" phrasal verbs not only provide valuable information about the direction of the force, but also give implicit confirmation that the force is being applied to the correct component: if the instruction is "pry up", but the component the reader is manipulating can only be moved in a downward direction, the reader will suspect thats s/he has probably misidentified the feature or part in question. Here Bolinger's comment, "in its core meaning, the particle must contain two features, one of motion, the other of terminus or result" $(1971, p .85)$, becomes revealing: Non-figurative phrasal verbs in lay technical manuals serve to provide the general reader with more concrete descriptions of location, direction, or completion.

Moreover, the same is true for certain two-word items which are not only figurative, but genuinely idiomatic. In the Devronizer Systems Manual, the jargon-like expression "to doctor off" is found. The expression is figurative: "to doctor" = "to alter subtly"; "off" = "in an outward direction"; but "to doctor off" = "to draw off in a subtle or delicate manner", and the intent of the sentence,

this cross-directional wall of high velocity steam on the leading edge of the Devronizer doctors off the cold air travelling with the sheet and creates optimal conditions of steam condensation.

(Devron-Hercules, 1990a, Systems Information p. 2) 
Note how much more information it conveys than its single word synonyms of "extract" or "evacuate".

"Walk off" in the VW text is a similar case of an idiomatic two-word item used not for informality but added precision, for, "...walk the wire clip off the valve cover" (Muir, 1990, p. 100) means "take off the clip in a back and forth (walking) manner", the expression being far more informative than its often used single word synonym, "remove". Also in the Ford Fiesta Shop Manual we find, "...the throttle will be in the kickdown position" (Ford Motor Company, 1977a, p. 24-8). "Kickdown" is clearly figurative and metaphorical, there are no feet involved here. Probably "kickdown" is derived from the equally figurative "kick in" (i.e., to activate automatically), but here there is the even greater precision, for "kickdown" is equivalent in meaning to "activate automatically in a downward direction".

On the other hand, as the citation from Muir on page 70 of this study makes clear, informality is also an aspect of "user-friendliness". And although the degree of informality can vary from manual to manual, with Muir representing one extreme, one goal of the lay manual writer is to instill confidence, to encourage the reader attempting to perform an unfamiliar task. Accordingly, the style of lay manuals may sometimes become more informal because the writer and manual user "[are] work[ing] as a team" (Muir, 1990, p.3). Such perceptions might also extend to other ESP areas, in that studies have shown that "working as a team" is a highly held and specifically mentioned value in today's corporate culture (McSwain \& Morihara, 1990). Therefore, a partial reason for the higher frequencies of figurative twoword items in lay manuals when compared to expert technical manuals is that to a certain degree they are appropriately and considerately less formal. This seems to be precisely the point Brusaw (1982, p. 229) wants to make when he says, "Technical writing, although not as formal as it once was, is nonetheless formal" . A point which is confirmed when some of the conventional stylistic choices in even the most "user-friendly" manuals are considered: "insert" is always chosen over "put in"; and "remove" usually appears where we might use "take off" or "take out" in oral instructions. 
However Brusaw (1982) also take pains to stress that there are ways in which technical writing is different from other kinds of formal writing. In particular, he distinguishes technical writing from more literary forms, in that "[technical writing] stresses exactness rather than elegance" (p. 589). This leads to the issue of lexical variance and suggests that this index may also aid in establishing the function of many two-word items in technical manuals.

\section{LEXICAL VARIENCE}

Lexical variance is the ratio of types (number of different items) to tokens (total number of items). For example, say that in a text the phrasal verb "glop up" appears seven times, "frit out" occurs once, and "chauve down" is used twice. The lexical variance is therefore 1:3 or 33\%. Consequently, the higher the lexical variance, the fewer times an item is repeated. Thus, in partial response to Research Question 1 , results for lexical variance were found to differ significantly according to text genre: $X^{2}(1, N=267)=$ $14.46, \mathrm{p}<.001$, and appear in Figure 6 on the following page.

For phrasal verbs, although the decline is gradual, a definite pattern of decreasing lexical variance in the three corpora. That is to say, the same phrasal verbs are being used more often, suggesting a greater concern for exactitude and explicit cohesion in the instruction manuals. In contrast, in the general text far fewer phrasal verbs are repeated, suggesting that here, there is a greater concem for variety, colorful expression, and implicit cohesion. Consequently, the technical texts, in accordance with their instrumental function, seem to show an increasing concern for clarity and rigorously explicit exposition.

This pattern is even more pronounced in the case of lexical counterparts. The lay corpus shows less than half the variability of the general corpus, and the expert corpus has only one third the variance of "The Oregonian" sample. A look at Table $6(\mathrm{p} .90)$ gives an idea why this is the case. Of the most common lexical counterparts, words like "input/output", "inlet/outlet", and "shutoff" are found; words 
probably first associated with technical contexts in any case, and words which do not have readily identifiable synonyms. These words are chosen for their descriptive accuracy. Similarly, another category of frequent lexical counterparts is neologisms like "pageup", "pagedown", "pop-up" and "pull-apart"--all created to identify a feature by means of its function. Again the concem, one associated with technical exposition, is not for colorful, interesting language; but clear presentation with emphasis on concision.

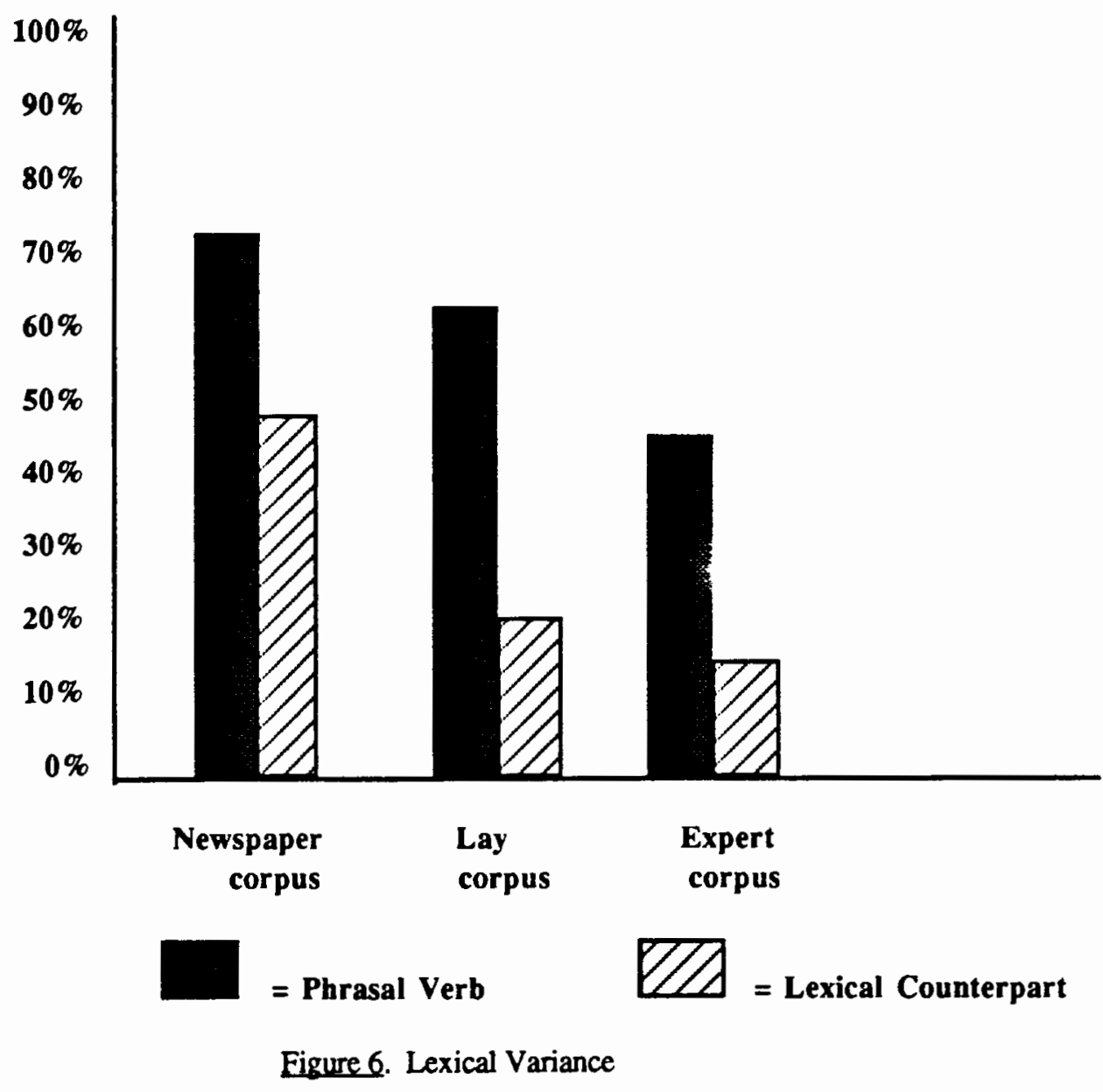

This is not surprising. Tumer (1974) admonishes technical writing students to avoid, "one of the pitfalls of technical writing...that writers often refer to one item using different words. [For example], 'grub', 'screw', 'lockscrew', 'collet', etc., are used to describe the same item" (p. 121). Thus for Turner, repetition of lexical items is often a vital matter of clarity and cohesion. This is undoubtedly why lexical 
counterparts, as nouns which identify or label, have such low lexical variance in the technical corpora: once you identify a feature or device with a particular expression you continue to use that expression and that expression only, to refer to the feature. One benefit of such repetition is that the majority of the figurative two-word items in the expert corpus are typically low lexical variance items, making them easier to comprehend and learn.

Another consequence of low lexical variance is that many of the two-word expressions become more specialized. They become part of that aspect of sub-technical vocabulary which is defined as "those common words that have taken on special meanings, in certain scientific fields" (Trimble et al., 1979, p. 93). An example is the word "plate", which has several general meanings, but also specialized meanings according to the technical/scientific domain where it occurs: "plate" has a different referent in geology, dentistry, metallurgy, and electronics.

In fact it seems that such "technical resignification" brings home the neutrality of two-word figurative items in technical manuals. As was noted earlier that there seems to be no informality in the use of "line up" in technical documents. Similarly, in this study, such two-word items as "turn off" and "go on" (i.e. "illuminate") were excluded from the figurative category, because these expressions were too frequent and too fundamental to technical discourse to be a genuine source of comprehension problems. True, by the criteria for "figurativeness" (item meaning does not equal the sum of its constituent meanings) used in this study, "tum on" is figurative, but it would go against better judgement to characterize this expression as "idiomatic" or as "a Figure of speech". In technical contexts, expressions in the "turn on/off" lexical paradigm are quite concrete and seem very literal in sense. Indeed, compare the technical sense of "feedback" (from The Oxford English Dictionary; Simpson \& Weiner,1989): "the returning of a fraction of the ouput of an electric oscillation to the input to which the fraction is added at the proper base" to, "Don't give me any feedback!" (i.e. "Don't dispute me!"); or "Line up the mark on the distributor with the split in the crankcase." to, "I lined her up with Paul for the dance this weekend". In fact, it almost seems as if these two-word expressions are sub-technical in an inverse sense: they are 
not common words that have taken on specialized meanings, but specialized words that have received additional informal meanings in everyday contexts through metaphorical extension--a hypothesis that seems partially confirmed by the etymological data on "feedback", "line up", "burnt-out", and "turn on" in The Oxford English Dictionary*.

Therefore even figurative two-word items in technical manuals tend to have neutral, quite concrete meaning. They are often chosen for their descriptive accuracy, and one account of their relatively high frequency in technical contexts is that the repetition increases clarity and cohesion. However their frequency also varies according to the rhetorical function of the discourse.

\section{RHETORICAL FUNCTION}

The sentences where two-word items were found were categorized using critieria established by Trimble (1985, see pp. 9-10, 42-43 \& $47-48$ of this study) in an attempt to respond to Research Question 3 (see p. 5 of this study). The applicability of these criteria was established through tests of inter-rater reliability on a 8,400 word section of the expert technical corpus. Reliablity for rhetorical functions was determined through the use of the coefficient of reliability (cf. Chadwick et al., 1982). Our reliability coefficient was $98 \%$, far above the theshhold of acceptability of $60 \%$. Therefore the evaluative criteria were found to be reliable.

* "Feedback" in a technical sense is first cited in 1900. "Feedback" in the sense of behaviour doesn't appear until 1943, and "feedback' in the sense it is used here, as a synonym for "backtalk" is not yet an entry. The time gap between "line up" meaning "align", and "line up" as "introduce" is shorter but still evident: 1891 and 1906 respectively. Other examples are "burnt-out" meaning "extinguished", which is first cited in DeQuincy in 1887, and "burnt-out" as "exhausted" or "enervated", where Graham Greene's, $\mathbf{A}$ Burnt-Out Case (1959), supplies the first reference. "Turn on" in the sense of "activate" first appears in 1833, but surprisingly, the first citation of "tum on" as to "arouse or excite" is not from some source in the 60s, but Henry James in The Ambassadors, published in 1903. As for "turn off", it is the exception. "Tum off" in the sense of "to be disgusted; to cause to lose interest" is first cited in 1667, while the technical sense does not appear until 1833 (Simpson \& Weiner, 1989). 
In collecting data, items were categorized as Figurative and Non-Figurative for each Rhetorical Function (see Table III below). Unfortunately it was impossible to establish statistical significance using the chi-square method, because for this type of analysis to operate, there must be an expected frequency of at least five members in each category. Fortunately, in terms of this investigation, the only interesting consequence of making the additional distinction of figurative and non-figurative in relation to rhetorical function was the number of figurative phrasal verbs apppearing in both Instruction categories of the lay corpus. This is fortunate because the two Instruction categories account for $81 \%$ of all the figurative phrasal verbs in the lay corpus, and of those, the "pure" Instruction category accounts for 54\%. Clearly, this large difference is meaningful, regardless of whether or not it is possible to perform a specific statistical analysis.

However, to be able to establish some statistical significance, we grouped figurative and nonfigurative categories together. Even so, there were some categories which lacked sufficient members for chi-square analysis (the implications of these low frequencies to be discussed below). Therefore statistical significance could be established for the following rhetorical functions in partial response to Research Question 3 (see p. 5 of this study):

for PHRASAL VERBS (lay vs. expert corpora): the rhetorical functions of Physical Description, Function Description, Process Description, "pure" Instruction, and Instructional Information: $X^{2}(1, N=522)=82.45, p<.001$

for LEXICAL COUNTERPARTS (lay vs. expert corpora): the rhetorical functions of Physical Description, Function Description, "pure" Instruction, Instructional Information, Visual-Verbal Relations, and Table: $X^{2}(1, N=656)=94.02, p<.001$. 
TABLE III

RHETORICAL FUNCTION OF SENTENCES CONTAINING FIGURATIVE (FIG) AND NON FIGURATIVE (N/F) TWO-WORD ITEMS

\begin{tabular}{|c|c|c|c|c|c|c|c|c|}
\hline & \multicolumn{2}{|c|}{ Lay PVs } & \multicolumn{2}{|c|}{ Expert PVs } & \multicolumn{2}{|c|}{ Lay LexCs } & \multicolumn{2}{|c|}{ Expert LexCs } \\
\hline & FIG & $\mathbf{N} / \mathbf{F}$ & FIG & $\mathbf{N} / \mathbf{F}$ & FIG & $\mathbf{N} / \overline{\mathbf{F}}$ & FIG & $\mathbf{N} / \mathbf{F}$ \\
\hline Physical & 1 & 11 & 3 & 4 & 6 & 13 & 6 & 88 \\
\hline Function & 9 & 21 & 5 & 11 & 5 & 22 & 15 & 74 \\
\hline Process & 8 & 2 & 8 & 22 & 3 & 0 & 8 & 21 \\
\hline Definition & 0 & 0 & 1 & 0 & 1 & 3 & 2 & 7 \\
\hline Classification & 0 & 0 & 0 & 0 & 0 & 0 & 0 & 0 \\
\hline $\begin{array}{l}\text { "Pure" } \\
\text { Instruction }\end{array}$ & 55 & 200 & 7 & 35 & 8 & 55 & 11 & 41 \\
\hline $\begin{array}{l}\text { Instructional } \\
\text { Information }\end{array}$ & 28 & 42 & 6 & 24 & 6 & 22 & 12 & 32 \\
\hline $\begin{array}{l}\text { Visual- } \\
\text { Verbal }\end{array}$ & 0 & 2 & 3 & 1 & 9 & 11 & 14 & 103 \\
\hline Table & 1 & 18 & 0 & 0 & 6 & 16 & 12 & 69 \\
\hline
\end{tabular}

The results of considering the distribution by thetorical function of combined figurative and non-figurative two-word items can be seen in Figures 7 and 8 on the following pages.

A first observation regarding the figures above is that the general importance of two-word items in the combined Instruction categories. Forty-eight percent of all two-word items $\propto c c u r$ in sentences that are thetorically instructional. In fact, considering the lay corpus alone, the percentage of two-word items in the Combined Instruction functions climbed to $63 \%$ of all two-word items found.

The significance of this concentration of two-word items in one type of rhetorical function in the lay corpus is that it gives them a prominence that goes far beyond their actual frequency in the total corpus. 
For as Trimble (1985) has noted, technical manuals are made primarily to instruct, and as was established earlier with some care (cf. pp. 46-47 of this thesis), large sections of technical manuals typically remain unused because their information is supplementary, or at best complementary to the user's primary aim. Therefore in the lay corpus, the majority of two-word items appear in those rhetorical contexts which are (1) crucial to successfully using a manual, and (2) those sections of the manual most often read.

$$
\text { \# of tokens }
$$
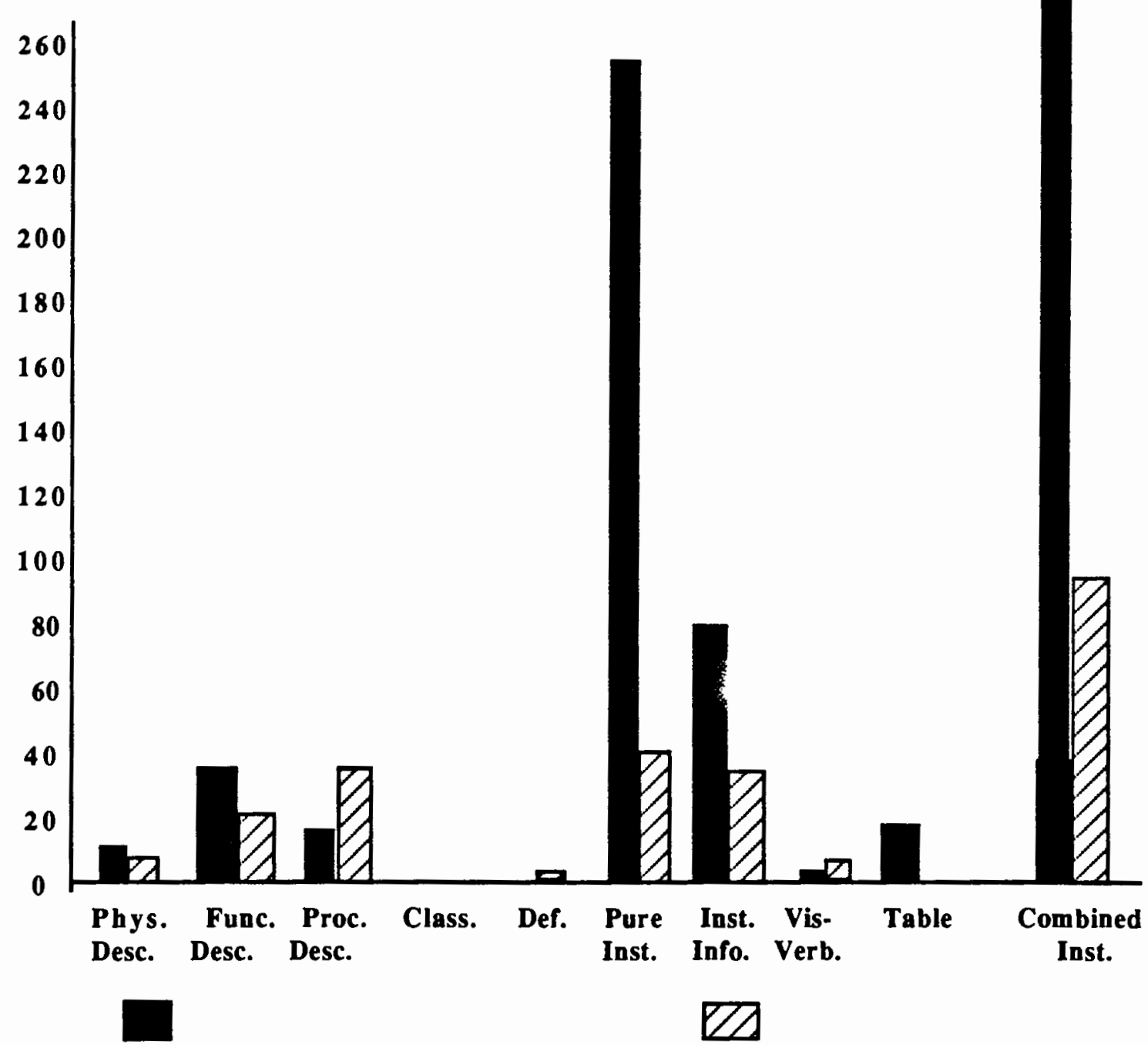

Lay Corpus

Expert Corpus

Figure 7. Frequency of Phrasal Verbs by Rhetorical Function 


\section{\# of tokens}
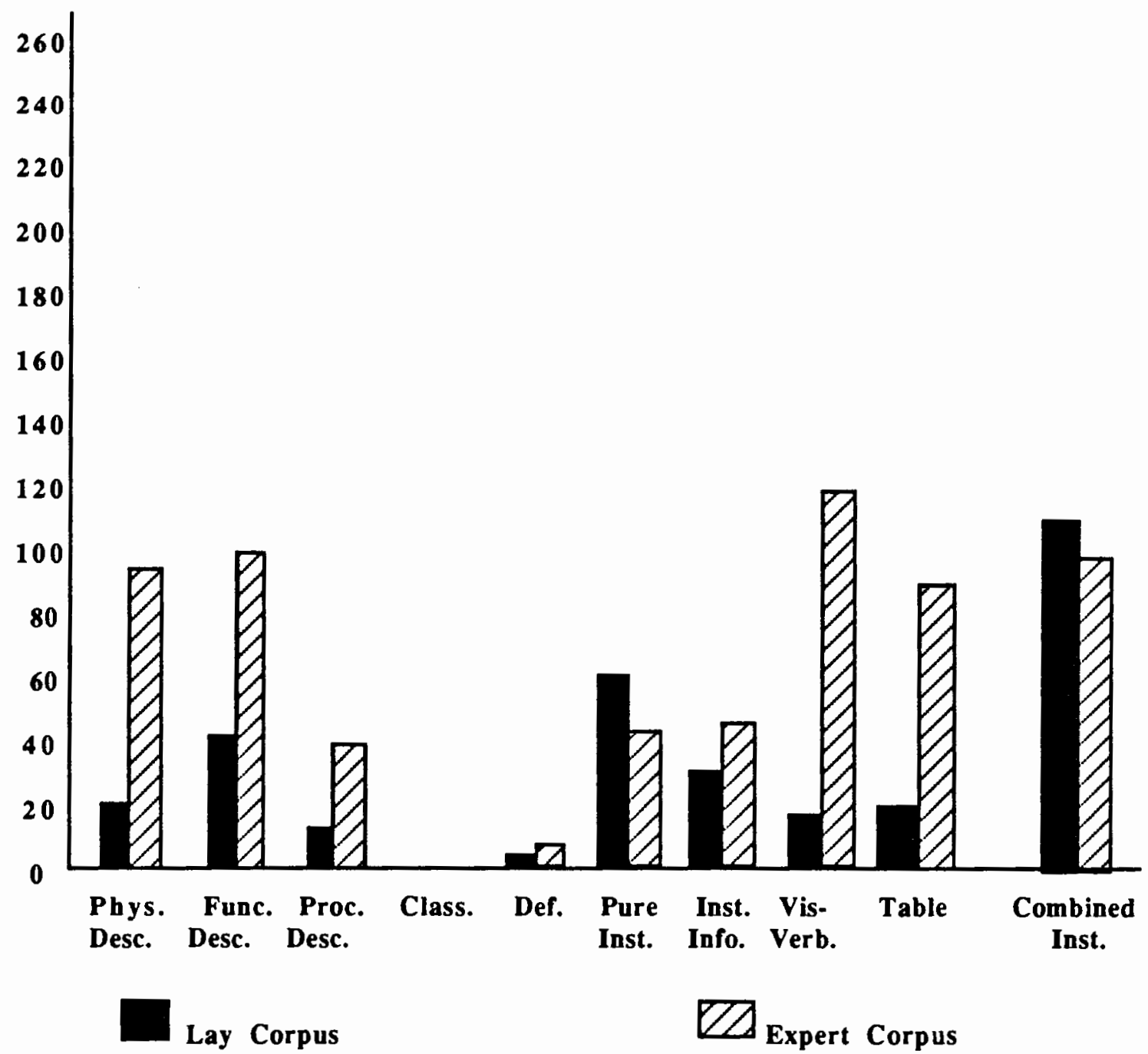

Eigure 8. Frequency of Lexical Counterparts by Rhetorical Function

On the other hand, as to two-word item frequencies, there were a number of rhetorical functions which did not attain an expected frequency of five members. Some of these categories should be of no surprise. For example, phrasal verbs were of very low frequency in the rhetorical functions of Visual-Verbal Relations and Table. These rhetorical functions tend to name, identify or label; so accordingly, complete sentences and even phrases where verbs of any kind could occur are uncommon. In fact, the majority of phrasal verbs that did appear in the thetorical function of Table were participials. So the lack of phrasal verbs appearing in these rhetorical functions is completely understandable, it's a simple matter of how 
information in these functions is structured.

However, reasons for low frequencies of two-word items in other thetorical functions are less evident. For example, there was not one instance of a two-word item appearing in a Classification sentence. This does not mean that sentences having the rhetorical function of Classification are non-existent in technical manuals. On the other hand it would be absurd to suggest that this finding indicates that two-word items are somehow antithetical to classification. Therefore it is reasonable to assume that Classification is not a major rhetorical function of technical manuals. In a sense this seems appropriate, for the focus of technical manuals is post-taxonomic: their concern is the operation, maintenance, and repair of a device, not its relation to other items. Even in systems manuals where different devices are discussed, the focus is on their interaction not their membership in larger groups. Trimble (1979) states that a writer classifies, "whenever he answers the question, 'Where does this (species, idea, object, etc,) belong in the scheme of things?'" (Trimble et al., pp. 362-363). As such, classification seems to be more an activity concerning the general knowledge or theory of a domain, rather than a matter of specific application (as is always the case with technical manuals). It may therefore be that classification plays a large role in textbooks, lectures, and even promotional materials about product lines, but it seems at best incidental to the aims of technical manuais.

Another rhetorical function where two-word items appeared very rarely was that of Definition. Trimble (1979) distinguishes between three types of definition: formal, semi-formal and non-formal. Formal Definition has three parts: Term. Class, and Difference; Semi-Formal Definition omits class; and presumably, Non-Formal supplies only a definition with no comparison to anything other (cf. Trimble et al., pp. 365, 368, \&371). However, when the examples that Trimble fumishes are considered (cf. Trimble et al., 1979, pp. $381 \& 385$; and Trimble, 1985, p. 89), any term being defined is found in an indefinite construction and is followed by a stative verb (especially "to be" or "to have"). These distinctions may seem trivial, but I believe they are important: the choice of indefinite construction serves to generalize, and the use of stative verbs sets up the "equivalence relationship" so typical of all the 
conventional definition constructions. It could be argued that any Physical or Functional Description is an instance of non-formal definition, yet surely Trimble did not intend this or he would not have developed these metorical function categories. No, definition has certain characteristic grammatical and/or lexical features (e.g. "to define", "to be known as", "is called"), and while physical description and functional description may at times fufill the role of definition, this is not non-formal definition but incidental definition.

Thus, true definition is relatively insignificant in technical manuals. Again I believe one reason for this is that the aim of technical manuals, unlike some other genres in Science and Technology, is not the integration of knowledge, but the application of knowledge. So the technical manual user is not usually concerned with "what it is", but "how does it solve my problem, how do I identify it, and what do I then do with it?" An example may be seen in Figure 9, on the next page, from the Devronizer text (DevronHercules, 1990a). It is part of a description (indeed, labelled "Description") of the main features of the "Actuator". It might be claimed that the text "defines" the features named by the sub-headings, but the usually set up, or how it must be operated. Indeed, in the rhetorical analysis of the technical corpora, the few occasions where categorizing a sentence as Definition was considered, the sentence turned out to be a case of what Trimble (1979) calls "Partition", which he takes pains to distinguish from both classification and definition: "partition is the process of naming all the parts an object consists of". IIt is distinct from] Classification and Definition because it deals with only one object [instead of several]" (Trimble et al., p. 373).

As for the relative lack of two-word items appearing in the rhetorical function of Process, this too is appropriate. A frequent function of Process Description is to relate that "underlying theory" which is usually not a part of technical manuals (cf. p. 40 of this study). In fact traditionally, technical manuals have made few attempts to compensate for readers' possible lack of background. On the other hand, if this language used is not that of definition: we don't learn what a feature is, we learn where it is, or how it is is the case, it seems initially odd, for the frequency of two-word items in the Process function is higher in 
Steam Supply Inlet

Flow-Control Valve To Adjust Steam Flow

Condensate Taps

Hot Lips
In its operating position, the Devronizer is precisely positioned (usually $10 \mathrm{~mm}$ or $3 / 8$ inch from the sheet surface): It is not designed to support any forcign load.

The mill's pressure-controlled steam supply is usually connected to the Devronizer on the drive side.

To allow the Devronizer uninhibited movement, flexible, insulated steam hosing is used between the mill's isolating valve and the unit. A pressed neck flange connects the hosing with the steam inlet header on the Devronizer.

Neither the flexible hosing nor the inlet header are meant to support any foreign load.

While steam supply into the Devronizer is pressure controlled, once inside the unit, steam is flow controlled.

A flow-control valve located on the tending-side endplate enables manual adjustment of steam flow to the steam curtain-preheat section.

The balance of the steam goes to the actuator profiling section and is adjusted via the remote control station.

The endplate on the tending side, and often the endplate on the drive side, have condensate drain taps which are always situated at the lowest point of each internal chamber.

These taps drain internal condensate and must be fully open at machine(startup and then adjusted to ' $c$ racked oper' position after warmup find during operation.

The external cross machine edges of the Devronizer are heated so that water droplets evaporate rapidly. Units with 'hot lips' should have waming decals on these extremely hot surfaces. 
the expert corpus than in the lay corpus. The lay corpus, which is presumably more "user-friendly", should be supplying its users with more information. However there are many kinds of "more information". It's not clear that a lengthy (usually several sentences) explanation of the "hows and whys" of the interworkings of the whole device is useful to the reader who has limited previous experience in the area. We recall Schulman's remark (1971, p. 45) that, "the theory of operation may turn out to be a total waste of effort as far as most readers are concerned...going into detail beyond their needs". In fach the type of "compensatory" information often supplied in lay technical manuals is the type which permits the user to perform the operation without understanding any more of the device's process than is necessary. Remember Muir's statement (1990, p. 5) that his intention is "to fill the gap between what to do and how to do it". Elsewhere he notes, "the idea is to never let you get hung up about what to do in any situation", and says that his manual, "is designed to give step-by-step instructions for the performance of an operation with the minimum of thought, proficiency, and ingenuity on the part of the personnel." (ibid). Therefore, the low-frequency of two-word items found in the rhetorical function of Process in lay manuals is probably because of a lesser amount of Process Description, for such description is of limited use to the general public.

As to the rhetorical functions where two-word items occurred frequently enough to be significant, the most salient finding is the extremely high number of phrasal verbs found in "pure" Instruction. Clearly this thetorical function is conducive to phrasal verb use, a fact we may better understand by examining some stylistic considerations concerning instructions. One problem Brusaw (1982) notes about poorly written instructions is that they are written in "telegraphic style". He therefore counsels technical writers to "keep in mind your reader's level of knowledge and experience", and "phrase instructions concisely , but not as if they were telegrams", for one shouldn't, "sacrifice clarity in order to be concise". This advice is followed by an example instruction which is improved by the insertion of a phrasal verb, which makes the sentence "clearer" (pp. 303-304). Tumer (1974) also remarks that "the writer's meaning becomes clearer if these Anglo-Saxon words (i.e. two-word items) are used" (p. 163), and again we recall Bolinger's remarks (1971, p. xii) that, "[two-word items] are always motivated and hence strikingly expressive" . 
Therefore lay technical manual writers, in attempting to compensate for the general public's potential lack of experience, continue to try to furnish clear and concise information (as with manuals for any audience) but with special attention to orientation, precision, and feature identification. One stylistic difference between expert and lay manuals, as a result of this attempt, is an increased use of phrasal verbs.

Note that four-fifths of the phrasal verbs that appear in the "pure' instruction category are nonfigurative (see Table IV on the following page). That is, they are precisely those two-word compounds where the particle gives the verb a sense of direction or completion, a sense that is often lacking in the latinate doublets of these two-word items (compare "an output" to "a yield", "lift out" to "remove"). Moreover, of the 55 figurative phrasal verbs which appear in "pure" instruction, 35\% were tokens of items like "line up", where although the item was figurative, the completive sense of its particle was maintained. Thus phrasal verbs are used in instructions to lay audiences because of their concise specificity.

Correspondingly, while most phrasal verbs and many lexical counterparts in the expert corpus are found in "pure" instruction, their frequency here is not so dramatically different from the rest of the distribution. This is appropriate. It is not necessary to provide such precise orientation to a trained specialist. Indeed this may explain why the Physical and Function Description functions of the expert corpus have a noticeably higher lexical counterpart count than either Instruction category: if experts know the characteristics of a device or a feature, they can use previous knowledge to manipulate it. A good analogy is the electrical system of an automobile: for an electrical expert, a schematic will suffice, but the lay person will need something far more Figureic, representing the actual lay-out of wires and devices.

Such presumptions about the reader's background may also explain the high frequency of lexical counterparts found in the rhetorical function of Visual-Verbal Relations in the expert corpus: following a reasoning similar to Widdowson's, the trained expert is skilled in interpreting visuals (indeed, one of 
Widdowson's main proposals is to use the visuals of EST documents to teach the language in their texts) and therefore requires less textual support to supplement illustrative material (cf. Widdowson, 1979).

\section{TABLE IV}

FIGURATIVE PHRASAL VERBS FOUND IN "PURE" INSTRUCTION IN THE LAY MANUAL
Item
\# of tokens
Item
\# of tokens

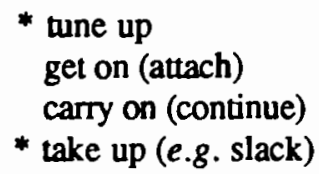

3
3
3
2

* line up

10

find out (discover)

get out (find)

6

turn over (reverse)

2

(all remaining items appeared only once)

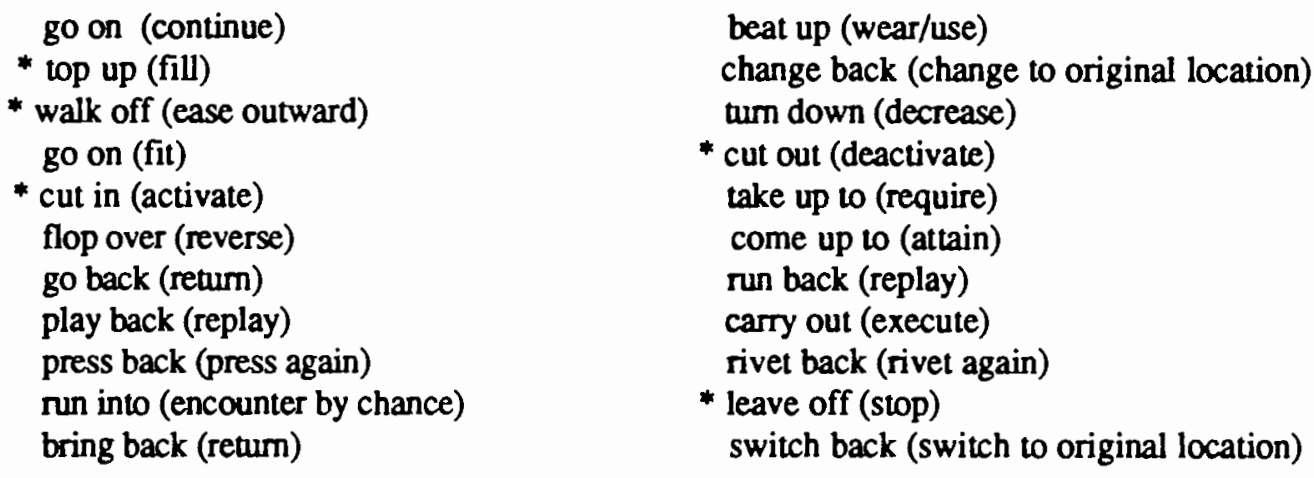

* indicates items where the particle retains its base or completive sense

\section{SEMANTIC FEATURES}

The most frequent phrasal verbs and lexical counterparts found in the two technical corpora were recorded and listed by frequency rank (i.e. number of tokens/lexical item) and range (number of different texts where an item appears: the expert corpus was composed of 7 texts, and the lay corpus contained 13). All two-word items which appeared more than once were included in Tables V \& VI (pp. 88-90), 
making them a quite representative sample.

Recording the items' ranges was done (1) to provide a manageable data base for semantic analysis; (2) to obtain a better idea of items' distribution (i.e. if an item appears in a number of different texts it is more likely to be widely-used, so it is a good candidate for instruction); and (3) to avoid overemphasizing the prominence of items which appeared many times but in a very limited context. An example of this is the lexical counterpart "blowout" which occurred 18 times but only in the Trimble Text (in fact, 17 of the 18 occurrences were in one section of the Trimble Text).

However, assumptions based on the range of an item must remain tentative. First there is the question of sufficient range. The lexical counterpart "output" has 172 tokens over a range of 10 texts, but in relation to the 172 tokens, is it "as many as" 10 texts or "only" ten texts? Conversely, every token of "outstanding" is found in a different text, but with only two tokens recorded, is this important? Similarly the expression "feedback" appears 16 times, but only in one text. Does this mean that "feedback" is not an useful word for electrical engineers to know? In the same fashion, some common technically-oriented terms like "breakdown", "to tighten down", and "to burn out" did not appear here at all. Does this mean they should not be included in instruction? Clearly such lists can provide instructors with rule-of-thumb suggestions, but suggestions which must be supplemented by intuition for other items should be included in materials if they meet criteria such as those proposed by Comell (1985, cf. p. 51 of this thesis).

As to semantic analysis, my main interest was the semantic contribution of the particle to the whole of the two-word item, for this provided a means to address Research Question 4 (see p. 5 of this study). Identifying this contribution for non-figurative items is rather easy: with "literal" items the particle has a sense of "orientation". For the completive items the particle accordingly carries a sense of "completion". For most figurative items, it is not meaningful to speak of the particle's contribution to meaning, but as was already noted, some particles in certain figurative two-word items retain an extra intensive sense of precision/completion (e.g. "line up"). Additionally, sometimes particles contribute a sense which is non- 
TABLE V

MOST FREQUENT PHRASAL VERBS FOUND IN THE TECHNICAL CORPORA

\begin{tabular}{|c|c|c|c|c|c|}
\hline Rank & Item & \# of tokend & Range & $\begin{array}{l}\text { Particle } \\
\text { Sense }\end{array}$ & $\begin{array}{l}\text { Semantic } \\
\text { Field }\end{array}$ \\
\hline $\begin{array}{l}1 \\
2 \\
3 \\
4 \\
5 \\
6 \\
7 \\
8 \\
9 \\
- \\
- \\
- \\
10 \\
11 \\
- \\
- \\
- \\
- \\
- \\
- \\
- \\
12 \\
- \\
- \\
- \\
13 \\
- \\
- \\
- \\
- \\
- \\
- \\
- \\
- \\
- \\
- \\
- \\
- \\
- \\
- \\
- \\
- \\
- \\
- \\
- \\
- \\
- \\
- \\
- \\
- \\
- \\
- \\
- \\
- \\
- \\
-\end{array}$ & $\begin{array}{l}\text { turn on } \\
\text { be on } \\
\text { turn off } \\
\text { shut off } \\
\text { hold down } \\
\text { plug in } \\
\text { be off } \\
\text { line up } \\
\text { move up } \\
\text { move down } \\
\text { cut out (deactivate) } \\
\text { carry out (execute) } \\
\text { pull down } \\
\text { push down } \\
\text { turn over (reverse) } \\
\text { put on } \\
\text { pull out } \\
\text { lift out } \\
\text { shut down } \\
\text { find out } \\
\text { set up (organize) } \\
\text { lift off } \\
\text { hose down } \\
\text { run out (consume) } \\
\text { lift up } \\
\text { switch off } \\
\text { put in } \\
\text { pull off } \\
\text { take off } \\
\text { cut off } \\
\text { speed up (accelerate) } \\
\text { go out (deactivate) } \\
\text { record over } \\
\text { save to (enter) } \\
\text { cut in (activate) } \\
\text { get in (enter) } \\
\text { move away } \\
\text { pry off } \\
\text { pick up (take) } \\
\text { time out (clock) } \\
\text { blow out (short-circuit) } \\
\text { move back } \\
\text { sol }\end{array}$ & $\begin{array}{l}35 \\
23 \\
20 \\
19 \\
18 \\
15 \\
14 \\
12 \\
9 \\
9 \\
9 \\
9 \\
8 \\
6 \\
6 \\
6 \\
6 \\
6 \\
6 \\
6 \\
6 \\
5 \\
5 \\
5 \\
5 \\
4 \\
4 \\
4 \\
4 \\
4 \\
4 \\
4 \\
3 \\
3 \\
3 \\
3 \\
3 \\
3 \\
3 \\
3 \\
3 \\
3\end{array}$ & $\begin{array}{r}8 \\
7 \\
8 \\
10 \\
4 \\
3 \\
6 \\
5 \\
1 \\
1 \\
3 \\
6 \\
1 \\
4 \\
5 \\
2 \\
2 \\
4 \\
5 \\
3 \\
5 \\
4 \\
1 \\
4 \\
4 \\
1 \\
2 \\
1 \\
3 \\
2 \\
3 \\
3 \\
1 \\
1 \\
1 \\
1 \\
2 \\
1 \\
2 \\
1 \\
1 \\
3\end{array}$ & $\begin{array}{l}\text { other } \\
\text { other } \\
\text { completion } \\
\text { completion } \\
\text { orientation } \\
\text { orientation } \\
\text { completion } \\
\text { completion } \\
\text { orientation } \\
\text { orientation } \\
\text { other } \\
\text { other } \\
\text { orientation } \\
\text { orientation } \\
\text { other } \\
\text { orientation } \\
\text { orientation } \\
\text { orientation } \\
\text { completion } \\
\text { other } \\
\text { other } \\
\text { orientation } \\
\text { completion } \\
\text { completion } \\
\text { orientation } \\
\text { completion } \\
\text { orientation } \\
\text { orientation } \\
\text { orientation } \\
\text { orientation } \\
\text { other } \\
\text { completion } \\
\text { orientation } \\
\text { orientation } \\
\text { other } \\
\text { orientation } \\
\text { orientation } \\
\text { orientation } \\
\text { orientation } \\
\text { completion } \\
\text { completion } \\
\text { orientation }\end{array}$ & $\begin{array}{l}\text { activation } \\
\text { activation } \\
\text { activation } \\
\text { activation } \\
\text { attachment } \\
\text { attachment } \\
\text { activation } \\
\text { movement } \\
\text { movement } \\
\text { movement } \\
\text { activation } \\
\text {-- } \\
\text { movement } \\
\text { movement } \\
\text { movement } \\
\text { attachment } \\
\text { attachment } \\
\text { attachment } \\
\text { activation } \\
\text {-- } \\
\text {-- } \\
\text { attachment } \\
\text { cleaning } \\
\text { consumption } \\
\text { attachment } \\
\text { activation } \\
\text { attachment } \\
\text { attachment } \\
\text { attachment } \\
\text { movement } \\
\text { movement } \\
\text { activation } \\
\text {-- } \\
\text {-- } \\
\text { activation } \\
\text { movement } \\
\text { attachment } \\
\text { movement } \\
\text { movement } \\
\text {-- } \\
\text { consumption } \\
\text { movement }\end{array}$ \\
\hline
\end{tabular}


MOST FREQUENT PHRASAL VERBS FOUND IN THE TECHNICAL CORPORA (continued)

\begin{tabular}{|c|c|c|c|c|c|}
\hline Rank & Item & \# of tokens & Range & $\begin{array}{l}\text { Particle } \\
\text { Sense }\end{array}$ & $\begin{array}{l}\text { Semantic } \\
\text { Field }\end{array}$ \\
\hline $\begin{array}{l}- \\
- \\
- \\
14 \\
- \\
- \\
- \\
15 \\
- \\
- \\
- \\
- \\
- \\
- \\
- \\
- \\
- \\
- \\
- \\
- \\
- \\
- \\
- \\
- \\
- \\
- \\
- \\
- \\
- \\
- \\
- \\
-\end{array}$ & $\begin{array}{l}\text { go back (return) } \\
\text { bring about (make happen) } \\
\text { give up (renounce) } \\
\text { be made up of } \\
\text { wear out } \\
\text { pipe off } \\
\text { tune up } \\
\text { use together } \\
\text { pull up } \\
\text { break out } \\
\text { come out (extend) } \\
\text { bypass } \\
\text { get out (leave) } \\
\text { strike over } \\
\text { fold down } \\
\text { burn up } \\
\text { drain out } \\
\text { jack up } \\
\text { give off (emit) } \\
\text { slip out } \\
\text { put out } \\
\text { clean out } \\
\text { slide back } \\
\text { build up } \\
\text { hold on } \\
\text { take out } \\
\text { get on (attach) } \\
\text { hook under } \\
\text { wash down } \\
\text { switch on } \\
\text { lock out } \\
\text { put together } \\
\text { put back }\end{array}$ & $\begin{array}{l}3 \\
3 \\
3 \\
3 \\
3 \\
3 \\
3 \\
2 \\
2 \\
2 \\
2 \\
2 \\
2 \\
2 \\
2 \\
2 \\
2 \\
2 \\
2 \\
2 \\
2 \\
2 \\
2 \\
2 \\
2 \\
2 \\
2 \\
2 \\
2 \\
2 \\
2 \\
2 \\
2\end{array}$ & $\begin{array}{l}3 \\
2 \\
3 \\
3 \\
3 \\
1 \\
1 \\
2 \\
1 \\
1 \\
2 \\
1 \\
2 \\
1 \\
1 \\
2 \\
1 \\
2 \\
2 \\
1 \\
2 \\
2 \\
1 \\
1 \\
2 \\
2 \\
1 \\
1 \\
1 \\
1 \\
1 \\
2 \\
1\end{array}$ & $\begin{array}{l}\text { direction } \\
\text { other } \\
\text { other } \\
\text { other } \\
\text { completion } \\
\text { orientation } \\
\text { completion } \\
\text { other } \\
\text { orientation } \\
\text { orientation } \\
\text { orientation } \\
\text { orientation } \\
\text { orientation } \\
\text { orientation } \\
\text { orientation } \\
\text { completion } \\
\text { orientation } \\
\text { orientation } \\
\text { orientation } \\
\text { orientation } \\
\text { orientation } \\
\text { completion } \\
\text { orientation } \\
\text { orientation } \\
\text { orientation } \\
\text { orientation } \\
\text { orientation } \\
\text { orientation } \\
\text { completion } \\
\text { other } \\
\text { completion } \\
\text { other } \\
\text { orientation }\end{array}$ & $\begin{array}{l}\text { movement } \\
.- \\
-- \\
\text { consumption } \\
\text { movement } \\
-- \\
\text { attachment } \\
\text { movement } \\
\text { attachment } \\
\text { movement } \\
\text { movement } \\
\text { movement } \\
\text { movement } \\
\text { movement } \\
\text { consumption } \\
\text { movement } \\
\text { movement } \\
\text {-- } \\
\text { attachment } \\
\text { movement } \\
\text { cleaning } \\
\text { movement } \\
\text { movement } \\
\text { attachment } \\
\text { attachment } \\
\text { attachment } \\
\text { attachment } \\
\text { cleaning } \\
\text { activation } \\
-- \\
\text { attachment } \\
\text { movement }\end{array}$ \\
\hline
\end{tabular}


TABLE VI

MOST FREQUENT LEXICAL COUNTERPARTS FOUND IN THE TECHNICAL CORPORA

\begin{tabular}{|c|c|c|c|c|c|}
\hline Rank & Item & \# of tokens & Range & $\begin{array}{l}\text { Particle } \\
\text { Sense }\end{array}$ & $\begin{array}{l}\text { Semantic } \\
\text { Field }\end{array}$ \\
\hline $\begin{array}{c}1 \\
2 \\
3 \\
4 \\
5 \\
- \\
6 \\
- \\
7 \\
\overline{8} \\
10 \\
11 \\
- \\
- \\
- \\
12 \\
- \\
- \\
13 \\
- \\
- \\
14 \\
- \\
- \\
15 \\
- \\
- \\
- \\
- \\
- \\
-\end{array}$ & $\begin{array}{l}\text { output } \\
\text { input } \\
\text { inlet } \\
\text { backspace } \\
\text { intake } \\
\text { outlet } \\
\text { blowout } \\
\text { startup } \\
\text { feedback } \\
\text { pop-up } \\
\text { bypass } \\
\text { pickup (sensor) } \\
\text { takeup (e.g. slack) } \\
\text { built-in } \\
\text { build-up } \\
\text { lineout } \\
\text { backup } \\
\text { pulldown } \\
\text { shutoff } \\
\text { warmup } \\
\text { wordout } \\
\text { liftoff } \\
\text { pageup } \\
\text { pagedown } \\
\text { hold down } \\
\text { pull-up } \\
\text { shutdown } \\
\text { takeoff } \\
\text { setup } \\
\text { coverup } \\
\text { playback } \\
\text { auto-off } \\
\text { outstanding }\end{array}$ & $\begin{array}{r}172 \\
159 \\
31 \\
29 \\
20 \\
20 \\
18 \\
18 \\
16 \\
14 \\
12 \\
11 \\
8 \\
8 \\
8 \\
8 \\
7 \\
7 \\
7 \\
6 \\
6 \\
6 \\
4 \\
4 \\
4 \\
3 \\
3 \\
3 \\
3 \\
2 \\
2 \\
2 \\
2\end{array}$ & $\begin{array}{r}10 \\
7 \\
3 \\
3 \\
5 \\
6 \\
1 \\
2 \\
1 \\
1 \\
2 \\
2 \\
2 \\
4 \\
4 \\
1 \\
3 \\
2 \\
2 \\
2 \\
1 \\
1 \\
1 \\
1 \\
2 \\
1 \\
1 \\
1 \\
2 \\
1 \\
1 \\
1 \\
2\end{array}$ & $\begin{array}{l}\text { orientation } \\
\text { orientation } \\
\text { orientation } \\
\text { orientation } \\
\text { orientation } \\
\text { orientation } \\
\text { completion } \\
\text { completion } \\
\text { orientation } \\
\text { orientation } \\
\text { orientation } \\
\text { other } \\
\text { completion } \\
\text { orientation } \\
\text { orientation } \\
\text { completion } \\
\text { completion } \\
\text { orientation } \\
\text { completion } \\
\text { completion } \\
\text { completion } \\
\text { orientation } \\
\text { orientation } \\
\text { orientation } \\
\text { orientation } \\
\text { orientation } \\
\text { completion } \\
\text { orientation } \\
\text { other } \\
\text { completion } \\
\text { other } \\
\text { completion } \\
\text { other }\end{array}$ & $\begin{array}{l}\text { flow } \\
\text { flow } \\
\text { flow } \\
\text { movement } \\
\text { flow } \\
\text { flow } \\
\text { eliminate } \\
\text { activation } \\
\text { flow } \\
\text { movement } \\
\text { flow } \\
\quad-- \\
\text { movement } \\
\text { movement } \\
\text { movement } \\
\text { elimination } \\
\text {-- } \\
\text { movement } \\
\text { activation } \\
\text { activation } \\
\text { elimination } \\
\text { elimination } \\
\text { movement } \\
\text { movement } \\
\text { attachment } \\
\text { movement } \\
\text { activation } \\
\text { movement } \\
\text {-- } \\
\text { elimination } \\
--- \\
\text { activation } \\
\text {-- }\end{array}$ \\
\hline
\end{tabular}


literal yet systematic, like those metaphor sets mentioned by Lakoff \& Johnson (1980), where the converse particle pair (e.g. "up/down") corresponds to the notions of "increase/decrease".

Of the most frequent phrasal verbs (see the lists on the preceding pages), 57\% had a sense of orientation, $23 \%$ had a sense of completion, and $20 \%$ were "Other". Of the most frequent lexical counterparts, $85 \%$ of the particles carried a sense of orientation, $9 \%$ a sense of completion, and $6 \%$ had other senses. Clearly, this again confirms that for most two-word items in technical manuals, and especially lexical counterparts, their function is to provide precision in a concise fashion.

In the particle sense category "Other" were found the following systematic meanings, the study of which might be included in a unit of phrasal verb instruction:

\author{
Metaphor Sets: on/off--activate/deactivate (e.g. tum on/turn off) \\ up/down--increase/decrease (e.g. startup/shutdown) \\ on/out--activate/deactivate (e.g. the light goes on/out)
}

Other Systematic Senses: over = reverse (e.g. turn over)

$$
\begin{aligned}
& \text { over = again (e.g. record over) } \\
& \text { back = return to origin (e.g. change back) } \\
& \text { back = again (e.g. call back) }
\end{aligned}
$$

\title{
SEMANTIC FIELDS
}

Given that the primary function of most particles in the technical corpora is to supply an "orientation" component to the compound's meaning, it is not surprising that the most important semantic field of two-word items in this research is that of Movement. In more detail, of the 75 phrasal verbs tokens that occur in the technical manuals more than one time, all but 12 can be characterized as 
belonging to the following semantic fields:

Activation/Deactivation $=11$

Attachment/Detachment $=18$

Movement $=28$

Consumption $=3$

Cleaning $=3$

Those that express the notions of Activation/Deactivation are typically figurative, yet the particle has an intensive aspect (e.g. "shut down" which doesn't mean "shut completely", but" stop definitively"). Many of these items $\propto c u r$ in converse pairs (e.g. "turn on/turn off", "warm up/cool down", "start up/close down") so the items could be presented systematically in a semantically unified grouping.

Phrasal verbs of Attachment/Detachment are more clearly literal, and there seems to be a rather even distribution of "in/out", "on/off" particles, which would allow for neally structured presentation in instructional activities.

Phrasal verbs of Movement use a great variety of particles. Fortunately they are predominantly literal, easing comprehension. Also because of their orientational element, phrasal verbs could be effectively introduced through a review of Prepositions of Place. On the other hand, phrasal verbs of consumption (e.g. "burn up") generally tend to use only the particles "up/down" and "out", and could be practiced by adding the apppropriate particle to common verbs with a potential aspect of "consumption" (e.g. "use" "lear", and "wear"). Phrasal verbs of "cleaning" are a similar case, with the majority of verbs taking the particle set "up/down", although they also combine with "out" as in "wipe out", so it must also be included. Perhaps the two-word items in these two fields could be presented in the same unit sequentially, to reinforce these particle senses and build students' confidence in their ability to interpret and produce. 
Of the 33 lexical counterparts which occur more than one time in the two technical corpora (see page 90), the majority fall into the following categories:

Movement $=12$

Circuit/Flow $=7$

Activation/Deactivation $=5$

Elimination $/$ Removal $=4$

The semantic field "circuit/flow" was created to describe expressions like "input/ouput", "inlet/outlet", "feedback", "intake", and "bypass". Clearly their particle components are diverse, however these items might very easily be treated by presenting, in a Widdowsonian manner, a circuit diagram and then discussing the possible movements and interactions (see Appendix B for a sample lesson). Elimination/Removal was composed primarily of keyboard descriptions such as "wordout", "lineout", "liftoff" ribbon, and "coverup" ribbon. These items may not have wide applicability.

\section{SUMMARY}

Judging from frequency counts and rhetorical context, it is clear that phrasal verbs and their lexical counterparts play an important role in technical manuals when compared to more general texts. It appears that the primary function of these items is not as markers of informality, although they occasionally play this role in lay technical manuals as part of an attempt to make the manual more "user-friendly". Indeed, many of the figurative two-word items found in the technical manuals do not have an identifiable pragmatic function. As for the non-figurative two word items which account for the majority of tokens in the technical corpora, their function is usually to furnish additional orientation or specification-information which is more properly semantic, as it is provided through particle meaning. This may explain why so many phrasal verbs appear in Instruction rhetorical functions of lay manuals: they provide extra orientation for the untrained reader. Expert manuals however, are usually considered more 
formal, and appropriately they exhibit a comparative reduction of figurative two-word expressions, a decrease in lexical variance, and the omission of much information which is presupposed by the writer. Given this formality, and given that the expert technical corpus in this study displayed about the same number of phrasal verbs as the general newspaper corpus yet 5 times as many lexical counterparts, and given that lexical counterparts are typically less polysemous than their corresponding phrasal verbs, it is probable that lexical counterparts have at least neutral formality, and may even be considered more appropriate in some formal contexts than phrasal verbs. 


\section{CHAPTER V}

\section{CONCLUSION}

In response to the Research Questions, this study supports the claim that phrasal verbs are more frequent in technical manuals than in more general informational texts: phrasal verbs and their lexical counterparts occur frequently in manuals, and in rhetorical contexts which show that they play an important role in conveying information. The information they convey is added precision, and in technical contexts where a premium is placed on accuracy, the ability to comprehend such items is crucial, and their inclusion in EST instruction necessary. Generally in technical manuals, two-word items are not informal but neutral, although there are suggestions that informality, and those figurative two-word items associated with it, may to a certain degree be desirable in lay technical manuals where their colloquial quality serves to make them more "user-friendly".

However, the distinction is crucial: informal, figurative two-word items appear infrequently in technical manuals, while those few figurative items and most non-figurative items which are found usually provide added orientational or specifying information. This is important for a number of reasons: (1) two-word items in technical manuals are often more precise than their single word synonyms, (2) two. word items in technical manuals are typically non-figurative and are therefore less likely to cause comprehension problems for Non-Native Speakers, (3) such non-figurative items are more susceptible to systematic treatment in ESL instruction, and (4) this distinction should affect stylistic decisions made by technical writers, especially those engaged in the production of lay technical manuals. 
As was noted in the "Review of Literature", authorities on technical writing tend to alternately condemn two-word items as "vague", "wordy", and "colloquial"; and praise them as "precise", "concise", and "effective". The contradiction comes from failing to perceive the stylistic effect of the two kinds of two-word items: figurative items often mark informality but non-figurative compounds are usually pragmatically neutral. Given the results of the lay corpus rhetorical analysis and the positive role played by non-figurative phrasal verbs in the thetorical category of "pure" Instruction, it would seem beneficial to make technical writers aware of the stylistic impact of this distinction: Yes, some phrasal verbs are slangy and colloquial, but not all. Others are actually more precise than their leaméd, latinate counterparts and should be used. A similar point could be made for lexical counterparts: technical writing inevitably entails creating neologisms. On the other hand, one should avoid the tendency to lapse into jargon. Lexical counterparts, through their capacity to identify a feature by its function, can permit the coining of new terms while reducing potential comprehension difficulties.

\section{IMPLICATIONS FOR INSTRUCTION}

Additionally, this study has provided some reasonable assumptions to be used in developing efficient and relevant instructional techniques and materials. The first and foremost is that because of the extra information they convey, the additional precision they offer, two-word items must be understood and in some cases produced by non-native speakers working in technical domains. However the nature of twoword item instruction can vary greatly according to the context of English use. For those students in technical fields who need ELIT (English as a Language of Information Transfer), especially because they are likely to encounter only expert technical manuals, instruction concerning two-word items can be straight-forward, simple, and very limited: (1) two-word items are less figurative in technical manuals than in general texts, especially in expert technical manuals, suggesting fewer comprehension problems;

(2) the lexical variance of all two-word items in expert technical manuals is relatively low, implying generally a limited range of vocabulary to teach; but it is especially low for the figurative expressions which appear, implying few difficult figurative two-word expressions, and that those few idiomatic 
compounds which do appear will be of high utility; (3) the majority of the two-word items in technical manuals are lexical counterparts, which are typically less polysemous than phrasal verbs, meaning they will be easier to learn, easier to remember, and cause fewer comprehension problems. Consequently, all of these points suggest that the most effective approach for ELIT learner might be to teach the most salient two-word compounds as simple vocabulary items and ignore their syntactic and semantic complexities. However, if a more extensive treatment is deemed appropriate, at least these two-word items are susceptible to a straight-forward systematic treatment, simply because they are predominanty non-figurative.

As for those students in technical fields who are frequently involved with Native English Speakers , some of the points above (like the accessibility of non-figurative items, and the typical monosemy of lexical counterparts which facilitates their production), remain valid. However here, to varying degrees, the concem is for both comprehension and production, very probably in both written and oral modes. Therefore an understanding of two-word items becomes very important. Not only must EST clients be able to access the extra information that two-word items can provide, but they must also be able to produce them to make their own communication more precise. This is all the more the case, as complete mastery of a second language is rarely acheived: occasionally the extra precision that two-word items can provide could compensate for other minor errors or lack of clarity.

Accordingly, especially given the frustration students can experience when trying to learn two-word items, it is crucial to explicitly insist on the specifying role that many of these items have in technical texts. This can help motivate students, for it provides a genuine justification for the time and effort spent in studying these sometimes difficult compound items.

But any case, attending to two-word item instruction for EST clients in anglophone environments is not a great inconvenience. First off, as Celce-Murcia \& Larsen-Freeman note (1983), EST learners in such English-Speaking contexts will need to be exposed to a systematic treatment of phrasal verbs simply 
to be able to participate effectively in general communcation. Therefore, since this type of item has to be treated anyway, the ideal basis for such a systematic presentation would be precisely those two-word items that are frequent or important in technical manuals. Typically these compounds are less idiomatic than many of their more "conversational" counterparts. Therefore if they are used, students can concentrate more on manipulating the insertable direct object and particle, or on mastering the systematic contributions to meaning that the particle constituent gives, instead of doing all this while trying to grasp and remember "illogical" idiomatic expressions.

Additionally, for the ESL student studying EST in or for an Anglophone environment, it is important to practice working with two-word items by using expressions drawn from appropriate technical contexts rather than from general usage. One reason is that (cf. p. 49 of this thesis), the most frequent verbs in technical manuals are often not the most common verbs of everyday language and vice versa. Since this pattern seems to hold for two-word items as well, basing two-word item instruction on technical materials helps ensure that EST students are learning the vocabulary they need most. Another reason for drawing two-word item instruction from relevant technical materials is that EST students often regard English instrumentally, and since much of their English use will be in technical contexts, it is only simple courtesy to select those compound iterns most applicable to technical contexts when developing class presentations.

One final point of consideration is just this matter of technical contexts. However, the following suggestions are advanced only tentatively. The primary reason this research considered the function of two-word items in technical manuals was to determine if these expressions were prominent enough to warrant their inclusion in EST instruction. However, one motivation for choosing technical manuals as an object of research was that they seemed somehow the most representative and formal of genre in the technical domain. Having found that two-word items play an important role in this written, formal style of discourse, it may be tentatively suggested that two-word items also play an important role in less formal and/or oral discourse, and that the function of these compound expressions is similar in all 
technical contexts. If anything, given the difficulty we've had in disassociating phrasal verbs from informal contexts, it is entirely possible that two-word items play an even more important role in oral technical discourse. Certainly the shop-floor interchanges reported by Fanselow (1980), leave no doubt as to the highly colloquial nature of some oral technical discourse. Consequently, until further research is available, this writer will cautiously advance the results of this study as a basis for the instruction of two word items in all technical contexts.

\section{SUGGESTIONS FOR FURTHER RESEARCH}

As was just noted, one important area of research concerns the prominence of two-word items in other technical discourse contexts, especially oral ones. Additionally, frequency analysis concerning less specialized discourse areas would be very useful, permitting comparisons such as the most frequent phrasal verbs in technical vs. general contexts.

Another important area of study concerns actual evaluative studies with ESL sudents, both in general studies and in ESP-oriented classes, to determine what two-word items actually cause comprehension problems. One limitation of the present study was that it could only make indirect claims about comprehensibility using the measure of "idiomaticity". Also, such testing could be extended beyond the comprehensibility of two-word items; it would be interesting to know how significant phrasal verbs are as a comprehension problem in comparison to "polyword" idioms in general (cf. Nattinger \& DeCarrico, 1990). In fact, frequency counts of two-word items and "other" idioms would be interesting, especially conceming the issue of formality: do newspapers and technical manuals show the same ratio of two-word items to other idioms?

Another useful study would be to look at the frequency of phrasal verbs in relation to total number of verbs. Because of the size of the corpora here considered, it was necessary to count two-word item frequencies in term of total number of words, because the total number of words could be easily 
established by calculating the average number of words per line. To compare phrasal verbs to all verbs would require counting each verb; a time-consuming process, which for the effort involved, is of questionable value. Still, if such data were available, we might be able to make stronger statements as to the real importance of phrasal verbs within a corpus .

It might also be interesting to see if the nature of the technical manual data varied between subject areas. At one point in this study, it began to seem that manuals on electronics and computers used fewer phrasal verbs and more lexical counterparts, and that the most significant rhetorical functions for two-word items in electronically-oriented manuals were physical and functional description, while instruction was most important for more purely mechanical texts. Given that physical movement is more evident in mechanics than electronics, such assumptions seemed reasonable. A preliminary study was run; however, the results were inconclusive, so this remains an avenue of future research.

Finally, no teaching materials have been developed as a result of this study (but see Appendix B for a sample lesson on certain lexical counterparts), nor has the effectiveness of different methods of presenting two-word items been assessed in a class-room situation. It is likely just this type of research that most ESP instructors would desire. 


\section{REFERENCES}

Allen, J.P.B. \& Widdowson, H.G. (1974), Teaching the Communicative Use of English, IRAL 12, 1: 120, reprinted in Episodes in ESP (1985), ed. Swales, J.; London, Eng., Pergamon Press, pp. 69-89

Asher, J. (1977), Learning Another Language through Actions: The Complete Teacher's Guidebook, Los Gatos, CA, Sky Oak Productions

Barber, C.L. (1962), Some Measurable Characteristics of Modem Scientific Prose; in Contributions to English Syntax and Phonology; eds. Almquist \& Wiksell, Stockholm. Reprinted in Episodes in ESP (1985), ed. Swales, J.; London, Eng., Pergamon Press, pp. 1-16

Bartolic, L. (1977), Nominal Compounds in Technical English; in Collected Research Papers, Faculty of Mechnical Engineering and Naval Architecture, Zagreb, Yugoslavia, Univ. of Zagreb. Reprinted in Trimble et al., English for Specific Purposes: Science and Technology; Corvallis, OR., English Language Institute, 1979, pp. 257-277

Blicq, R.S. (1986), Technically-Write: Communicating in a Technological Era; Englewood Cliffs, NJ, Prentice Hall

Bolinger, D. (1971), The Phrasal Verb in English; Cambridge, MA, Harvard University Press

Bosworth-Gerome, S., Helye-Lebas, C., \& Marret, R. (1987), Lire l'Anglais Scientifique et Technique: L.A.S.T; Paris, France, Edition Marketing

Brown, J. D. (1988), Understanding Research in Second Language Research: A Teacher's Guide to Statistics and Research Design; Cambridge, Eng., Cambridge University Press

Brusaw, C. T. (1982), Handbook of Technical Writing; N.Y., NY, St. Martins

Burnaby, B. \& Sun, Y. (1989), Chinese Teachers' Views of Western Language Teaching: Context Informs Paradigms; TESOL Quarterly 23, 2: 219-238

Burwell, D. (1990), English in the Workplace: A Matrix of Instructional Materials and Selected Evaluations. Unpublished M.A. thesis, Portland, OR, Portland State University.

Celce-Murcia, M. \& Larsen-Freeman, D. (1983), The Grammar Book: An ESL/EFL Teacher's Course; Cambridge, MA, Newbury House, pp. 265-279

Celce-Murcia, M. \& Rosenweig, F. (1979), Teaching Vocabulary in the ESL Classroom, in CelceMurcia \& McIntosh, L., eds., Teaching English as a Second or Foreign Language; Rowley, MA, Newbury House, 1979, pp. 241-258

Chadwick, B., Bahr, H., \& Albrecht, S. (1984), Social Science Research Methods; Englewood Cliffs, NJ, Prentice Hall 
Cobb, D. (1972), Aural Comprehension Materials for Tertiary Level Science and Technical Students; RELC Journal, 3: 70-87

Coffey, B. (1984), English for Specific Purposes; in Language Teaching and Linguistic Abstracts; 17,1: $2-6$

Cornell, A. (1985), Realistic Goals for Learning Phrasal Verbs, IRAL 23, 4: 269-279

Courtney, R. (1983) Longman Dictionary of Phrasal Verbs; London, Eng., Longman

Cowan, J.R. (1974), Lexical and Syntactic Research for the Design of EFL Reading Materials; TESOL Quarterly, 8, 4: 389-399

Cowie, A.P. \& Mackin, R. (1976), Oxford Dictionary of Current Idiomatic English, Vol. 1: Verbs and Prepositions or Particles; Oxford, Eng., Oxford Univ. Press

Crookes, G. T. (1984), Towards a Validated Analysis of Scientific Text Structure; Applied Linguistics, 7, 1:57.70

DeCarrico, J. \& Nattinger, J. (1988), Lexical Phrases for the Comprehension of Academic Lectures; English for Special Purposes, 7: 91-102

Devron-Hercules, (1990a), Auto-Slice System Manual; Vancouver, B.C., Devron-Hercules, Training and Publications Depe.

Devion-Hercules, (1990b), Devronizer System Manual; Vancouver, B.C., Devron-Hercules, Training and Publications Dept.

Dieterich, T. \& Sohn-Vasbinder, A. (1990), The Structure of English; Unpublished manuscript, Portland, OR, Portland State University

Du Vigan, J., Cortese, S., Dunne, K., \& Brady, B. (1988), JAE Instructional Method, Vols. 1-25, 5th ed., Paris, France, JAE

Eichler, M. (1990), Against All Odds: Speaking Naturally with Idioms; Rowley, MA, Newbury House

Elliman, J. (1979), EST: TTI, Al-Manakh 4,1: 33-47, cited in de Osuna, A.A. (1982), The CoreLanguage of Biology: Lexical and Morphosyntactical Features (A Statistical Approach); ESP Newsletter, 69: 1, Corvallis, OR, English Language Institute

Ewer, J.R. \& Hugh-Davies, E. (1971-72) Further Notes on Developing an English Program for Students of Science and Technology; ELT 26,1 \& 3: 65-70 \& 269-273, reprinted in Episodes in ESP (1985), ed. Swales, J.; London, Eng., Pergamon Press, pp. $45-57$

Fanselow, J. (1980), "It's too Damn Tight!"--Media in ESOL Classrooms: Structural Features in Technical/Subtechnical English; TESOL Quarterly 14, 2: 69-89

Feare, R. (1988), Practice with ldioms; London, Oxford Univ. Press

Ford Parts and Service Division (1977a), 1978 Ford Fiesta Shop Manual; Dearborn, Michigan; Ford Motor Company 
Ford Parts and Service Division (1977b), 1978 Ford Ignition Systems Shop Manual; Dearborn,

Michigan; Ford Motor Company

Frank, M. (1972), Modern English: A Practical Reference Guide, Englewood Cliffs, NJ, Prentice Hall

Fraser, J.B. (1976, The Verb-Particle Combination in English; N.Y., NY, Academic Press

Gaims, R. \& Redman, S. (1986), Working with Words: A Guide to Teaching and Learning Vocabulary; Cambridge, Eng., Cambridge Univ. Press

Grimas, B. (1987), Simplified English in Maintenance Manuals, Journal for the Society of Technical Communications 34, 1: 24-30

Halliday, M.A.K., \& Hasan, R. (1976), Cohesion in English; London, Eng., Longman

Hara, M. (1979), Developing Skills for Reading Technical Manuals, in English for Specific Purposes: Science and Technology; eds. Trimble, L., Trimble, M., Drobnic, K., Corvallis, OR, English Language Institute, pp. 133-153

Hatch, E \& Farhady, I. (1982), Research Design and Statistics for Applied Linguistics; Rowley, MA, Newbury House

Hicks, T. (1961), Writing for Engineering and Science, N. Y., NY, McGraw \& Hill

Higgins, J. (1967), Hard Facts (Notes on Teaching English to Science Students), ELT 21, 1, reprinted in Episodes in ESP (1985), ed. Swales, J.; London, Eng., Pergamon Press, pp.27-37

Hillard, W.A. ed. (1990) The Oregonian; Portland, OR, Newhouse Newspapers, editions of 10/16/90, $10 / 20 / 90$. 10/26/90, 11/1/90, 11/2/90, 12/17/90.

Hook, J.N. (1981), Two Word Verbs in English; N.Y., NY, Harcourt, Brace \& Jovanovich

Howe, A.C. (1940), Handbook of English in Engineering Usage; N.Y., NY, Wiley \& Sons

Hutchinson, T. \& Waters, A. (1980), ESP at the Crossroads; English for Special Purposes 36; Oregon State University, reprinted in Episodes in ESP (1985), ed. Swales, J.; London, Eng., Pergamon Press, pp. 174-187

Lakoff, G. \& Johnson, M. (1980), Metaphors We Live By, Chicago, Chicago University Press

Masters, P. (1986) Science, Medicine and Technology: English Grammar and Technical Writing; Englewood Cliffs, NJ, Prentice Hall

MacArthur, T. (1989), The Long-Neglected Phrasal Verb; English Today, 5, 2: 38-44

McSwain, M. \& Morihara, B. (1990), The Transition to ESL Teaching in Business; paper presented at the 1990 Tri-TESOL Conference, Portland, OR

Meyer, G. (1975), The Two-Word Verb: A Dictionary of the Verb-Preposition Phrases in American English; The Hague, Mouton

Muir, J. (1990), How to Keep Your Volkswagen Alive: A Manual of Step by Step Procedures for the Compleat Idiot, 14th edition. Santa Fe, John Muir Publications 
Munby, J. (1978), Communicative Syllabus Design, Cambridge,Eng., Cambridge Univ. Press

Naranjo-Lombeida, E., The Treatment of Technical-Scientific Vocabulary in Foreign Language Education, unpublished M.A. Thesis, Austin, TX, Univ. of Texas

Nattinger, J. \& DeCarrico, J. (1990), Phrasal Verbs in a Lexical Phrases Approach to Teaching; Unpublished manuscriph, Portland, OR, Portland State University.

Newmeyer, F. J. (1980), Linguistic Theory in America: The First Quarter Century of Transformational Grammar; N.Y., NY, Academic Press

Palmer, F.R. (1968), A Linguistic Study of the English Verb; Coral Gables, FL., Univ. of Miami

Phillips, M.K. \& Shettlesworth, C.C. (1978), How to Arm your Students: A Consideration of Two Approaches to Providing Materials for ESP, ELT Documents: ESP, London, The British Council, reprinted in Episodes in ESP (1985), ed. Swales, J.; London, Eng., Pergamon Press, pp. 102-117

Pierce, R. (1990), Phrasal Verbs in Academic Lectures; unpublished M.A. thesis, Portland, OR, Portland State University.

Quirk, R.S., Greenbaum, S., Leech, G. \& Svartvik, J. (1985), A Comprehensive Grammar of the English Language; London, Eng., Longman

Reisman, SJ. (1963), A Style Manual for Technical Writers and Editors; N.Y., NY, MacMillan

Rogers, P. \& Olorenshaw, R. (1985), Les 100 Pièges de l'Anglais, Alleur, Belgium, Marabout Press

Salager, F. (1979), The Language of Technical English Literature: Pattern Classification and Semantic

Features; unpublished research paper, Merida, Venezeula, Univ., of the Andes

Sanderlin, S. (1988), Preparing Instruction Manuals for Non-English Readers; Journal for the Society of Technical Communication 35, 2: 96-102

Schulman, J. (1971), Chapter 1, Instructional Manuals, pp. 3-71, in Jordan, S., Kleinman, J. \& Shimberg, H.L., Handbook of Technical Writing, Vol. I Practices; N.Y., NY, Wiley \& Sons

Selinker, L. (1968) Some Early Observations on EST, Journal of English as a Second Language 3,1:168174, reprinted in English for Specific Purposes: Science and Technology, eds. Trimble, L., Trimble, M., Drobnic, K.; Corvallis, OR, English Language Institute, 1979, pp. 1-8

Simpson, J.A. \& Weiner, E.S.C. eds. (1989), The Oxford English Dictionary; 2nd ed., Oxford, Eng., Clarendon Press

Strevens, P. (1972) Technical, Technological, and Scientific English (TTSE); ELT 27, 3: 223-233

Strevens, P. (1977), Special Purpose Language Learning: A Perspective; Language Teaching and Linguistics Abstracts, 10, 3: 145-163

Strevens, P., (1980) English for Special Purposes: An Analysis and Study; in Readings on English as a Second Language: For Teachers and Teacher Trainers (1980), ed. Croft, K., Rowley, MA, Newbury House, pp. 458-472

Swales, J. (1980) ESP--Heart of the Matter or End of the Affair, in Issues in ESP, Waters, A., ed., Oxford, Eng., Pergamon Press, pp. 212-223 
Swales, J. (1981) Aspects of Article Introductions; Birmingham, Eng, Univ. of Aston

Swales, J., ed. (1985), Episodes in ESP; London, Eng. Pergamon Press

Tarone, E.; Dwyer, S., Gillette, S., \& Icke, J. (1981), On the Use of the Passive in Two Astrophysics Journal Papers; The ESP Journal, 1,2. Reprinted in Swales, J., ed. (1985), Episodes in ESP, London, Eng., Pergamon Press, pp. 188-205

Texas Instruments (1979), The Bipolar Microcomputer Component Databook for Design Engineers; 2nd ed., Dallas, Texas Instruments

Tinkham, T. (1979), Linguistic Aspects of a Technical Manual; unpublished manuscript, Agana, Guam, T. Tinkham

Thorton, M. (1969), Writing Technical Manuals; paper presented at the 9th Annual Course on Technical Writing, University of Washington, Seattle. Cited in English for Specific Purposes: Science and Technology, eds. Trimble, L., Trimble, M., Drobnic, K., Corvallis, OR, English Language Institute, 1979, p. 70

Townsend, R. (1970), Up the Organization; N.Y., NY, Alfred A. Knopf, p. 11

Trimble, L., Trimble, M., \& Drobnic, K. (1979), English for Specific Purposes: Science and Technology; Corvallis, OR, English Language Institute

Trimble, L., \& Trimble, M. (1979), The Development of EFL Materials for Occupational English: The Technical Manual; in Trimble, L., Trimble, M., Drobnic, K. eds., English for Specific Purposes: Science and Technology; Corvallis, OR, English Language Institute, 1979, pp. 74-132

Trimble, L. (1985), English for Science and Technology: A Discourse Approach; Cambridge, Eng., Cambridge University Press

Turner, B. (1974), Effective Technical Writing and Speaking; London, Eng., Business Books

Warringer, J. \& Griffith, F. (1977) Warringer's English Grammar and Composition, Fourth Course; N.Y., NY, Harcour, Brace \& Jovanovich

Weiss, E. (1982), The Writing System for Engineers and Scientists; Englewood Cliffs, NJ, Prentice Hall Widdowson, H.G. (1979), Explorations in Applied Linguistics; London, Eng., Oxford Univ. Press 
APPENDIX A

SIMPLE COMPOUNDS RESSEMBLING LEXICAL COUNTERPARTS FOUND IN ALL CORPORA

in-line
off-idle
on-machine
onscreen
outline
overall
overview (N \& V)
overstress
overheat
overcome
override (N\&V)
overlook
overnight
overhead
overfill
overhaul
overload
overlength
overwidth
overinflate
overtighten
straight-through
throughout
underground
underhood
underinflate
undertake
update (N\&V)
upgrade (N \& V)

(compound verbs based on lexical counterparts)

to backspace

to input

to output

to overstrike 


\section{APPENDIX B}

A SAMPLE LESSON FOR LEXICAL COUNTERPART INSTRUCTION

CIRCuITS: Study the picture to translate the English words below into your language.

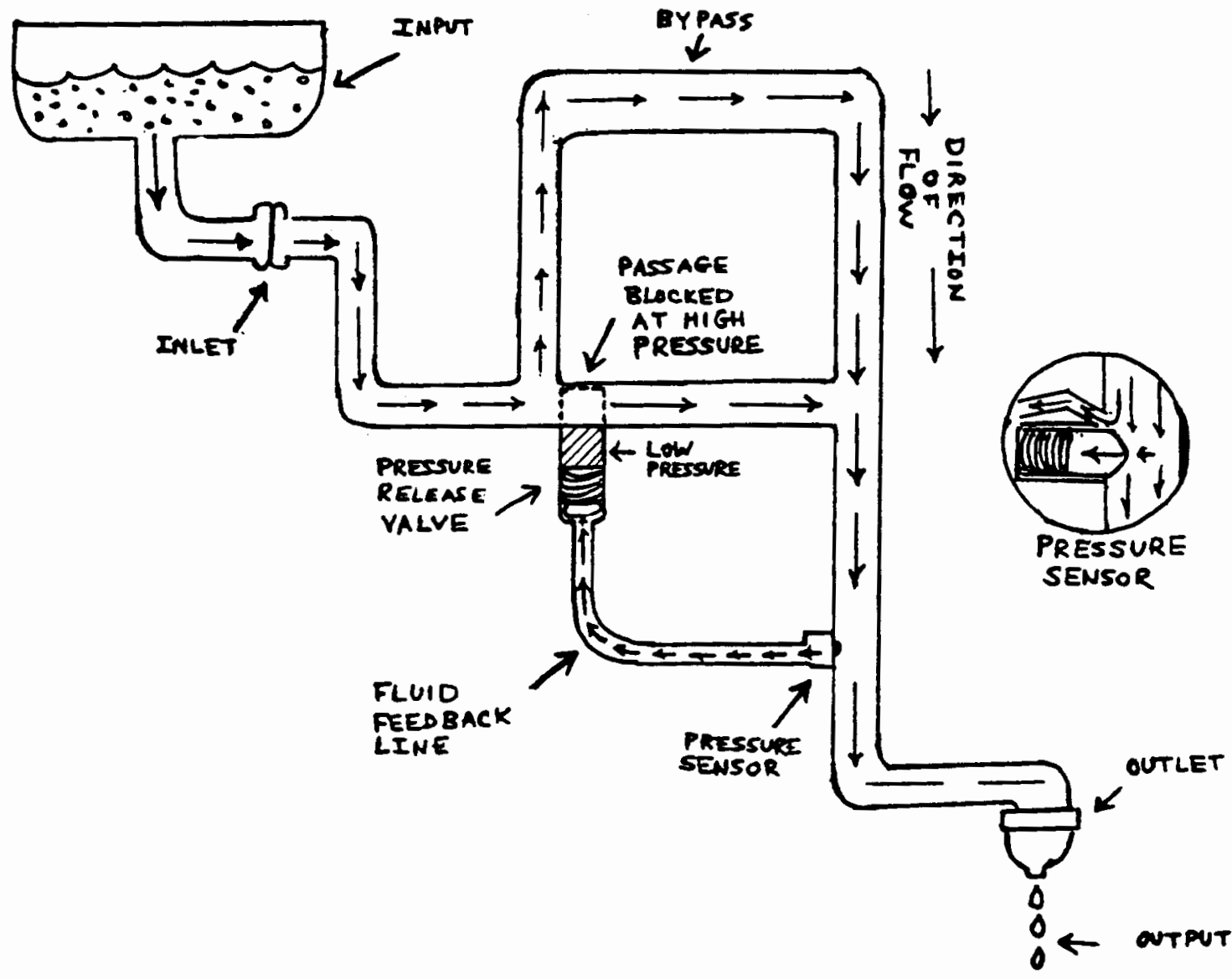
A. (input)
B. (inlet)
c. (valve)
D. (pressure-gm/ $\left.\mathrm{cm}^{\prime}\right)$
E. (bypass)
F. (feedback)
G. (flow)

H. (blocked)

I. (sensor)

J. (outlet)

K. (output) 


\section{CIRCUITS}

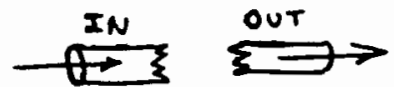

an input $\sharp$ an output (esp. electricity)

an inlet $\neq$ an outlet (esp. fluids)

an intake $\neq$ an exhaust (esp. gases)

(??-not an outake)

to feed: The intake manifold

feeds the gas/air

mixture to the engine.

He was feeding the fire by putting paper into it.
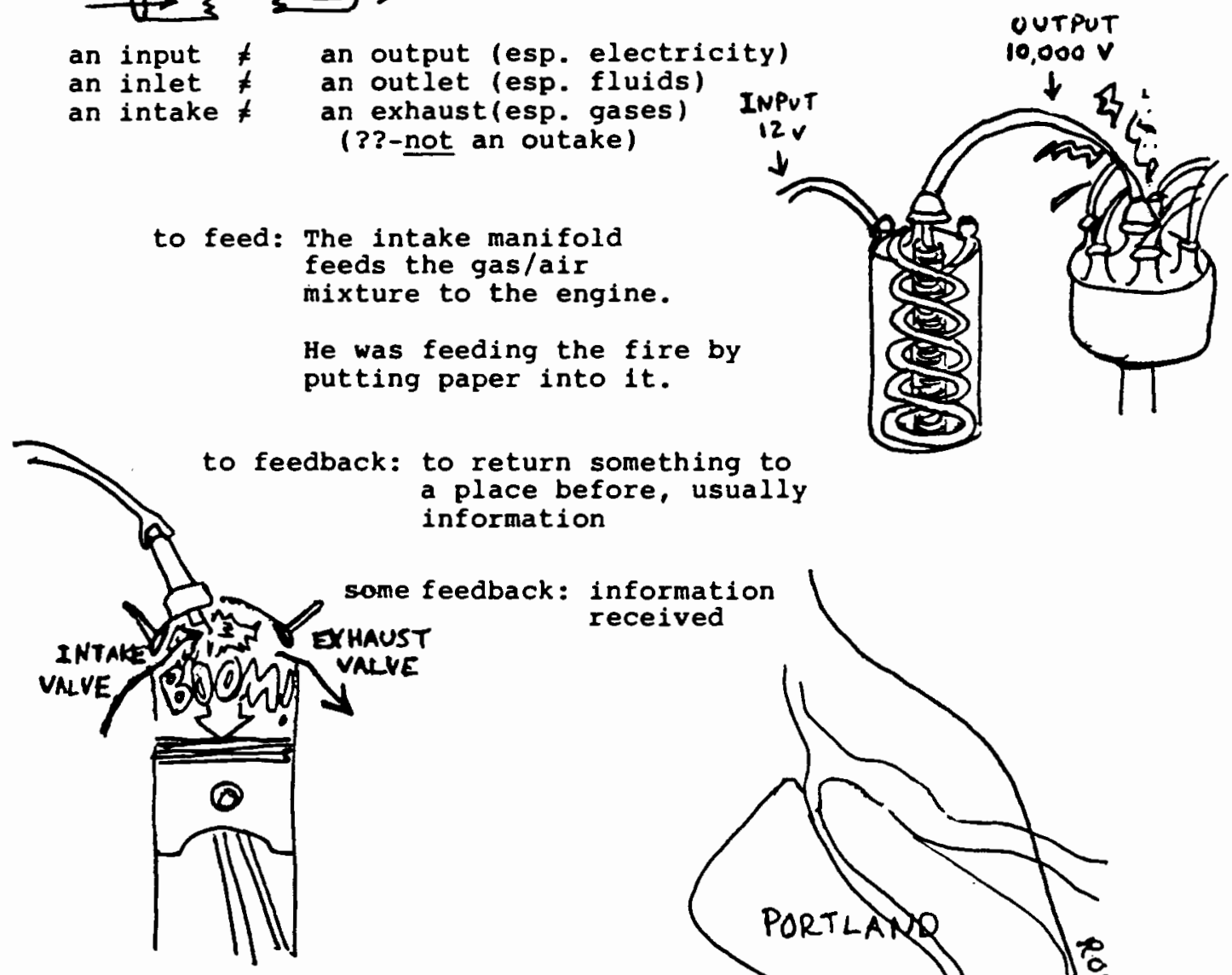

a bypass:

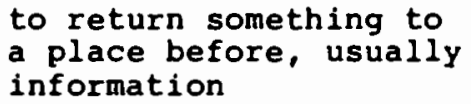

place before, usually information

a valve: blocks or changes the pressure of a fluid or gas in a pipe

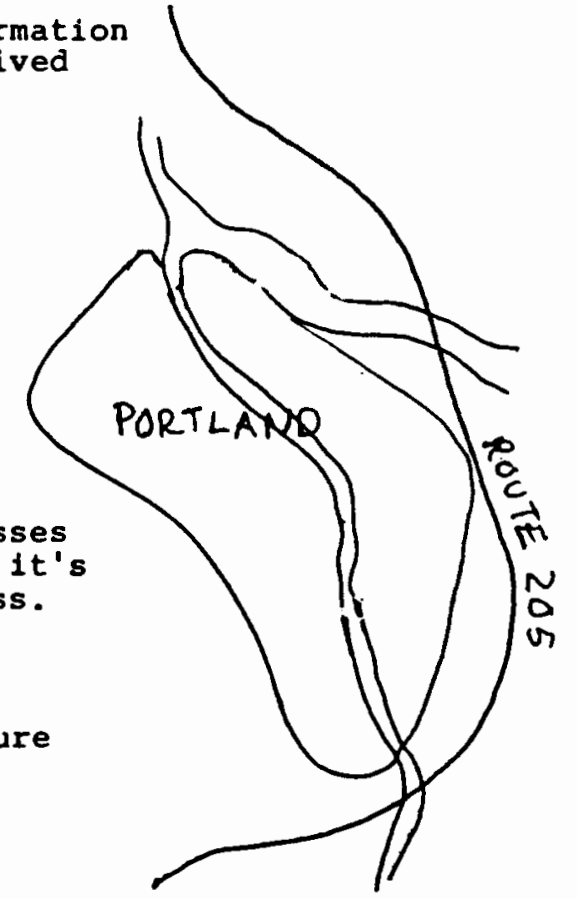


CIRCUITS: Finish the diagram below

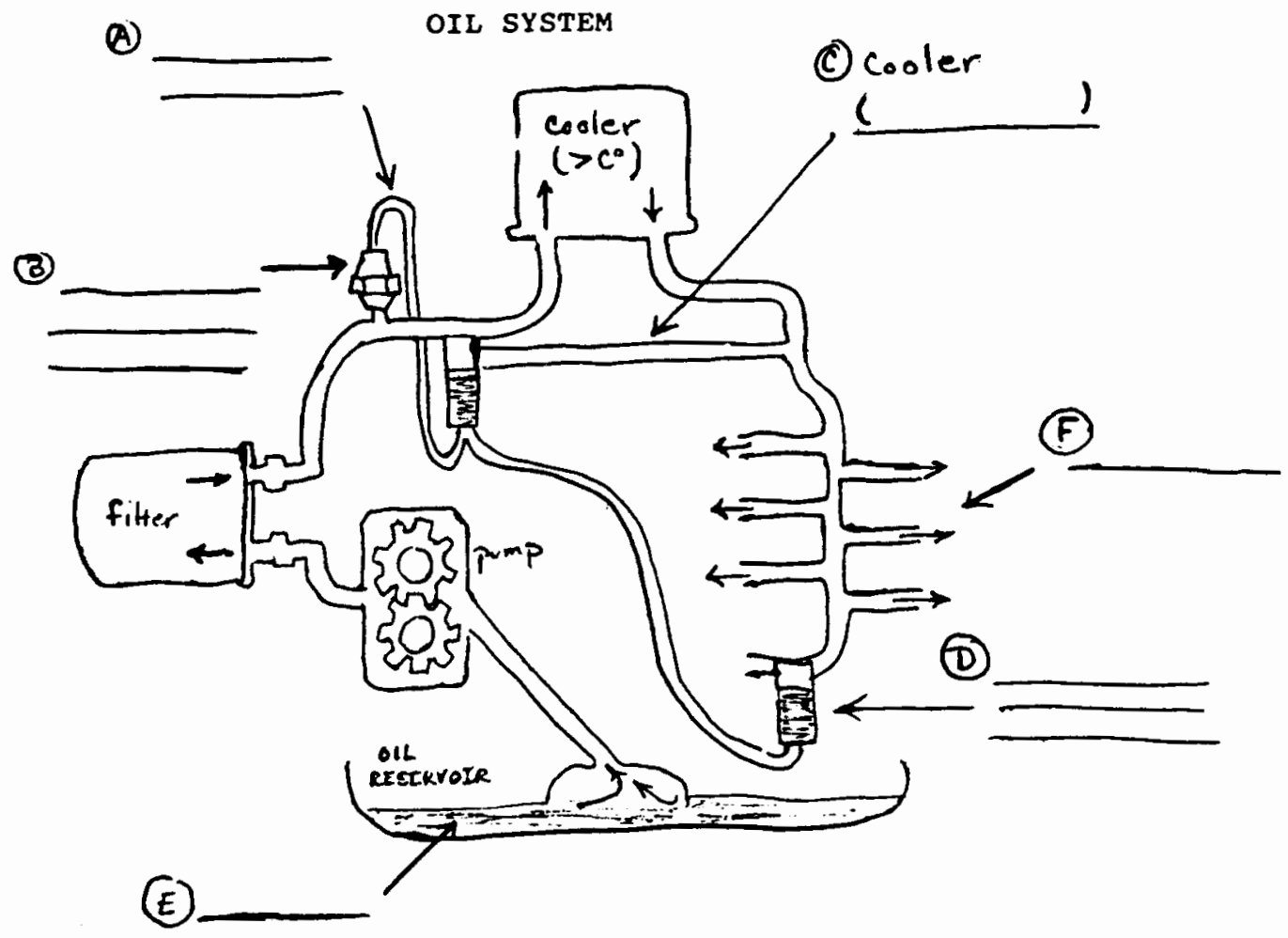

Finish these sentences with a word from the lesson

1. If the engine becomes too hot, a sensor

to a warning light in front of the driver.

2. To drain water from a sink, you must open the

3. The pipe went around the main system. It was a

4. The oil pump oil to the engine.

5. The shut-off stops the flow of gas.

6. A is a kind of measuring machine.

7. The is the result or product of a process

8. The opposite $(\neq)$ of "inlet" is and the opposite of

"output" is , but the opposite of "intake" is 


\section{APPENDIX C}

\section{A SECTION FROM THE DEVRONIZER TEXT (1990a) OF THE EXPERT TECHNICAL CORPUS}

INSTALLATION

CHECKLIST BEFORE INITIAL STARTUP
Prior to initial startug, carefully check each item listed:

Steam Supply -

- Supply control valve is functional

- Insulation is of good quality and workmarship.

- Steam line has been purged of condensate.

- Automatic condensate trap is functioning.

- Flexible steam supply hose allows uninhibited movement of the Devronizer.

- Pressure relief valve is functional.

- Availabie steam pressure at (ntefflange is maximum $100 \mathrm{kPa}$ (15 psig or $1 \mathrm{bar}$ ) with minimum temperature of $120^{\circ} \mathrm{C}\left(250^{\circ} \mathrm{F}\right)$.

- Pressure, temperature, and flow indicators are operating.

Devronizer -

- Distance and alignment between Devronizer and sheet are correct.

- Devronizer is mounted properly and in correct position as specified by Devron-Hercules.

- Adjustment bolts on mounting brackets are torqued

Aownproperly.

- Support brackets have been doweled

- Actuator valve sequence is correct.

- Retraction air cylinders are mounted as specified

- Retraction mechanism is connected to 4 way solenoid valve and valve is electrically connected.

- Retraction mechanism air pressure supply is adequate.

- Condensate taps are accessible (extended if necessary with valve relocated at lower end of extension line).

- All condensate taps are fully opened.

- Interlocks are properly sequenced and functional.

Steam supply to the Devronizer must be Fut off in the absence of the sheet, or whenever the unit is in the retracted position.

Actuator Air Pressure Supply -

- A minimum air pressure of $210 \mathrm{kPa}$ (30 psig or $2 \mathrm{bar}$ ) is available to each actuator through the control station.

- Check integrity of instrument air connections at quick disconnect coupling, actuators, and control station. 
Your Devronizer will either be computer (automatically) controlled or manually controlled. For computer controlled systems, please see Control System Operation manual for operating.

For manually controlled Devronizer systems, proceed to the following steps only after completing theiwamup procedure.

1. Record, or obtain a $\sqrt{\text { printout }}$ of the following variables:

- Weight of paper

- Moisture profile

- Felt temperatures

- Press roil temperatures

- Sheet temperature - before the Devronizer

- after the Devronizer

- Steam flow/pressure to dryers and the Devionizer

- Calculate the total flow to the dryers and the Devronizer.

2. Move the Devronizer to the operating position.

3. Open all profiling actuator valves to $50 \%$.

4. Slowly increase the steam flow to $0.04 \mathrm{ts} / \mathrm{tp}$ (approximately $14 \mathrm{kPa}$ or 2 psig or $0.14 \mathrm{bar}$ ).

5. Select the area of highest moisture content from the moisture profile.

Open the corresponding actuator valve to $100 \%$ and record its position.

Continue to modify actuator setpoints according to the moisture profile by applying more steam to the wetter areas and reducing it to the drier areas.

6. Allow three scans of the measurement system, or 10 minutes to elapse.

Record all variables again. 


\section{OPERATION}

INITAL WARMUP:
AND COLD STARTUP

This procedure is used for the initia startup and for any subsequent cold/startupi

- Devronizer - retracted position (Manual Override).

- Condensate drain taps - fully open.

- Steam curtain - 100\% open.

- All actuator valves - 0\% open.

- Steam supply at inlet lange to the Devronizer - set at $0.02 \mathrm{ts} / \mathrm{t}$ or approximately $7 \mathrm{kPa}$ (1 psig or $.07 \mathrm{bar}$ ). Manual Override).

- Watch for condersate coming from the drain taps. Wait until condensate is reduced to droplets or for a minimum of 10 minutes.

Close drain taps to a 'cracked open' position; droplets of condersate or a small amount of steam should still emerge from the taps.

- Proceed to Begin Operating on next page.

The steam flow to the Devronizer is very important.

The unit is designed for a specific operating range for the grades produced on your machine.

Optimum steam flow to the unit must be determined for each grade.

This flow, typically expressed as a ratio of tonnes of steam (ts) per tonne of product (tp), usually falls within a range of 0.08 to $0.20 \mathrm{ts} / \mathrm{tp}$.

Remember: On the Manual Control Console Clockwise closes the actuator valve to apply less steam to that profiling zone. 


\section{APPENDIX D}

A SECTION FROM THE VOLKSWAGEN TEXT OF THE LAY CORPUS (Muir, 14th ed., 1990)

IV. Check Vacuum Advance

A. Take off discributor cap, pull rotor.

B. Pull hose from distributor to carburetor.

C. Suck on the hose and watch the points plate-the whole plate should move.

v. Change Oil

A. Remove 2 Imon drain plug or entire sump plate on newer madels

B. Remove and clean screen and replace. Remember oil filler.

C. Put in oil

VI. Compression Check

A. Have engine at operating temperature

B. Remove spark plug connections, then the spark plugs. Check spark plug color (tan to brown OK; black, no good).

C. Place tester in each hole while a friend tums the engine over six times with the key Rernember your stocking cap! Safery!

D. They should all be over 100 and within $S$ lbs. of each ocher.

vil. Spark Plugs

A. Gap $.025^{\prime \prime}(.6 \mathrm{~mm})$

vill. Coil

B. Replace

A. Pull center wire from distributor cap and hold it $1 / 4$ "to $1 / 4$ " from a ground: bright blue tc white, good Yellow, OK. Orange, bad.
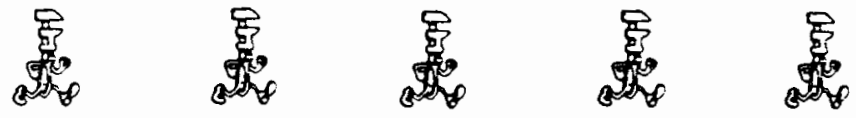

\section{PhocedLRE fOR falVE ADJUSTMENT, Phase I}

Condition: 3000 milc maintenance. Please note: 1978 and 79 buses have non-adjustable hydraulic vaives, so 78 and 79 Bus owners skip this Procedure.

Tools and Materials: Phase I tool kit, valve cover gaskets, quick-drying giue, wheel bearing grease.

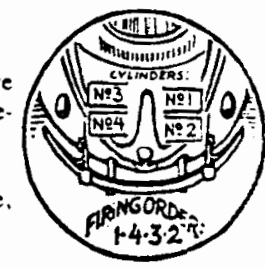

Stcp 1. Get Ready

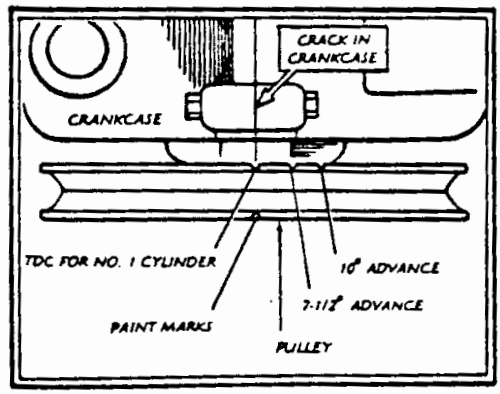

Throughout this book we use directional conventions to make pointing to things easier. Frons is always the front of the car, making left the driver's side. When you are doing this work, remember, Front is front. Read "Engine Comparument Orientation" in Chapter Vu.

The night before you are going to adjust your vaives and do a tune-up, park your car in a nice place to work, as you cannot start the engine before setting the valies. Block the car so it won't roll when it's out of gear. Open the engine comparunent and put your stool down in back of the car, tools at hand and friend ready to read you these words: the ideal way to run Procedures. 


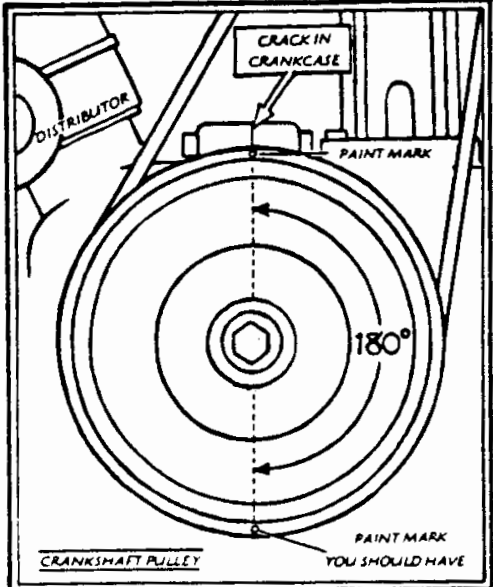

Step 2. Mark Crankshan Pulley or Crankchan-Fan-Pulley

First thing is to get the $21 \mathrm{~mm}$ or crescen wrench on the nut that holds the generator pulley on. so you can rotate the engine at. will. If tuming this pulley doesn't tum the engine, your belt is too loose, so tum right now to Chapter VIII and tighten the fan belt per the procedure. Tum the engine over clockwise a couple of twists just to get the feel of it

Now find the crankshafi pulley at the other end of the belt. The crankshaft puliey has some filed notches on the front of the pulley (front, remember) There may be one, two or three norches and I'll clue you about them later as they are the timing notches. There should be a paint mark on the back side of the pulley (the side closest to you) and one opposite it $\left(180^{\circ}\right)$. If these aren't there, you have to paint them on, so send somebody for a paint stick or equalwhite is best. If your pant marks are there, go on 10 Siep 3.

When the paini stick comes, make a white mark on the crankshaft pulley uhere you can easily see it by the notches, then get a ruler and carefully make a mark jusi opposite or $180^{\circ}$ around the pulley. See sketches on this and preceding page.

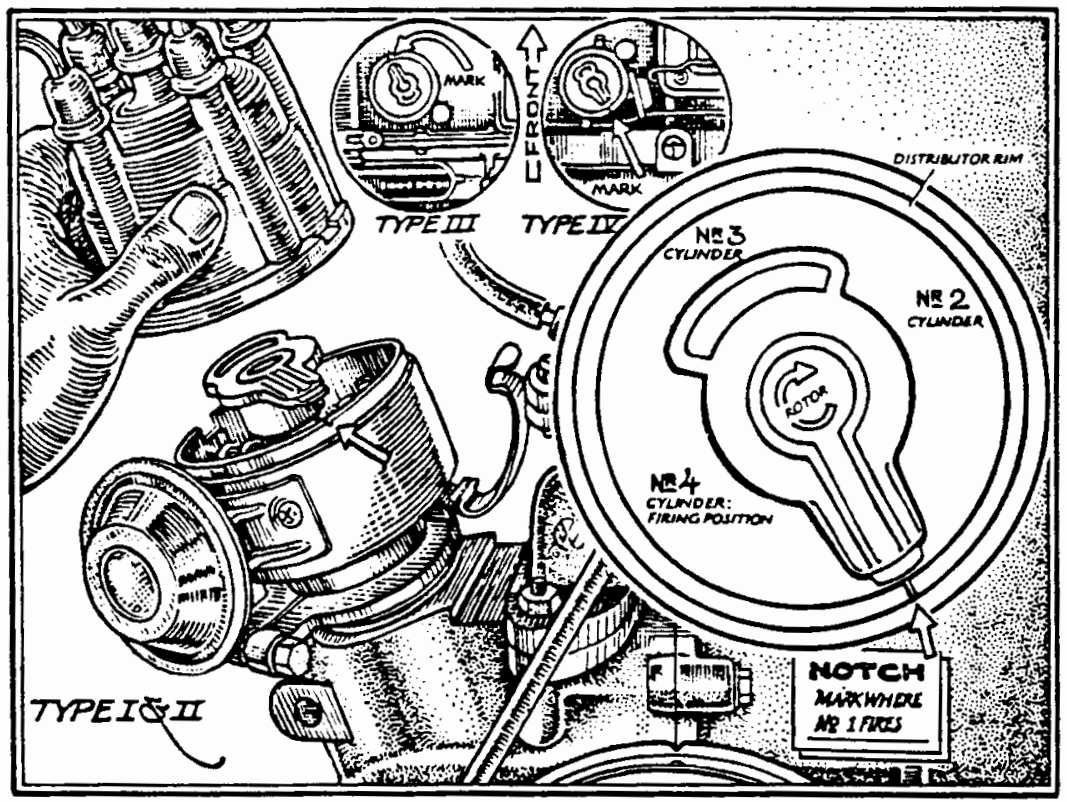


Type IU, IV and 1972-77 Bus

Your pulley is different but the action you cake is the same. You need a mark $180^{\circ}$ from the 0 mark on your kind of pulley so you can tell when the valves in the next cylinder are at top dead center-ready to set.

\section{Step 3. Get Cylinder No, 1 into Firing Position}

\section{All Models}

Find the distributor. The cap is held on by wo spring clips, so take the medium serewdriver and pry them off the cap. Lift the cap and push it out of the way. Find the filed line on the distributor rim (where you just took off the cap). See sketch on preceding page.

Type I (All) and Type II (through 1971)

Rotate the engine clockwise (forward, the way it runs) until the distributor rotor points to the line on the rim. Now line up your TDC mark with the notch or crack in the crankcase. This is Top Dead Center (TDC) for Cylinder No. 1. See sketch on preceding page.

Type III

Find the generator belt cover (rear of generator), pry the two spring clips off with a large screwdriver and remove the cover plate. Now you can see the generator belt and the crankshaft pulley. A bove the center of the pulley is a hole with a nubbet plug in it. Pull the plug out, stick your large screwdriver in the hole anj catch the point of the serewdriver in between the teeth of the pulley. Pull or push the handle of the screwdriver to either side so the engine turns. Turn the engine until the distributor rotor lines up with the line on the rim of the distributor. Take the screwdriver out and look down the hole at the pulley. There will be two. three or four lines on the edge of the pulley. Stick your screwdrive back into position and tum the engine until the line furthest to the LEFT lines up with the pointer t the pointer is a proirusion on the aluminum fan housingl. This is top dead center (TDC) for cylinder No. 1, where you adjust the valves for cylinder No. 1. Here's what you're seeing

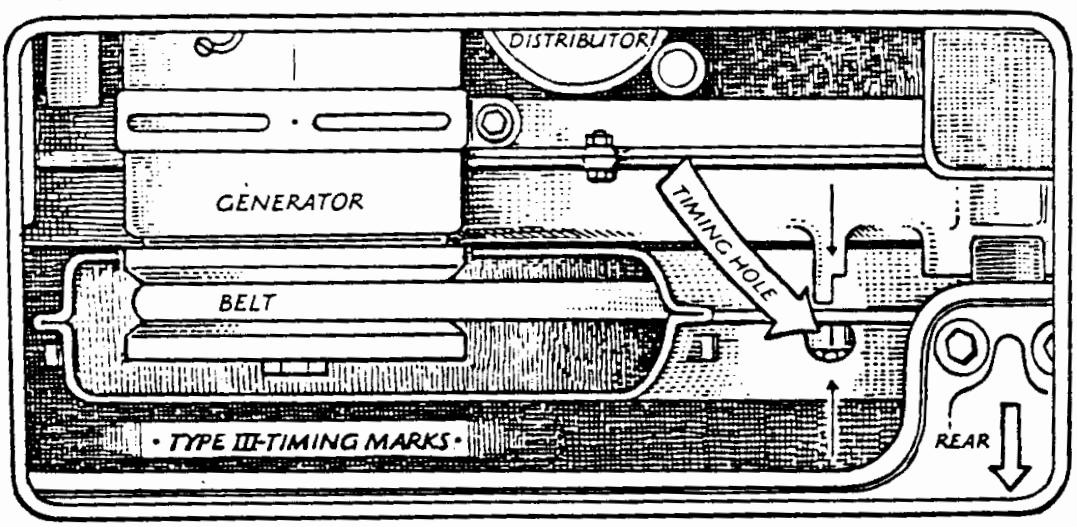

1972-77 Bus-Your work is the same as for the Type I's, but you have to use a $24 \mathrm{~mm}$ or erescent wrench on the altemator nut to turn your engine. The timing notch on your pulley must line up with the " 0 " mark on the scale (those numbers going half way round the circle). This is top dead center (TDC) for cylinder No. 1, where you adjust the valves for this cylinder.

Type IV-Tum your engine the same as 1972-77 Bus. You have noo doches on the crankshafifan-pulley which you can see by removing the large plug in the top of the fan bousing above the pulley. 


\section{APPENDIX E}

TWO "OREGONIAN" ARTICLES FROM THE GENERAL CORPUS (Hillard, W. ed., 1990)

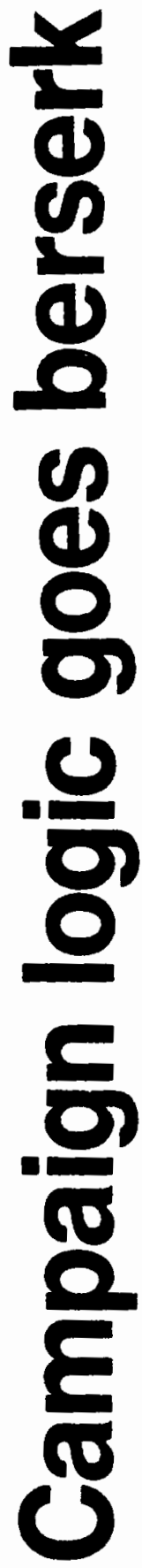

\section{$\square$ Negative advertising and the voters' penchant for independence has thrown races into chaos}

\section{By JEFF MAPES}

of The Oregonian stat:

Rep. Ron Wyden was flabbergast ed the othel day when two senior citizens told him why they were going to vote for Democrat Harry Lonsdale over Sen. Mark O. Hatfield

They didn't care about Social Security, Medi. care or any of the senior citizen issues that Repub. lican Hatfield has championed in traditionally win. ning strong sup. port from the elderly.

"They said they were going to vote

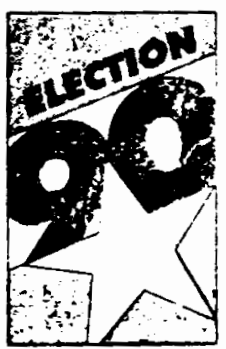
for Lonsdale because Hatfield was in the establishment," said Wyden, "and that was it. Lonsdale has just taken his base away."

-It is," added the Portland Demo. crat, "a remarkable statement about how politics have changed."

Changed indeed. The state is entering the last nine days of an intense, emotional and even bitter election campaign that has taken more sudden twists than Mr. Toad's Wild Ride.

"In the 15 years I've been in Oregon politics," said Tim Hibbitts, the pollster and KATU (2) political anaZ lyst, "this is the most tumultuous and surprising year I've ever seen."

Two short months ago, Hatfield thought he was coasting to an easy reelection to a fifth term in the Sen. ate against political neophyte Lons. dale. But his poll numbers came tumbling down as soon as Lonsdale launched a sophisticated TV advertising campaign that tied Hatfield to toxic polluters and greedy Washing. ton insiders.

Two short months ago, political observers were proclaiming the race for governor a snore as Republican Dave Frohnmayer held a clear lead over Democrat Barbara Roberts in both the polls and in the size of his campaign bank account.

Now, Roberts appears to be the front-runner and Frohnmayer is desperately trying to woo back conservatives from independent $A$ l Nobley

On top of that, a stidden jump in real estate values $h E s$ once again fueled a tax revolt pushing for yet another ballot measure to limit property taxes. Swirling around this are nationally watched ballot meas ures to curtail legalized abortion, grant tax credits for private education and require tough recy. cling standards for packaging. And Rep. Denny Smith, R-Ore., finds himself one of the few incumbent members of the House - with all of their franking privileges, perks and sky-high re-election rates - who are in real danger of being defeated any. where in the country.

"Everything that logic told you in April has been blown aut the window," said Paul Romain, a veteran lobbyist who has been involved in 1 Frohnmayer's campaign.

f, No simple theory explains the closeness of so many races. Hatfield surely got into trouble because of his previous insistence on sticking to an old-fashioned campaign style that eschewed political polls and re-

"The Oregonian", October 26th, 1990 


\section{Gresham student}

\section{turns up in NY}

\section{$\Xi$ Shermin Voshmgir, an Austrian teen-ager who was in an exchange program, is safe after an unexplained four-day bus journey across the United States}

\section{BY HOLLEY GILBERT}

of The Oregonian staff

A missing Austrian exchange studen 2 was found safe in New York City on Sun. day afteriruning away from her Gresham host fami shome Wedncsday.

"I'm more than happy." said her host father. Rohert Hambach. "I can't tell you how happy we are she's been found. This has been a hellacious four days for us. 3 My wife and I are justworn out."

Gresham police used tracking dogs and followed tips to search for Shermin foshmgir. 16. of Vienna. who had been

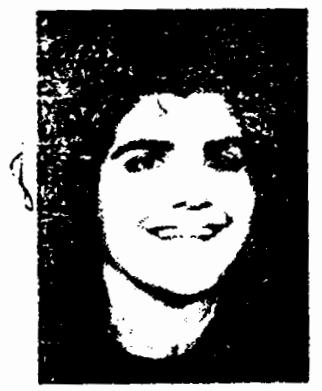

VOSHMGIR

for with oregon
Multnomah County and rode it to New York.

"I don': think she knows either," Stal. lard said. "She's a mixed-up girl."

But Stallard said Voshmgir stressed that she didn't run away because of any problems with her host family, her school in Gresham.

"She asked if she could come back," Stallard said.

But Stallard said Voshmgir wouldn't be permitted to come back to Oregon.

"Her place is at home now," she said missing since she left her host family's Gresham home for a nearby Fred Meyer store last week.

Shortly before 6 p.m. Sunday, the Ore. gon office of the Education Foundation for Foreign Study, Voshmgir's sponsoring agency, called Gresham police to saly the girl had turned up at a New York City shel. ter.

Dianne Stallard, the program's regiona! coordinator, took a call from Covenant House early Sunday evening. She spoke first to a counselor at the shelter. then to Voshmgir. But Stallard said she still didn't know why Voshmgir jumped on a bus in

But another foundation official said her I family and the group would decide together whether she can return.

Capt. Gerald Johnson, who headed the Gresham Police Department's search, said the Covenant House counselor called the foundation office after Voshmgir walked in Sunday because Voshmgir is a minor, and shelter officials were required to notify an adult.

Police believe Voshmgir took a bus from the Portland area Wednesday night, after withdrawing nearly $\$ 130$ from a teller machine 30 minutes after leaving the Ham. bach home. The bus arrived in New York on Sunday.
Please turn to FOUND, Page A16 